Aus der Klinik für Nephrologie und Rheumatologie

(Univ.-Prof. Dr. med. G. A. Müller)

der Medizinischen Fakultät der Universität Göttingen

\title{
Assoziationen von krankheits- und therapiebezogenen Parametern sowie Einfluss von Serum-IL-6- und IL-10-Spiegeln bei Patienten mit Parodontitis und rheumatoider Arthritis unter immunsuppressiver Therapie
}

\author{
INAUGURAL-DISSERTATION \\ zur Erlangung des Doktorgrades \\ für Zahnmedizin \\ der Medizinischen Fakultät der \\ Georg-August-Universität zu Göttingen
}

vorgelegt von

Laura Bothmann

aus

Göttingen

Göttingen 2020 
Dekan:

Referent/in

Ko-Referent/in:
Prof. Dr. med. W. Brück PD Dr. med. S. Patschan Prof. Dr. med. N. Miosge

Datum der mündlichen Prüfung: 09.09.2021 
Hiermit erkläre ich, die Dissertation mit dem Titel „Assoziationen von krankheits- und therapiebezogenen Parametern sowie Einfluss von Serum-IL-6- und IL-10-Spiegeln bei Patienten mit Parodontitis und rheumatoider Arthritis unter immunsuppressiver Therapie" eigenständig angefertigt und keine anderen als die von mir angegebenen Quellen und Hilfsmittel verwendet zu haben.

Göttingen, den 
Die Daten, auf denen die vorliegende Arbeit basiert, wurden teilweise publiziert:

Bothmann L, Ziebolz D, Patschan D, Patschan S: Krankheits- und therapiebezogene Charakteristika sowie Zahngesundheit von Patientinnen/-en mit rheumatoider Arthritis. Posterpräsentation im Rahmen des 46. Kongresses der Deutschen Gesellschaft für Rheumatologie (DGRh), 32. Jahrestagung der Deutschen Gesellschaft für Orthopädische Rheumatologie (DGORh), Wissenschaftliche Herbsttagung der Gesellschaft für Kinder- und Jugendrheumatologie (GKJR), Mannheim, 19.09.-22.09.2018

Bothmann L, Ziebolz D, Patschan D, Patschan S: Dentaler und parodontaler Mundgesundheitszustand bei rheumatoider Arthritis - cytokine profiling. Posterpräsentation im Rahmen des 46. Kongresses der Deutschen Gesellschaft für Rheumatologie (DGRh), 32. Jahrestagung der Deutschen Gesellschaft für Orthopädische Rheumatologie (DGORh), Wissenschaftliche Herbsttagung der Gesellschaft für Kinder- und Jugendrheumatologie (GKJR), Mannheim, 19.09.22.09.2018

Patschan S, Bothmann L, Patschan D, Henze E, Schmalz G, Ritter O, Ziebolz D (2020): Association of cytokine patterns and clinical/laboratory parameters, medication and periodontal burden in patients with rheumatoid arthritis (RA). Odontology $\underline{108}, 441-449$ 


\section{Inhaltsverzeichnis}

Abbildungsverzeichnis.................................................................................III

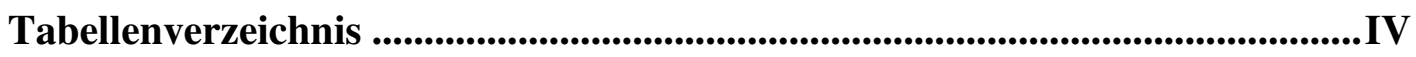

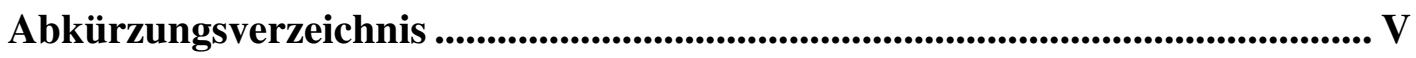

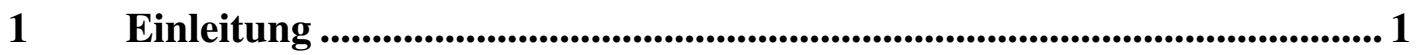

1.1 Einführung in die Pathogenese der rheumatoiden Arthritis .......................................3

1.2 Einführung in die Pathogenese der chronischen Parodontitis...................................

1.3 Datenlage zu Assoziationen von rheumatoider Arthritis und Parodontitis ............... 12

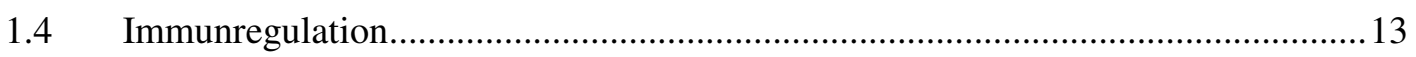

1.4.1 Rolle der Zytokine im lokalen Entzündungsprozess bei rheumatoider Arthritis und

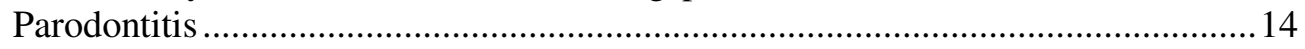

1.5 Marker systemischer Entzündung bei rheumatoider Arthritis und Parodontitis......16

1.6 Datenlage zu Assoziationen von systemischer Entzündung bei rheumatoider Arthritis und Parodontitis..................................................................................... 18

1.7 Medikamentöse Therapie der rheumatoiden Arthritis ............................................20

1.7.1 Konventionelle synthetische krankheitsmodifizierende Antirheumatika

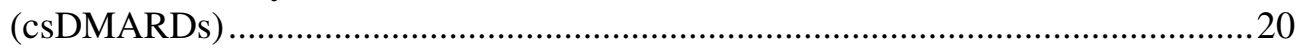

1.7.2 Biologische krankheitsmodifizierende Antirheumatika (Biologika) .......................21

$2 \quad$ Material und Methoden ..................................................................................... 23

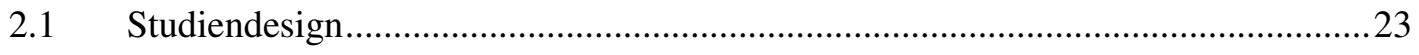

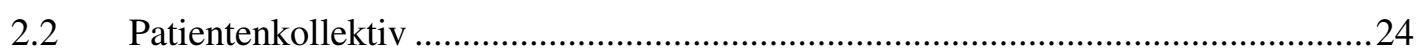

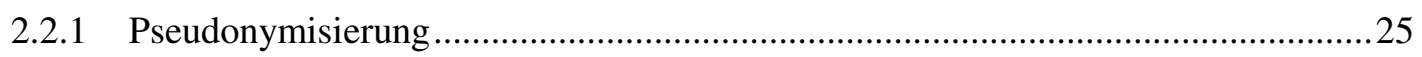

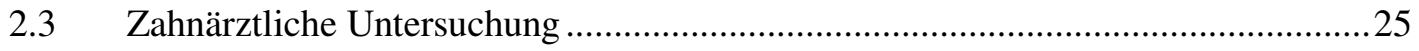

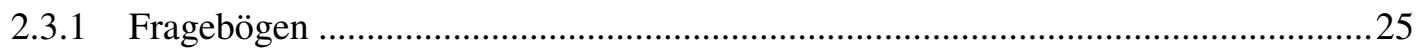

2.3.2 Klinisch-zahnmedizinische Untersuchung............................................................26

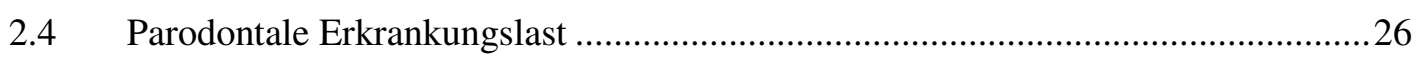

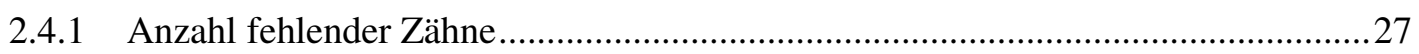

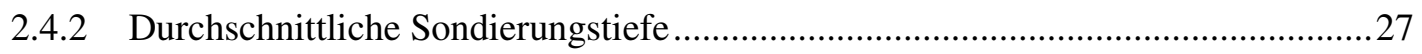

2.4.3 Durchschnittlicher klinischer Attachmentverlust ..................................................28

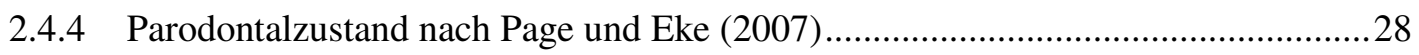

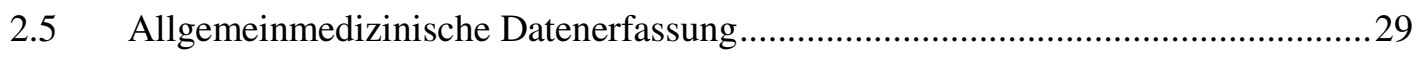

2.5.1 Klinisch-rheumatologische und serologische Parameter .........................................29

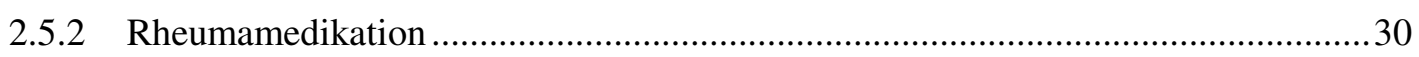

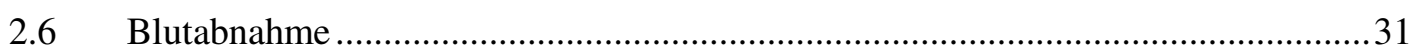

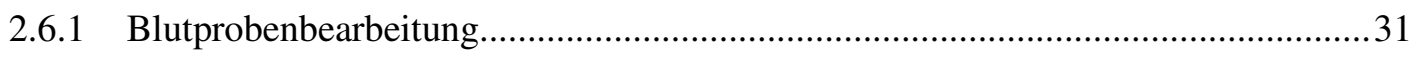

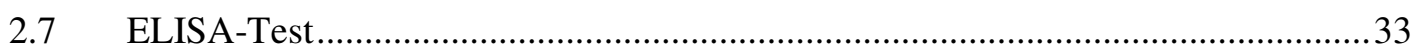

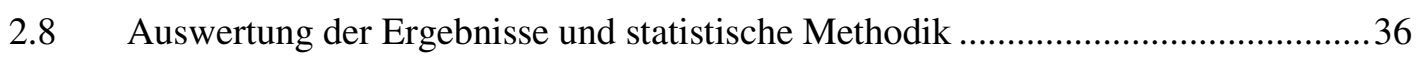

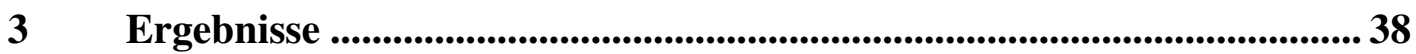




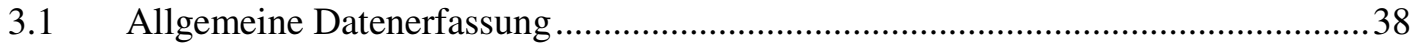

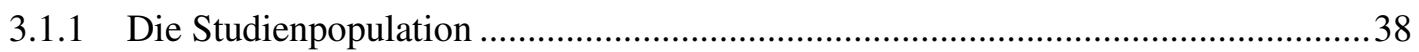

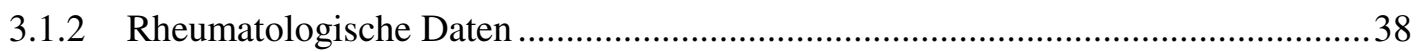

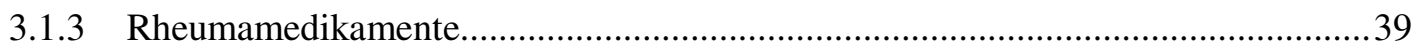

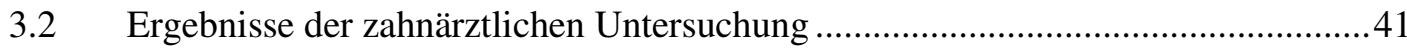

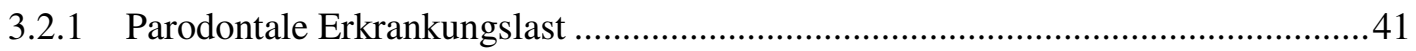

3.3 Ergebnisse deskriptiver anamnestischer Erhebungen ..........................................42

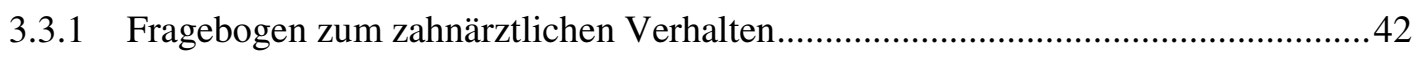

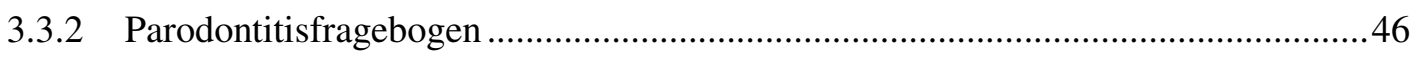

3.4 Assoziationen zwischen dem Schweregrad der Parodontalerkrankung und

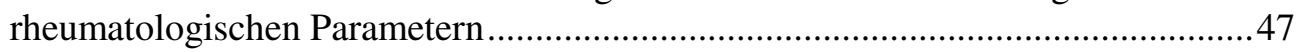

3.4.1 Klinisch rheumatologische Parameter ……........................................................ 48

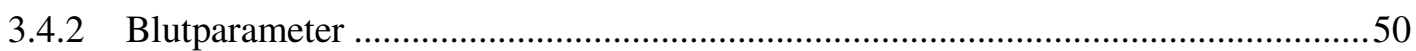

3.5 Assoziationen zwischen dem Schweregrad der Parodontalerkrankung und der Einnahmedauer der Rheumamedikamente ………….............................................53

3.6 Assoziationen zwischen Medikamenteneinnahme und Zytokinspiegeln im Blut....55

3.7 Zusammenfassung der wichtigsten Ergebnisse .....................................................57

4 Diskussion.........................................................................................5

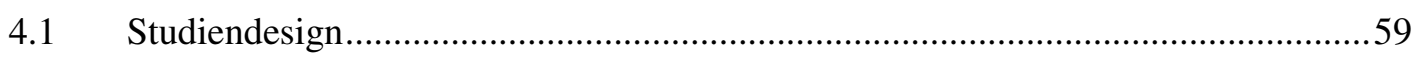

4.2 Assoziationen zwischen dem Schweregrad der Parodontalerkrankung und rheumatologischen Parametern.....

4.3 Assoziationen zwischen dem Schweregrad der Parodontalerkrankung und der Einnahmedauer der Rheumamedikamente ...........................................................67

4.4 Assoziationen zwischen Medikamenteneinnahme und Zytokinspiegeln im Blut....70

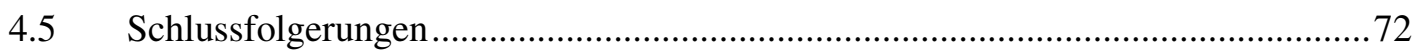

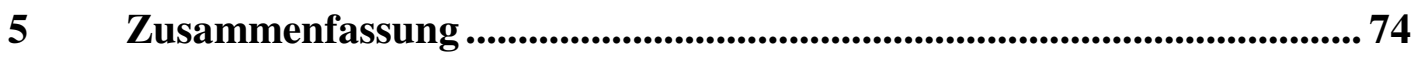

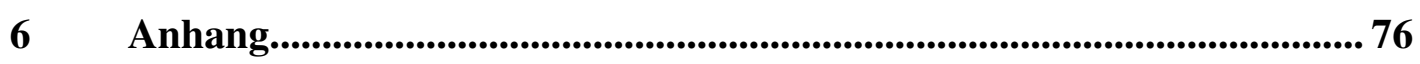

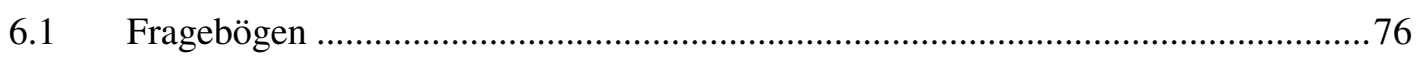

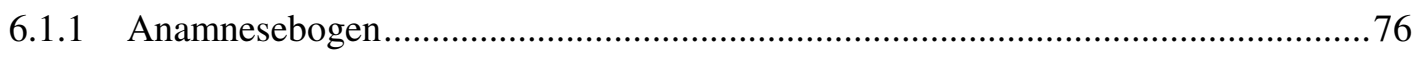

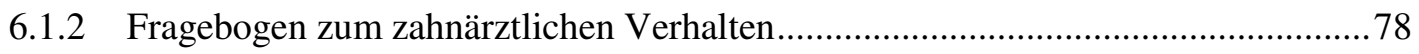

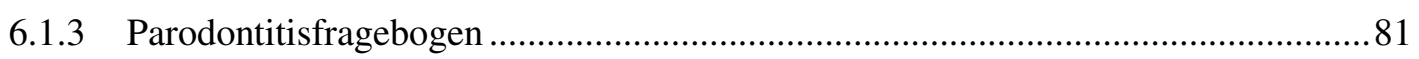

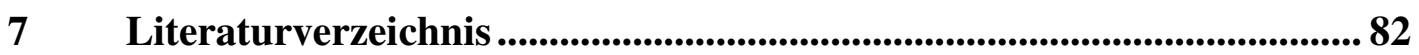




\section{Abbildungsverzeichnis}

Abbildung 1: Ätiologie und Pathogenese der Parodontitis nach Page und Kornman (1997)

Abbildung 2: Darstellung der Wirkungen von Interleukin-6 und Interleukin-10 im Entzündungsprozess von rheumatoider Arthritis und Parodontitis

Abbildung 3: Assoziationen von systemischer Entzündung bei rheumatoider Arthrits und Parodontitis

Abbildung 4: Übersicht der untersuchten Parameter und Abhängigkeiten in der vorliegenden Studie.

Abbildung 5: Zeitpunkte des letzten Zahnarztbesuches mit Angabe der prozentualen Verteilung innerhalb der Studienpopulation

Abbildung 6: Gründe für den letzten Zahnarztbesuch mit Angabe der prozentualen Verteilung innerhalb der Studienpopulation

Abbildung 7: Antworten der Studienpopulation auf Fragen zum Zusammenhang von Parodontitis und rheumatoider Arthritis aus dem Fragebogen ,Zahnärztliches Verhalten“"

Abbildung 8: Prozentuale Verteilung der zahnärztlichen Maßnahmen, die bei den Patienten der Studienpopulation im Rahmen einer Zahnsanierung durchgeführt wurden.

Abbildung 9: Antworten der Studienpopulation auf Fragen zur Mundhygiene aus dem Fragebogen „Zahnärztliches Verhalten“

Abbildung 10: Prozentuale Verteilung der bejahten Fragen des Parodontitisfragebogens.47

Abbildung 11: Darstellung des Alters bei Erstdiagnose bei unterschiedlicher Anzahl fehlender Zähne.

Abbildung 12: Darstellung der DAS28-Werte bei unterschiedlicher Anzahl fehlender Zähne

Abbildung 13: Darstellung der Dauer der Morgensteifigkeit bei unterschiedlichem durchschnittlichen klinischen Attachmentverlust

Abbildung 14: Darstellung der Konzentration des Rheumafaktors im Blut bei unterschiedlichem Schweregrad der Parodontitis nach Page und Eke (2007) .......51

Abbildung 15: Darstellung der Konzentration des Rheumafaktors im Blut bei unterschiedlichem durchschnittlichen klinischen Attachmentverlust

Abbildung 16: Darstellung der Blutsenkungsgeschwindigkeit nach einer Stunde Wartezeit bei unterschiedlichem durchschnittlichen Attachmentverlust.

Abbildung 17: Darstellung der Konzentration von Interleukin-6 im Blut bei den verschiedenen Medikamentengruppen

Abbildung 18: Übersicht über die Ergebnisse und Assoziationen der vorliegenden Studie. 


\section{Tabellenverzeichnis}

Tabelle 1: ACR/EULAR-Klassifikationskriterien für die rheumatoide Arthritis von 2010..6

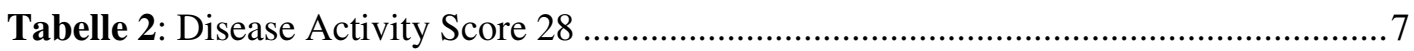

Tabelle 3: Einteilung des Parodontalzustandes nach Page und Eke (2007) ......................... 11

Tabelle 4: Hypothesen zur Kausalität der Wechselbeziehung zwischen rheumatoider Arthritis und Parodontitis

Tabelle 5: Übersicht über die im Text aufgeführten Medikamente zur Therapie der

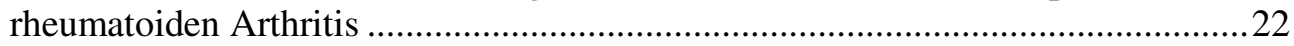

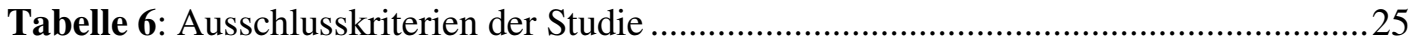

Tabelle 7: Gruppeneinteilung der Patienten anhand der Anzahl fehlender Zähne ...............27

Tabelle 8: Gruppeneinteilung der Patienten anhand der durchschnittlichen

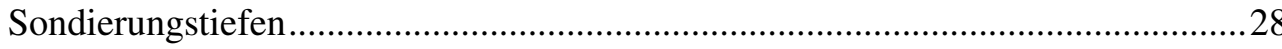

Tabelle 9: Gruppeneinteilung der Patienten anhand des durchschnittlichen klinischen Attachmentverlustes...

Tabelle 10: Gruppeneinteilung der Patienten anhand des Parodontalzustandes nach Page und Eke (2007)

Tabelle 11: Erhobene klinisch-rheumatologische sowie serologische Parameter zur Bestimmung der Krankheitsaktivität der rheumatoiden Arthritis ...........................30

Tabelle 12: Erfasste Medikamente zur Behandlung der rheumatoiden Arthritis ..................30

Tabelle 13: Liste der verwendeten Geräte zur Bearbeitung der Blutproben ........................32

Tabelle 14: Liste der verwendeten Verbrauchsmaterialien zur Bearbeitung der

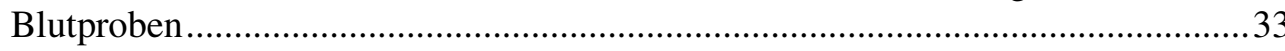

Tabelle 15: Liste der verwendeten Chemikalien zur Bearbeitung der Blutproben................33

Tabelle 16: Einteilung der Medikamentengruppen für den ELISA-Test .............................34

Tabelle 17: Liste der verwendeten Immunoasseys zur Bestimmung der Konzentration von

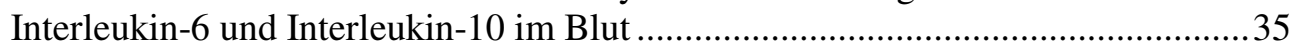

Tabelle 18: Geräte, Verbrauchsmaterialien und Chemikalien für den ELISA-Test..............36

Tabelle 19: Alter und Rauchgewohnheiten der Studienpopulation.......................................38

Tabelle 20: Klinisch-rheumatologische Parameter der Studienpopulation ...........................39

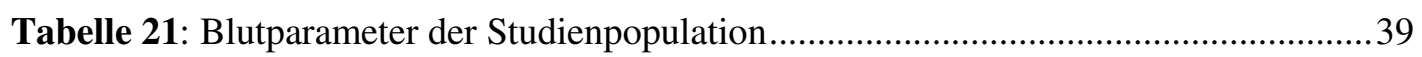

Tabelle 22: Rheumamedikation der Studienpopulation .....................................................40

Tabelle 23: Dentale Befunde der Studienpopulation..................................................... 41

Tabelle 24: Patientenverteilung in den einzelnen Gruppen der vier parodontalen Parameter.

Tabelle 25: Assoziationen zwischen parodontalen und klinisch-rheumatologischen Parametern sowie Blutparametern mit Angabe der entsprechenden p-Werte..........48

Tabelle 26: Assoziationen zwischen den vier parodontalen Parametern und der Einnahmedauer von Rheumamedikamenten mit Angabe der entsprechenden pWerte

Tabelle 27: Übersicht über die Konzentrationen von Interleukin-6 und Interleukin-10 im Blut unter dem Einfluss unterschiedlicher Rheumamedikation

Tabelle 28: Zusammenfassung der wichtigsten Ergebnisse der Studie................................57 


\section{Abkürzungsverzeichnis}

\begin{tabular}{|c|c|}
\hline ACPA & anti citrullinated peptid antibodies \\
\hline ACR & American College of Rheumatology \\
\hline Anti-CCP & Antikörper gegen cyclische citrullinierte Peptide \\
\hline BOP & bleeding on probing \\
\hline BSG & Blutsenkungsgeschwindigkeit \\
\hline CAL & clinical attachment loss \\
\hline CRP & C-reaktives Protein \\
\hline csDMARDs & conventional synthetic disease modifying anti-rheumatic drugs \\
\hline DAS28 & disease activity score 28 \\
\hline DMARDs & disease modifying anti-rheumatic drugs \\
\hline DMFT & Index zur Messung der Kariesinzidenz \\
\hline ELISA & enzyme-linked immunosorbent assay \\
\hline EULAR & European League Against Rheumatism \\
\hline GCF & gingival cervical fluid \\
\hline HLA & human leucocyte antigen \\
\hline $\mathrm{IgG}$ & Immunglobulin $\mathrm{G}$ \\
\hline $\operatorname{IgM}$ & Immunglobulin $\mathrm{M}$ \\
\hline IL & Interleukin \\
\hline IL-6 & Interleukin-6 \\
\hline IL-6R & membrangebundener Interleukin-6-Rezeptor \\
\hline IL-10 & Interleukin-10 \\
\hline MMPs & Matrixmetalloproteinasen \\
\hline M-T & missing teeth \\
\hline MTX & Methotrexat \\
\hline NSAR & Nichtsteroidale Antirheumatika \\
\hline OPG & Osteoprotegerin \\
\hline $\mathrm{PA}$ & Chronische Parodontitis \\
\hline $\begin{array}{l}\text { PZR } \\
\end{array}$ & Professionelle Zahnreinigung \\
\hline RA & Rheumatoide Arthritis \\
\hline RANK & receptor activator of $N F-\kappa B$ \\
\hline RANKL & receptor activator of $N F-\kappa B$ ligand \\
\hline $\mathrm{RF}$ & Rheumafaktor \\
\hline SA & Standardabweichung \\
\hline sIL-6R & löslicher Interleukin-6-Rezeptor \\
\hline
\end{tabular}




\begin{tabular}{|l|l|}
\hline ST & Sondierungstiefe \\
\hline TIMP & tissue inhibitors of metalloproteinases \\
\hline TZC & Tocilizumab \\
\hline UPT & Unterstuitzende Parodontitistherapie \\
\hline
\end{tabular}




\section{$1 \quad$ Einleitung}

Rheumatoide Arthritis (RA) und chronische Parodontitis (PA) sind die häufigsten chronischen entzündlichen Erkrankungen mit bemerkenswerten pathologischen und klinischen Ähnlichkeiten (Joseph et al. 2013).

Rheumatoide Arthritis ist eine chronische entzündliche Autoimmunerkrankung, die durch eine Entzündung der Synovia und dem Abbau von Knorpel und Knochen in den Gelenken charakterisiert ist, was zur Zerstörung der Gelenkstrukturen und damit zum Funktionsverlust führt (Kobayashi et al. 2014a). Als Systemerkrankung manifestiert sich die RA auch extraarticulär (Bartold et al. 2005). Die genaue Pathophysiologie der RA hat eine sehr hohe Komplexität, die noch nicht vollständig verstanden wird (McInnes und Schett 2011; Zampeli et al. 2015).

Parodontitis ist eine chronisch entzündliche Erkrankung des Parodonts, die durch Knochen- und Attachmentverlust gekennzeichnet ist und unbehandelt zum Zahnverlust führen kann. Parodontopathogene Mikroorganismen und Entzündungsmoleküle können über die gingivalen Blutgefäße in die systemische Zirkulation gelangen und sind mit zahlreichen Erkrankungen des Gesamtorganismus assoziiert (Meyle und Chapple 2015). Obwohl primär durch Bakterien verursacht, ist die Krankheit multifaktoriell und daher komplex.

Um die Assoziationen beider Krankheiten zu bewerten, wurden zahlreiche Studien durchgeführt. Signifikante Zusammenhänge konnten sowohl in klinischen als auch in deskriptiven und statistischen Studien nachgewiesen werden (Araújo et al. 2015). Es wurde berichtet, dass Patienten mit rheumatoider Arthritis eine erhöhte Prävalenz für Parodontitis haben (Mercado et al. 2001; Havemose-Poulsen et al. 2007; Pischon et al. 2008; Dissick et al. 2010), während Patienten mit mittelschwerer bis schwerer Parodontitis eine höhere Prävalenz von rheumatoider Arthritis aufweisen als Patienten ohne Parodontitis (Mercado et al. 2000; Dissick et al. 2010; Demmer et al. 2011).

Die Assoziationen dürften dabei unabhängig von anderen Risikofaktoren wie Rauchen oder schlechter Mundhygiene sein (Pischon et al. 2008). Zudem scheint es einen Zusammenhang zwischen dem Ausmaß und der Schwere der beiden Erkrankungen zu geben. Die Kausalität der Wechselbeziehung zwischen RA und PA blieb bisher jedoch fraglich. Beide Erkrankungen sind destruktive entzündliche Funktionsstörungen und resultieren aus der Dysregulation der entzündlichen Wirtsantwort. Beide Zustände potenzieren sich 
durch eine übertriebene entzündliche Immunantwort mit Erhöhung der lokalen und systemischen proinflammatorischen Mediatoren, was zur Zerstörung der weich- und hartgewebigen Strukturen des Zahnhalteapparats (Parodontium) und der Gelenke führt (Berthelot und Le Goff 2010; Detert et al. 2010; Culshaw et al. 2011). Dabei zeigen beide Erkrankungen ähnliche Zytokinprofile (Mercado et al. 2003).

Es werden Mechanismen beschrieben, die es jeder dieser chronischen entzündlichen Erkrankungen ermöglichen würde, über eine Zunahme der systemischen Entzündung, die andere Erkrankung zu initiieren oder zu verstärken (Payne et al. 2015). Die bidirektionale Beziehung zwischen den zwei Krankheiten könnte daher mit der allgemeinen Wirtsimmunantwort sowie mit der ähnlichen Pathophysiologie zusammenhängen (Kobayashi und Yoshie 2015).

Ein wichtiger Aspekt in diesem Zusammenhang ist die Heterogenität der RA-Patienten in Bezug auf ihre medikamentöse Therapie mit verschiedenen krankheitsmodifizierenden Antirheumatika (disease modifying anti-rheumatic drugs, DMARDs) (Zampeli et al. 2015). Besonders die parodontale Entzündung, aber auch entzündliche Marker könnten durch verschiedene immunsuppressive Medikamente beeinflusst werden (Han und Reynolds 2012; Kobayashi et al. 2014b).

Folglich war das Ziel der vorliegenden Studie bei Patienten mit rheumatoider Arthritis Parameter der Krankheitsaktivität (klinisch und serologisch) in Abhängigkeit von objektivierbaren Parametern des Parodontalzustandes zu erfassen. Des Weiteren wurde der Einfluss der immunsuppressiv wirkenden Rheumamedikamente auf den Parodontitisschweregrad und auf Serumspiegel definierter immunmodulatorischer Zytokine untersucht.

Dazu wurden zwei Annahmen formuliert. Die erste Hypothese besagt, dass der Parodontitisschweregrad im Zusammenhang mit der Erkrankungsaktivität von rheumatoider Arthritis steht, einschließlich erhöhter RA-bezogener Blutparameter. In einer zweiten Arbeitshypothese wurde angenommen, dass die Einnahme immunsuppressiver Rheumamedikamente einen Einfluss auf den Parodontitisschweregrad hat. Durch Abnahme proinflammatorisch wirkender Zytokine im Blut könnte die Einnahme der Immunsuppressiver zu einer Verbesserung des Parodontitisschweregrades führen.

Um die Ergebnisse in einen Kontext setzen zu können, wurde in Fragebögen das zahnärztliche Verhalten sowie das Auftreten parodontaler Veränderungen bei der Studienpopulation erfragt. 


\subsection{Einführung in die Pathogenese der rheumatoiden Arthritis}

Die rheumatoide Arthritis ist eine chronische, immunvermittelte entzündliche Erkrankung, die gekennzeichnet ist durch eine Entzündung der Synovialmembran (Synovialitis) und der progressiven Zerstörung von Knorpel und Knochen. Dieses führt zu strukturellen Schäden der Gelenke und dadurch zu Behinderungen und Funktionsverlust (de Pablo et al. 2009). Da es sich um eine systemische Erkrankung handelt, manifestiert sich die RA auch pulmonal, cardial, oculär, vasculär und an anderen Organen und Strukturen, die vom entzündlichen Prozess beeinflusst sind (Bartold et al. 2005).

Mit einer Prävalenz von 0,3 bis 1,0 \% der erwachsenen Bevölkerung ist die RA die häufigste entzündliche rheumatische Erkrankung (Pfeil et al. 2018). Sie kann grundsätzlich in jedem Lebensalter auftreten, der Gipfel der Neuerkrankungen liegt aber bei Frauen zwischen dem 55. und 64. Lebensjahr und bei Männern zwischen dem 65. und 75. Lebensjahr (Symmons 2002). Frauen erkranken dabei dreimal so häufig wie Männer (Lee und Weinblatt 2001; Pischon et al. 2008).

RA hat erhebliche negative Auswirkungen auf die Leistungsfähigkeit, sowohl im Alltag als auch bei der Berufsausübung und damit auf die Lebensqualität. Neben der zunehmenden Morbidität ist auch die Mortalität erhöht (Pincus et al. 1984; Solomon et al. 2003; Salaffi et al. 2009).

Die Ätiologie und pathophysiologischen Mechanismen von RA werden intensiv diskutiert (Bartold et al. 2005; Smolik et al. 2009). Die Auslöser, welche eine Verletzung der Immuntoleranz initiieren und anschließend zu einer Progression der klinisch relevanten Autoimmunität und damit zu den klinischen RA-Symptomen führen, sind noch unbekannt (Culshaw et al. 2011). Sie umfassen wahrscheinlich biomechanische Faktoren, neuroimmunologische Interaktionen und veränderte articuläre und mikrovasculäre Funktionen (McInnes und Schett 2007).

Sowohl individuelle Faktoren (Alter und Geschlecht) als auch genetische und ökologische Faktoren wie Rauchen (Heliövaara et al. 1993; Klareskog et al. 2006a; Lundström et al. 2009) und Infektionen (Hyrich und Inman 2001; Cox et al. 2003; Li et al. 2013) scheinen eine erhebliche Rolle bei der Krankheitsanfälligkeit zu spielen (Klareskog et al. 2006b). Es wird angenommen, dass ein umweltbedingter oder infektiöser Stimulus bei einer genetisch veranlagten Person eine Autoimmunreaktion auslösen kann (Lundberg et al. 2010) oder mit Rezidiven in Verbindung steht (Martinez-Martinez et al. 2009). 
Die RA ist genetisch mit dem HLA-DRB1-Allel des HLA-Komplexes (HLADRB1 * 0101, -DRB1 * 0401 und -DRB1 * 0404) assoziiert, die ein gemeinsames Epitop enthalten und für ein Gen kodieren, dass bei der Aktivierung von T-Lymphozyten von Bedeutung ist (Reichert et al. 2015). Es wird angenommen, dass diese HLA-Moleküle (human leucocyte antigen) die Krankheitspathogenese durch selektive Bindung arthrogener Peptide zur autoreaktiven Präsentation von CD4+ T-Zellen beeinflussen können (Gregersen et al. 1987). Die aktivierten T-Lymphozyten regen B-Lymphozyten zur Produktion von Immunglobulinen und Makrophagen zur Bildung von proinflammatorischen Zytokinen an (Bernhard und Villiger 2001).

Diese Hypothese wird durch die Entdeckung von Citrullin-spezifischer Autoimmunität unterstützt (Klareskog et al. 2008; Wegner et al. 2010). Citrullinierung ist die post-translationale Umwandlung von Peptidylarginin zu Peptidylcitrullin, wobei die terminal positiv geladene Aminogruppe des Arginins gespalten wird. Dies führt zu Strukturänderungen der Proteine, was ihre Bindungsaffinität zu den HLA-Molekülen signifikant erhöht und dadurch zur Erzeugung von Autoantikörpern gegen citrullinierte Peptide führt (Hill et al. 2003).

Autoimmunität manifestiert sich als die Produktion von Rheumafaktoren (RF) und/oder spezifischen Antikörpern gegen cyclische citrullinierte Peptide (anti citrullinated peptid antibodies, ACPA/Anti-CCP). Rheumafaktoren sind Autoantikörper (meist Immunglobulin M, IgM), die gegen Epitope der Fc-Abschnitte von Immunglobulin-G- (IgG) Antikörpern gerichtet sind (Renz 2009) und zur Komplementaktivierung sowie zur Verstärkung der Entzündung führen (Bernhard und Villiger 2001). Rheumafaktoren sind bei $65-80 \%$ der RA-Patienten positiv, kommen aber auch bei anderen rheumatischen Erkrankungen vor und sind bei ca. $5 \%$ gesunder Menschen nachweisbar. Daher liegt die Sensitivität von IgM-Rheumafaktoren für eine RA bei ca. $70 \%$, während die Spezifität $80 \%$ beträgt (Schneider et al. 2011). Erhöhte Level von Rheumafaktoren korrelieren jedoch häufig mit schweren Krankheitsverläufen, systemischer Manifestation und mit einer schlechteren Prognose (Hettenkofer et al. 2015).

„Als Antikörper gegen citrullinierte Peptide/Proteine (ACPA) werden (bislang) solche gegen cyclisches Citrullin (CCP), mutiertes (MCV) und nicht mutiertes $(\mathrm{Sa})$ citrulliniertes Vimentin sowie gegen citrulliniertes Fibrinogen zusammengefasst, die auch eine weitgehende Kreuzreaktivität aufweisen“" (Schneider et al. 2011). 
Diese sind zu $95 \%$ spezifisch und zu $68 \%$ sensitiv für RA (Avouac et al. 2006; Nishimura et al. 2007). Der Nachweis von ACPA kann einer klinisch manifesten RA um Jahre vorausgehen und hat einen hohen prädiktiven Wert für die Entwicklung einer RA (Rantapää-Dahlqvist et al. 2003; Nielen et al. 2004).

Der initialen Immunreaktion schließt sich eine komplexe Kaskade entzündlicher Prozesse an, die zu einer Synovitis führen (Bernhard und Villiger 2001). Charakteristisch für die RA ist die Ausbildung eines aggressiven Granulationsgewebes in der Synovialmembran, dem sogenannten Pannus (Abeles und Pillinger 2006). Dabei handelt es sich um einen dichten Zellverband aus synovialen Fibroblasten und aktivierten Makrophagen (Culshaw et al. 2011). Unter dem Einfluss von Entzündungsmediatoren sezernieren diese Zellen weitgehend autonom katabole Enzyme (Matrixmetalloproteinasen, MMPs) und stimulieren die Osteoklastengenese, was zur Destruktion von Knorpel und Kochen führt (Choy und Panayi 2001).

Als klinisches Leitsymptom imponiert eine schmerzhafte, symmetrische Polyarthritis (Bukhari et al. 2002), die vor allem an den Hand-, Fingergrund-, Fingermittel- und/oder Zehengrundgelenken auftritt. Die betroffenen Gelenke zeigen typische Entzündungszeichen, sind geschwollen, warm, druckdolent und steif. Ebenfalls kennzeichnend ist eine Morgensteifigkeit, die über eine Stunde anhält, im Tagesverlauf jedoch nicht wieder auftritt (Visser et al. 2002; van der Helm-van Mil et al. 2007).

Die Entzündungsaktivität führt zum Verlust des Gelenkknorpels und zu Erosionen am gelenkbildenden Knochen und damit zur Zerstörung der Gelenkoberfläche. Es resultieren Deformitäten der Gelenkkörper, was zu funktionellen Störungen und zur Atrophie der Muskulatur führt. Auch das periarticuläre Bindegewebe (Schleimbeutel, Sehnen, Sehnenscheiden) ist vielfach mit betroffen (Persson 2012). Begleitend können grippeähnliche Allgemeinsymptome auftreten und im Verlauf der Erkrankung kann es zu extraarticulären Manifestationen kommen (Thumb et al. 2001).

Die Grundlage der Diagnose einer RA sind die Anamnese und die klinische Untersuchung, ergänzt durch gezielte Laboruntersuchungen (Blutsenkungsgeschwindigkeit (BSG), C-reaktives Protein (CRP), Rheumafaktor, Anti-CCP) und bildgebende Diagnostik (Röntgenbilder, Magnetresonanztomographie) (Persson 2012).

Um Patienten bereits in einem frühen Erkrankungsstadium zu identifizieren, wurden in Zusammenarbeit von der European League Against Rheumatism (EULAR) und dem 
American College for Rheumatology (ACR) 2010 neue Klassifikationskriterien aufgestellt (Aletaha et al. 2010). Die in Tabelle 1 aufgeführten Bewertungspunkte der Kategorien A-D werden addiert, was einen Wert zwischen $0-10$ ergibt. Bei einem Wert $\geq 6$ Punkten kann die Diagnose einer definitiven RA gestellt werden.

Tabelle 1: ACR/EULAR-Klassifikationskriterien für die rheumatoide Arthritis von 2010 (Aletaha et al. 2010)

\begin{tabular}{|c|c|c|c|c|}
\hline A & B & $\mathbf{C}$ & D & \\
\hline $\begin{array}{l}\text { Gelenkbeteiligung } \\
\text { (Schwellung und } \\
\text { Druckdolenz) }\end{array}$ & $\begin{array}{l}\text { Serologie } \\
\text { Rheumafaktor (RF) } \\
\text { anti citrullinated pep- } \\
\text { tid antibodies (ACPA) }\end{array}$ & $\begin{array}{l}\text { Akute-Phase-Parameter } \\
\text { C-reaktives Protein (CRP) } \\
\text { Blutsenkungsgeschwin- } \\
\text { digkeit (BSG) }\end{array}$ & $\begin{array}{l}\text { Symp- } \\
\text { tom- } \\
\text { dauer }\end{array}$ & Punkte \\
\hline $\begin{array}{l}<1 \text { (mittel)großes } \\
\text { Gelenk }\end{array}$ & RF und ACPA negativ & CRP und BSG normal & $<6$ Wochen & 0 \\
\hline $\begin{array}{l}2-10 \text { (mittel)große } \\
\text { Gelenke }\end{array}$ & & CRP oder BSG erhöht & $\begin{array}{l}\geq 6 \\
\text { Wochen }\end{array}$ & 1 \\
\hline $\begin{array}{l}1 \text { - } 3 \text { kleine Gelenke } \\
\text { (mit/ohne Beteiligung } \\
\text { großer Gelenke) }\end{array}$ & $\begin{array}{l}\text { RF und ACPA niedrig } \\
\text { positiv }\end{array}$ & & & 2 \\
\hline $\begin{array}{l}4-10 \text { kleine Gelenke } \\
\text { (mit/ohne Beteiligung } \\
\text { großer Gelenke) }\end{array}$ & $\begin{array}{l}\text { RF und ACPA hoch } \\
\text { positiv }\end{array}$ & & & 3 \\
\hline $\begin{array}{l}>10 \text { Gelenke }(\text { davon } \geq \\
1 \text { kleines Gelenk) }\end{array}$ & & & & 5 \\
\hline \multicolumn{5}{|l|}{ Definitionen: } \\
\hline \multicolumn{5}{|c|}{$\begin{array}{l}\text { kleine Gelenke: Fingergrund- (MCP) und Fingermittelgelenke (PIP) } 1-5 \text {; Zehengrundgelenke (MTP) } \\
2-5, \text { Großzehenmittelgelenke (IP 1) und Handgelenke. Ausgeschlossen von der Bewertung sind: Dau- } \\
\text { mensattelgelenke (CMC 1), Großzehengrundgelenke (MTP 1), Finger- und Zehenendgelenke (DIP). } \\
\text { mittlere und große Gelenke: Schulter-, Ellenbogen-, Hüft-, Knie-, Sprunggelenke. }\end{array}$} \\
\hline \multicolumn{5}{|c|}{ Es wird jedes geschwollene oder druckschmerzhafte Gelenk der obigen Liste gewertet. } \\
\hline \multicolumn{5}{|c|}{$\begin{array}{l}\text { Serologie: Rheumafaktor oder ACPA werden als hoch-positiv gewertet, wenn deren Wert über dem 3- } \\
\text { fachen des oberen Normwertes liegt. Das Kriterium einer Akuten-Phase-Reaktion ist erfüllt, wenn CRP } \\
\text { oder BSG erhöht sind. Bei der BSG sind physiologisch erhöhte Werte (Alter, Geschlecht, Schwanger- } \\
\text { schaft) zu berücksichtigen und im Zweifelsfalle nicht zu werten. }\end{array}$} \\
\hline
\end{tabular}

(ACR: American College for Rheumatology, EULAR: European League Against Rheumatism) 
Um im klinischen Alltag die Krankheitsaktivität und ihren Verlauf sowie das individuelle Ansprechen auf die Therapie objektiv beurteilen zu können, wurde von der EULAR der disease activity score 28 (DAS28) als validierter Index entwickelt (Wells et al. 2008). Der DAS28 kombiniert die Informationen über geschwollene und druckschmerzhafte Gelenke, das Akute-Phase-Protein (CRP oder BSG) und den allgemeinen Gesundheitszustand miteinander und gibt so einen beständigen Maßstab für den Entzündungszustand (Fransen und van Riel 2005). Tabelle 2 zeigt die Definitionen des DAS28 mit den entsprechenden Score-Werten.

Tabelle 2: Disease Activity Score 28 (DAS28) (Fiehn et al. 2018)

\begin{tabular}{|l|l|}
\hline Definition & Score \\
\hline niedrige Krankheitsaktivität & $\geq 2,6-<3,2$ \\
\hline moderate Krankheitsaktivität & $3,2-<5,1$ \\
\hline hohe Krankheitsaktivität & $\geq 5,1$ \\
\hline
\end{tabular}

Eine ursächliche Therapie der RA ist zurzeit nicht möglich. Somit ist die Remission (DAS28 < 2,6) bzw. eine Kontrolle der Krankheitsaktivität (DAS28 $\leq 3,2$ ) das primäre therapeutische Ziel (Schneider et al. 2011; Fiehn et al. 2018). Um dies zu erreichen sollte idealerweise eine Therapie mit krankheitsmodifizierenden Substanzen innerhalb von drei Monaten nach Beginn der Symptome im Rahmen eines interdisziplinären Therapiekonzeptes begonnen werden (O’Dell 2002; Boers 2003).

\subsection{Einführung in die Pathogenese der chronischen Parodontitis}

Bei der Parodontitis kommt es aufgrund einer übersteigerten Immunreaktion auf das mikrobielle Keimspektrum zu einem chronisch entzündlichen Prozess des gesamten Zahnhalteapparates (Parodontiums). Dieser führt im Verlauf der Erkrankung zu einem irreversiblen Verlust von parodontalem Gewebe und unbehandelt zum Zahnverlust (Schütt und von Baehr 2012). Darüber hinaus ist Parodontitis mit systemischen Erkrankungen wie Diabetes mellitus, Atherosklerose, Adipositas und weiteren assoziiert (Schulze und Dommisch 2013). Es besteht ein ätiologischer oder krankheitsmodifizierender Einfluss (Detert et al. 2010). 
Mit einer Prävalenz von 11,2 \% ist PA weltweit die sechsthäufigste Erkrankung bei Erwachsenen (Kassebaum et al. 2014). Sie stellt die häufigste Ursache für Zahnverlust dar, mit steigender Krankheitslast im zunehmenden Alter (Petersen und Ogawa 2012). Laut der fünften deutschen Mundgesundheitsstudie ,,[...] ist jeder zweite [der 35 - 44-Jährigen] (52 Prozent) von einer parodontalen Erkrankung betroffen, davon weisen 43,4 Prozent eine moderate Parodontitis und rund jeder Zehnte eine schwere Parodontitis auf.“ (Institut der Deutschen Zahnärzte 2016). „[...] fast jeder Zweite in [der] Altersgruppe [der 65 - 74-Jährigen] [hat] eine moderate (44,8 Prozent) und jeder Fünfte eine schwere Parodontitis.“ (Institut der Deutschen Zahnärzte 2016).

Unter dem Begriff „,parodontale Erkrankungen“ werden sowohl entzündliche als auch degenerative Erkrankungen der Gingiva und des Parodonts zusammengefasst (Page und Schroeder 1982). Dabei ist die chronische, plaque-assoziierte Parodontitis die häufigste Form mit einer Prävalenz von 80 - 90 \% (Saini et al. 2009). Die Erkrankung kann in jedem Lebensalter entstehen, sie beginnt jedoch am häufigsten nach dem 35. Lebensjahr (Flemmig 1999). Dieser Prozess kann alle, mehrere oder nur einzelne Zähne bzw. Zahnflächen betreffen.

Die Ätiologie der Parodontitis ist multifaktoriell und damit komplex. Das mikrobielle Ökosystem der Mundhöhle ist ein Lebensraum für eine Vielzahl von bakteriellen und viralen Spezies. Im Gesunden besteht eine Symbiose zwischen den ansässigen Mikroorganismen des Biofilms und der entzündlichen Immunantwort des Wirtes auf den Biofilm (Meyle und Chapple 2015). Unter physiologischen Bedingungen sind auch Pathobionten wie Parodontitis-fördernde Keime (Porphyromonas gingivalis, Tanerella forsythia, Treponema denticola und Aggregatibacter actinomycetemcomitans) natürlicher Bestandteil der oralen Mikrobiota (Hajishengallis 2015).

Durch einen kontrollierten immunentzündlichen Zustand wird die Homöostase der Wirtsmikroben im Parodontium und dadurch die parodontale Gesundheit aufrechterhalten (Darveau 2014). Kommt es zu einem Ungleichgewicht in der relativen Häufigkeit oder dem Einfluss dieser proinflammatorisch wirkenden Keime, entsteht eine Dysbiose mit pathogener Entität (Hajishengallis und Lamont 2012; Abusleme et al. 2013; Han und Wang 2013). Ursächlich dafür können eine vermehrte Verfügbarkeit von Substraten im Sulkusfluid und im Speichel sowie eine verminderte kompetitive Hemmung durch andere Bakterienarten sein. Des Weiteren können Konditionen, die zu einer Zunahme der systemischen Entzündungslast führen, Einfluss nehmen (Wu et al. 2015). 
Durch den Schutz der Biofilmmatrix entgehen die Keime einer Eliminierung durch die zellulären und humoralen Elemente des parodontalen Immunsystems. Zudem wird die Entzündung durch die Synthese von Stoffwechselprodukten und spezifischen Virulenzfaktoren (Lipopolysaccharide) aufrechterhalten (Schlagenhauf 2017).

„Die hierdurch ausgelöste permanente Einwanderung von Entzündungszellen und Freisetzung großer Mengen proinflammatorisch wirksamer Substanzen wie Zytokine, gewebsauflösender Metallomatrixproteinasen und freier Sauerstoffradikale führt zur progredienten Zerstörung der Strukturen des Paradontiums.“ (Schlagenhauf 2017)

Somit zeigt sich die Immunantwort als Entzündungsreaktion im parodontalem Gewebe und ist bestimmend für das Ausmaß der parodontalen Destruktion (Chen 2001).

Die lokale und systemische Abwehrleistung kann durch genetische, umweltbezogene, erworbene und/oder angeborene Risikofaktoren beeinflusst werden und sich abhängig von Form und Phase der Erkrankung unterscheiden (Page und Beck 1997). Bei Abwesenheit von krankheitsmodifizierenden Risikofaktoren scheint die Wirtsantwort der bakteriellen Akkumulation angepasst, um sich gegen die bakterielle Invasion zu schützen. Dabei scheint der Wirt fähig zu sein, die parodontale Destruktion zu limitieren. Sind allerdings krankheitsmodifizierende Faktoren beteiligt, führt dies zu einer Veränderung der Immunantwort über die Grenzen der normalen Wirtreaktion hinaus. Es resultieren eine überschwängliche Wirtsantwort und/oder verminderte Reparaturmechanismen und somit eine destruierende Parodontitis (Kornman 2008).

Dabei scheinen einige Risikofaktoren, z. B. hereditäre Faktoren, ein Leben lang Bestand zu haben, während andere Faktoren wie Stress oder Rauchen in verschiedenen Lebensphasen unterschiedlich stark ins Gewicht fallen. Auch systemische Erkrankungen können Einfluss haben und in ihrer Entstehung und in ihrem Verlauf selbst durch eine PA beeinflusst werden (Page 1998). „Das resultierende klinische Bild ist somit das Ergebnis des komplexen Zusammenspiels zwischen mikrobieller Herausforderung, einer übersteigerten Immunantwort oder einer verminderten Erregerabwehr und Risikofaktoren $[\ldots]^{\text {“ }}$ (Stein 2010), wie in Abbildung 1 dargestellt wird. 


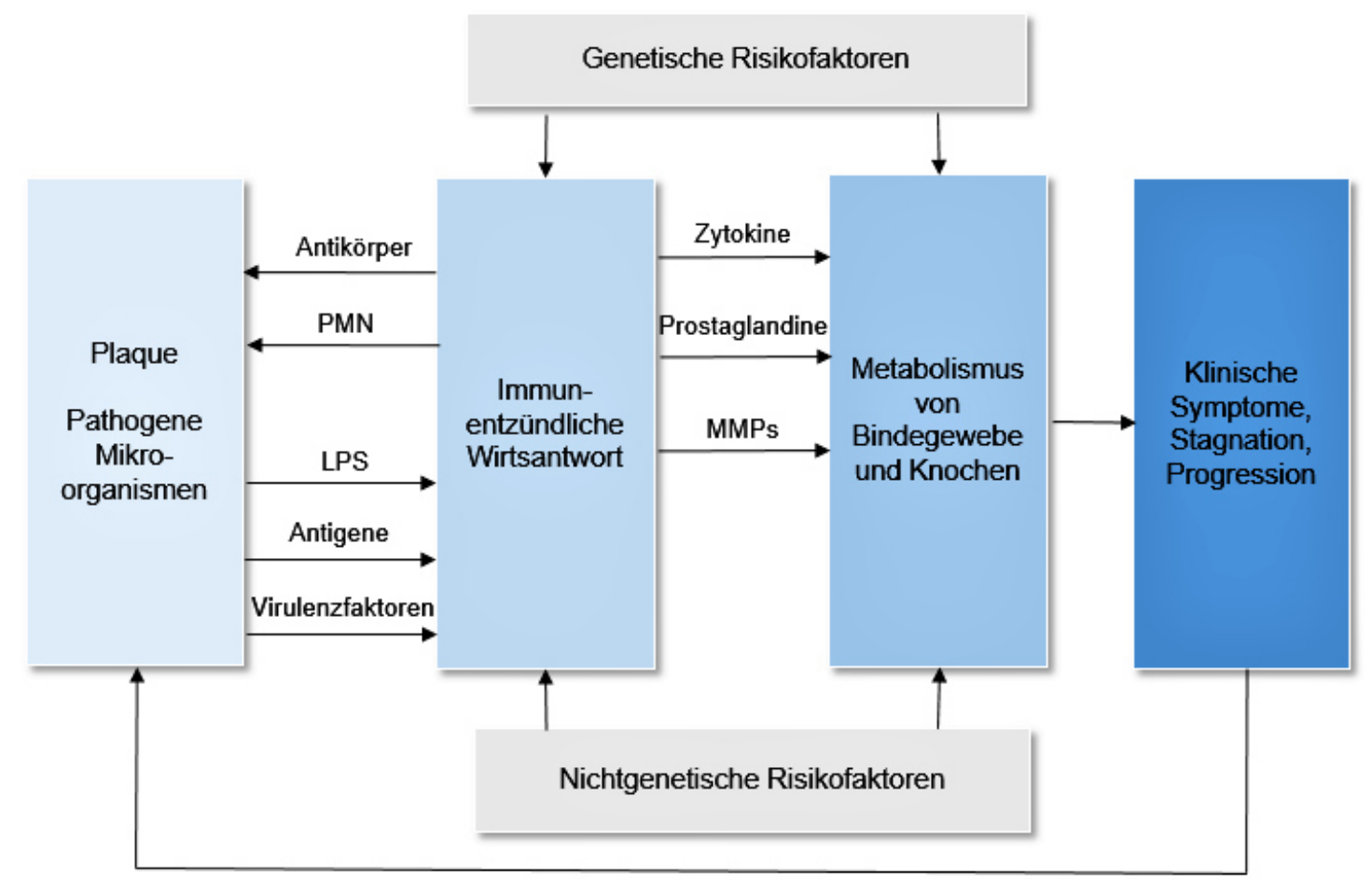

Abbildung 1: Ätiologie und Pathogenese der Parodontitis nach Page und Kornman (1997) (PMN: polymorphkernige neutrophile Granulozyten, LPS: Lipopolysaccharide, MMPs: Matrixmetalloproteinasen)

Durch den Stützgewebsverlust kommt es zur Taschenbildung, was eine weitere Belagsakkumulation im interdentalen- und Wurzelbereich begünstigt. Aktive Taschen zeigen positive Provokationsblutungen und eine vermehrte Absonderung von Sulkusflüssigkeit und Pus. Im Verlauf der Erkrankung kommt es zu Rezessionen, Furkationen, zunehmender pathologischer Zahnbeweglichkeit und Zahnstellungsänderungen, was sowohl zu funktionellen als auch zu ästhetischen Einschränkungen führt (Brunsvold 2005). Radiologisch zeigt sich ein horizontaler und vertikaler Knochenabbau.

Der messbare klinische Stützgewebsverlust (clinical attachment loss, CAL) nimmt mit Dauer des Bestehens der chronischen PA und mit steigendem Alter zu (Stein 2010). Ab ca. $80 \%$ Attachmentverlust an mehreren Zahnflächen ist ein Zahn nicht mehr erhaltungswürdig (McGuire und Nunn 1996).

Der Schweregrad der Erkrankung wird nach den Kriterien von Page und Eke (2007) anhand des klinischen Attachmentlevels (CAL) und der Sondierungstiefe (ST) bestimmt (siehe Tabelle 3). Zudem kann anhand der Anzahl der betroffenen Zahnflächen eine Unterteilung in eine „lokalisierte“ (weniger als 30 \% der Zahnflächen) oder „generalisierte“ Form (mehr als $30 \%$ betroffen) erfolgen (Armitage 1999). 
Tabelle 3: Einteilung des Parodontalzustandes nach Page und Eke (2007)

\begin{tabular}{|c|c|c|c|}
\hline \multirow{2}{*}{$\begin{array}{l}\text { Einteilung der } \\
\text { Krankheit }\end{array}$} & \multicolumn{3}{|c|}{ Klinische Definition } \\
\hline & $\begin{array}{l}\text { Klinischer Attachmentverlust } \\
\text { (CAL) }\end{array}$ & & $\begin{array}{l}\text { Sondierungstiefen } \\
\text { (ST) }\end{array}$ \\
\hline $\begin{array}{l}\text { keine/milde } \\
\text { Parodontitis }\end{array}$ & \multicolumn{3}{|c|}{ weder schwere noch moderate Parodontitis } \\
\hline $\begin{array}{l}\text { moderate } \\
\text { Parodontitis }\end{array}$ & $\begin{array}{l}\geq 2 \text { approximale Messstellen mit } \\
\text { CAL } \geq 4 \mathrm{~mm} \text { (nicht am selben } \\
\text { Zahn) }\end{array}$ & oder & $\begin{array}{l}\geq 2 \text { approximale Messstellen mit ST } \\
\geq 5 \mathrm{~mm} \text { (nicht am selben Zahn) }\end{array}$ \\
\hline $\begin{array}{l}\text { schwere } \\
\text { Parodontitis }\end{array}$ & $\begin{array}{l}\geq 2 \text { interproximale Messstellen mit } \\
\mathrm{CAL} \geq 6 \mathrm{~mm} \text { (nicht am selben } \\
\text { Zahn) }\end{array}$ & und & $\begin{array}{l}1 \text { interproximale Messstelle mit ST } \\
\geq 5 \mathrm{~mm} \text { (nicht am selben Zahn) }\end{array}$ \\
\hline
\end{tabular}

Die Therapie der Parodontitis erfolgt in mehreren systematisch aufeinander aufbauenden Behandlungsphasen mit dem Ziel, die bakteriellen Reize, die Entzündung sowie die Zahnfleischtaschen $\mathrm{zu}$ beseitigen. Eine weitere Destruktion des Parodontiums soll dadurch verhindert werden (Hierse 2017).

Zunächst kommt es in der Initialphase zu einer Effektivierung der Patientenhygiene, zu einer Verminderung der marginalen Entzündungszeichen sowie zur Herstellung eines hygienefähigen Gebisszustandes. Wenn keine Reizfaktoren mehr bestehen und die Mundhygiene adäquat ist, schließt sich eine korrektive Phase an, die die Entfernung des Biofilms und mineralisierter Biofilmbestandteile von Zahn- und Wurzeloberflächen beinhaltet. Durch Reduktion der parodontopathogenen Bakterien und der entzündlichen Aktivität soll eine Verschiebung der Keimflora induziert werden, damit sich ein natürliches ökologisches Gleichgewicht wiedereinstellen kann.

Anschließend sollte dem Gewebe mindestens drei Monate Zeit zu Heilungs- und Reorganisationsvorgängen gegeben werden. „Der Erfolg zeigt sich in einer Reduktion der Sondierungswerte, im Gewinn an klinischem Attachment sowie in der Ausprägung von Rezessionen.“ (Hierse 2017). Bei Persistenz von Resttaschen oder Entzündungsaktivität kann eine Reinstrumentierung oder eine parodontalchirurgisch-korrektive Therapie in Betracht gezogen werden.

Essenziell für die Aufrechterhaltung gesunder parodontaler Verhältnisse ist die Langzeitbetreuung im Rahmen der unterstützenden Parodontitistherapie (UTP) (Institut der Deutschen Zahnärzte 2016). Hier wird neben der Mundhygienekontrolle und parodontalen Untersuchung eine professionelle mechanische supra- und subgingivale 
Plaqueentfernung durchgeführt (Hierse 2017). Dabei wird das UTP-Intervall in Abhängigkeit von der parodontalen Diagnose sowie den patientenspezifischen Bedürfnissen und Risikofaktoren individuell festgelegt (Sanz et al. 2015).

\subsection{Datenlage zu Assoziationen von rheumatoider Arthritis und Parodontitis}

In zahlreichen Studien wurde bewiesen, dass Parodontitis und rheumatoide Arthritis viele gemeinsame pathologische Merkmale besitzen und ein Zusammenhang zwischen dem Ausmaß und der Schwere der beiden Erkrankungen besteht (Mercado et al. 2000; Mercado et al. 2001; Mercado et al. 2003; de Pablo et al. 2008; Pischon et al. 2008; de Pablo et al. 2009; Dissick et al. 2010; de Smit et al. 2012; Scher et al. 2012; Chen et al. 2013; Koziel et al. 2014; Mikuls et al. 2014).

So haben Patienten mit rheumatoider Arthritis eine signifikant höhere Inzidenz für Parodontitis gemessen an der Anzahl fehlender Zähne und dem Attachmentverlust (Kaur et al. 2013). Ebenso haben Patienten mit Parodontitis eine höhere Prävalenz an rheumatoider Arthritis zu erkranken als diejenigen ohne Parodontitis (Mercado et al. 2000; Dissick et al. 2010; Demmer et al. 2011). Dabei zeigen Studien eine Abhängigkeit vom Erkrankungsschweregrad. RA-Patienten mit schwerer PA wiesen eine höhere Krankheitsaktivität auf als Patienten mit moderater PA oder gesunde Kontrollgruppen (Mikuls et al. 2012).

Durch eine Parodontitistherapie kann die Aktivität der RA gesenkt werden (Ribeiro et al. 2005; Al-Katma et al. 2007; Ortiz et al. 2009; Calderaro et al. 2017). Umgekehrt wird durch eine Therapie der RA mit DMARDs auch die parodontale Situation verbessert, hier könnte es sich jedoch um einen direkten Effekt der Anti-Rheuma-Medikamente auf das Parodont handeln (Pers et al. 2008; Mayer et al. 2009; Mayer et al. 2013; RomeroSanchez et al. 2017).

Da die Kausalität der Wechselbeziehung zwischen RA und PA noch nicht vollständig geklärt wurde (de Pablo et al. 2008; Pischon et al. 2008; de Pablo et al. 2009; Detert et al. 2010; Bingham und Moni 2013), existieren hierzu mehrere Hypothesen, die in Tabelle 4 aufgeführt sind. 
Tabelle 4: Hypothesen zur Kausalität der Wechselbeziehung zwischen rheumatoider Arthritis und Parodontitis

\begin{tabular}{|c|l|}
\hline & $\begin{array}{l}\text { Hypothesen zur Kausalität der Wechselbeziehung zwischen rheumatoider Arthritis und } \\
\text { Parodontitis }\end{array}$ \\
\hline a & $\begin{array}{l}\text { Die Beziehung wird durch die Koexistenz gemeinsamer Risikofaktoren wie Alter, Rauchen und } \\
\text { Geschlecht verursacht (Reichert et al. 2015) }\end{array}$ \\
\hline b & $\begin{array}{l}\text { Assoziationen bestehen aufgrund zugrundeliegender genetischer Risikofaktoren (Bonfil et al. } \\
1999)\end{array}$ \\
\hline c & $\begin{array}{l}\text { Parodontopathogene Bakterien können zur Ätiologie von rheumatischen Erkrankungen beitragen } \\
\text { Loyola-Rodriguez et al. 2010) }\end{array}$ \\
\hline d & \begin{tabular}{l} 
Ursächlich ist ein gemeinsames immunregulatorisches Ungleichgewicht (Mercado et al. 2000) \\
\hline
\end{tabular} \\
\hline
\end{tabular}

Auf Punkt d soll im Folgenden weiter eingegangen werden.

\subsection{Immunregulation}

PA und RA entstehen durch destruktive entzündliche Veränderungen am Zahnhalteapparat und an den Gelenken. Dabei zeigen beide Erkrankungen ein gleiches immunentzündliches Profil (Bartold et al. 2005; Marotte et al. 2006) und demonstrieren die gleichen Zytokin-assoziierten Muster der Weich- und Hartgewebedestruktion. Diese Ähnlichkeiten zwischen RA und PA bestehen sowohl auf zellulärer als auch auf molekularer Ebene und werden im Folgenden dargestellt (Kornman et al. 1997; Reynolds und Meikle 1997; Culshaw et al. 2011; Schmalz et al. 2019).

„Cytokine sind Proteine, die von verschiedenen Zellen [...] produziert werden können und über spezifische Rezeptoren auf der Zellmembran Signale von oder auf Zellen des Immunsystems übertragen.“ (Rink et al. 2015). Eine Regulation des immunentzündlichen Prozesses ist so möglich. Hinsichtlich der Wirkungsweise von Zytokinen lassen sich mehrere Grundsätze zusammenfassen. Die Produktion der Zytokine erfolgt immer als Antwort auf einen Reiz. Indem sie untereinander in enger Wechselwirkung stehen und in einem Netzwerk synergistisch oder antagonistisch agieren, können sie die Proliferation oder Apoptose von Zellen steuern und eine adäquate Immunreaktion ermöglichen (Miehle et al. 2000).

„Jede Zelle kann mehrere Zytokine produzieren; jedes Zytokin wirkt auf mehr als eine Zellart. Ein bestimmter biologischer Effekt kann häufig durch mehrere Zytokine verursacht werden. Jedes Zytokin kann mehr als einen biologischen 
Effekt ausüben. [...] So kann ein Zytokin einen Effekt eines zweiten [...] hemmen, einen anderen Effekt jedoch unbeeinflußt lassen.“ (Miehle et al. 2000)

Aufgrund der komplexen Regulation und der kurzen Halbwertszeit wird sichergestellt, dass die Wirkung eines Zytokins nur so lange anhält, wie der Stimulus zur Produktion anwesend ist. Dies soll den Körper vor überschießenden Zytokinwirkungen und damit vor einer unangemessenen Immunreaktion schützen (Miehle et al. 2000). Durch übermäBige Produktion, Dysregulation oder inadäquate Hemmung kommt es zu pathophysiologischen Prozessen (Bartold et al. 2005).

\subsubsection{Rolle der Zytokine im lokalen Entzündungsprozess bei rheumatoider Arthritis und Parodontitis}

Während bei der rheumatoiden Arthritis die Ursache für die Aktivierung des athrogenen Zytokinnetzwerkes unbekannt ist, stellen bei der Parodontitis die Bakterien und ihre Stoffwechselprodukte den auslösenden Reiz dar. Trotzdem zeigen beide Erkrankungen sehr ähnliche Zytokinprofile bestehend aus anhaltend hohen proinflammatorischen Zytokinen (wie Interleukin-6, IL-6) und niedrigen Zytokinspiegeln, welche die immunoinflammatorische Antwort unterdrücken, z. B. Interleukin-10 (IL-10) (Bartold et al. 2005; Pers et al. 2008; Kaur et al. 2013).

Im Folgenden wird die Rolle der Zytokine IL-6 und IL-10 im Entzündungsprozess von RA und PA näher betrachtet.

Das proinflammatorische Zytokin IL-6 führt unter anderem zur Freisetzung von Matrixmetalloproteinasen (Deo und Bhongade 2010; Garlet 2010). Dies sind Proteasen, die bei gesunden Verhältnissen mit ihren Gegenspielern, den tissue inhibitors of metalloproteinases (TIMP), im Gleichgewicht stehen und an dem physiologischen Auf- und Abbau von extrazellulärer Matrix beteiligt sind. Kommt es bei einem Ungleichgewicht zu einer vermehrten Freisetzung von MMPs, kann dies zur Weich- und Hartgewebsdestruktion führen (Garlet 2010). Zudem wird durch die proinflammatorischen Zytokine (u. a. IL-6) die Expression von RANKL (receptor activator of $N F-\kappa B$ ligand) hochreguliert. Dies ist ein Ligand, der auf der Oberfläche von Osteoklastenvorläuferzellen an den Rezeptor RANK (receptor activator of $N F-\kappa B$ ) bindet, was diese zur Osteoklastendifferenzierung stimuliert und damit zur Knochenresorption führt (Garlet 2010; Kinane et al. 2011; Preshaw und Taylor 2011). 
Osteoprotegerin (OPG) ist der physiologische Gegenspieler, der durch Bindung an RANKL seine Ligation zu RANK verhindert. Sowohl bei der RA als auch bei der PA kann aufgrund des entzündlichen Milieus ein Ungleichgewicht zugunsten von RANKL vorliegen (Schulze und Dommisch 2013).

Zur Verhinderung eines chronischen Entzündungsgeschehens wird die initiierte Entzündungsantwort im Normalfall durch die zeitversetzte Ausschüttung von antientzündlichen Zytokinen wie IL-10 gebremst. Es hemmt die IL-6-Freisetzung und damit die proinflammatorischen Effekte. Zudem schützt IL-10 vor destruktiven Entzündungsvorgängen, indem es über die gesteigerte Freisetzung des MMP8-Gegenspielers TIMP den Gewebeabbau bremst. Zusätzlich verhindert IL-10 über die Induktion von Osteoprotegerin den Knochenbau, da OPG die Wirkung von RANKL an der Zielzelle und somit die Osteoklastenaktivierung hemmt (Zhang und Teng 2006). Abbildung 2 stellt die Wirkungen der oben genannten Zytokine zusammenfassend dar.

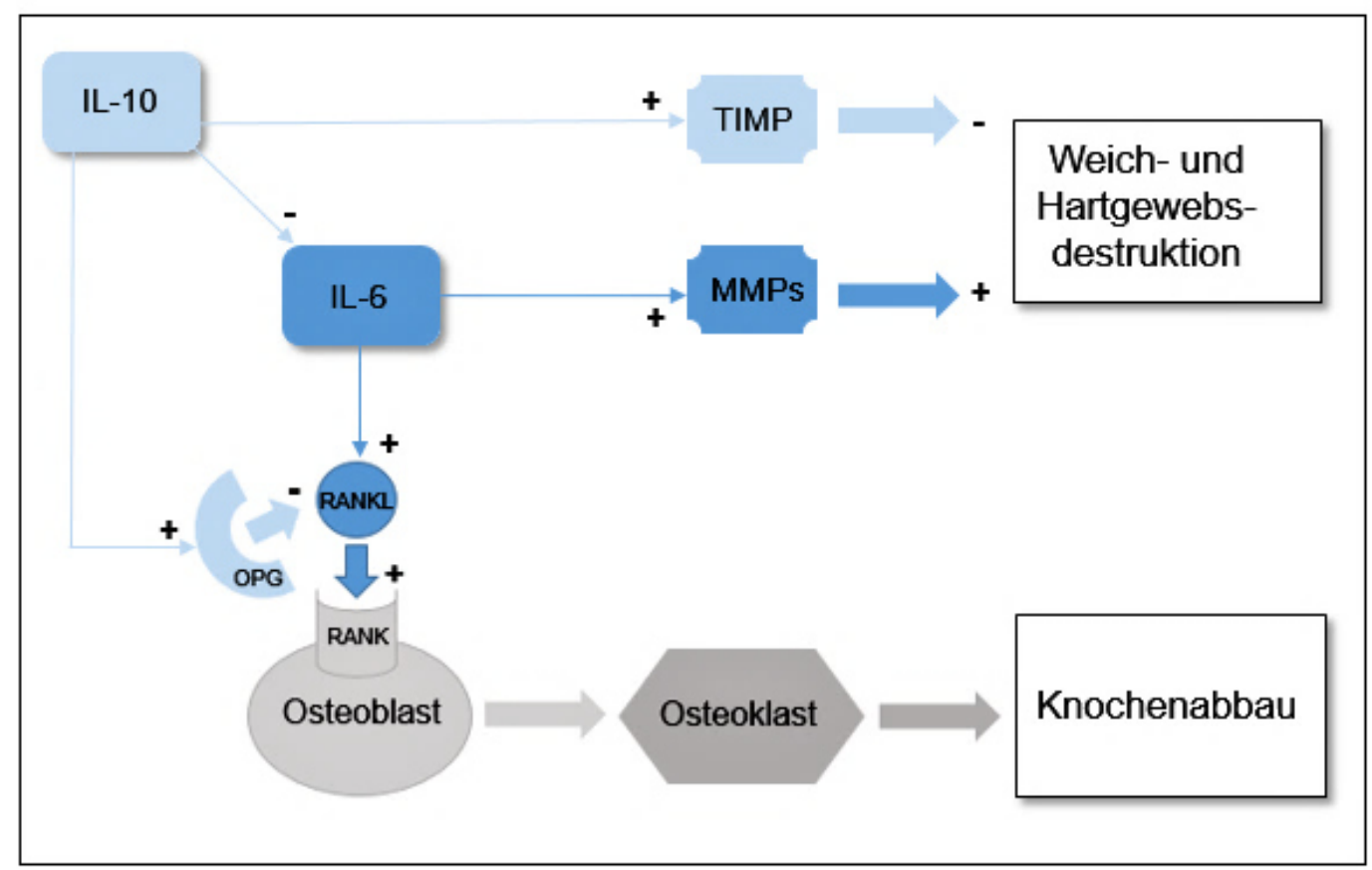

Abbildung 2: Darstellung der Wirkungen von Interleukin-6 (IL-6) und Interleukin-10 (IL-10) im Entzündungsprozess von rheumatoider Arthritis und Parodontitis

(-: Hemmung, +: Aktivierung, TIMP: tissue inhibitors of metalloproteinases, MMPs: Matrixmetalloproteinasen, OPG: Osteoprotegerin, RANKL: receptor activator of NF- $\kappa$ B-ligand, RANK: receptor activator of NF- $\kappa \mathrm{B})$ 
Bei beiden Erkrankungen liegt ein Ungleichgewicht zugunsten der destruierenden gegenüber den protektiven Faktoren vor, was zu Veränderungen des Bindegewebs- und Knochenmetabolismus mit der Folge eines verstärkten Abbaus von Weich- und Hartgewebe führt. Zudem entwickelt sich ein chronischer, selbst erhaltender und progredienter Entzündungszustand (Bernhard und Villiger 2001; Lee et al. 2015), der bei ausreichender Schwere und Dauer bei beiden Erkrankungen mit systemischer Entzündung verbunden ist (Payne et al. 2015).

\subsection{Marker systemischer Entzündung bei rheumatoider Arthritis und Parodontitis}

Sobald eine entzündliche Läsion im Parodontium etabliert ist, können Bakterien ihre Endotoxine und Antigene aus dem Zahnbelag durch das ulzerierte Sulkusepithel der parodontalen Tasche in das gingivale Gewebe eindringen und sich in den systemischen Kreislauf ausbreiten (Tomás et al. 2012). Das Ausmaß der Bakteriämie ist dabei vom Schweregrad der parodontalen Destruktion abhängig (Forner et al. 2006; Kinane et al. 2011). Dort können die parodontopathogenen Bakterien direkte Einflüsse auf Gewebe nehmen, aber auch Immunzellen stimulieren, die ihrerseits proinflammatorische Zytokine synthetisieren und damit im gesamten Körper immunentzündliche Abläufe modifizieren (Jepsen et al. 2011; Hajishengallis 2015). Zudem können die lokal produzierten proinflammatorischen Immunmediatoren wie IL-6 aus dem entzündeten Parodontalgewebe ebenfalls in den systemischen Kreislauf gelangen (Loos 2005).

So führen kurzlebige Bakteriämien und der regelmäßige Anstieg der zirkulierenden Entzündungsmediatoren zu einer chronischen, niedriggradigen, systemischen Entzündung (Walter et al. 2010; Petersen und Ogawa 2012; Kassebaum et al. 2014), die wiederum in anderen Geweben und Organen eine Erkrankung initiieren oder verstärken kann (de Smit et al. 2012; Arimatsu et al. 2014; Payne et al. 2015).

Analog zu anderen chronischen entzündlichen Prozessen kommt es zur Akute-Phase-Reaktion, die durch Fieber, erhöhte Gefäßpermeabilität und eine allgemeine Erhöhung von metabolischen Prozessen gekennzeichnet ist (Steel und Whitehead 1994). Eine chronische Parodontitis geht mit erhöhten Blutspiegeln des C-reaktiven Proteins einher (Paraskevas et al. 2008; Teeuw et al. 2014). Dies ist ein sicherer Marker für die AkutePhase-Antwort auf Infektionen oder Entzündungen. Aufgrund seiner Kinetik beschreibt es am besten den Entzündungsstaus eines Individuums (de Maat und Kluft 2001). Die 
Produktion von CRP in der Leber wird in der Regel durch einen entzündlichen Stimulus hervorgerufen und durch ein komplexes Netzwerk aus Zytokinen vermittelt, hauptsächlich IL-6 (Ablij und Meinders 2002). CRP-Werte > 10 mg/l gelten als Diagnose für eine bakterielle Infektion (Loos 2005).

Zudem ist CRP ein Aktivitätsparameter für die rheumatoide Arthritis, da ein erhöhtes CRP mit einem progressiv destruierenden Verlauf der Erkrankung korreliert. Fällt der CRP-Spiegel unter medikamentöser Therapie, kann dies als Zeichen des guten therapeutischen Ansprechens gewertet werden und ist zugleich ein „Surrogatmarker“ für eine Unterdrückung der destruktiven Potenz der RA (Schneider et al. 2011).

Die Blutsenkungsgeschwindigkeit ist ebenfalls ein unspezifischer Entzündungsparameter. Ursächlich für eine BSG-Beschleunigung während eines entzündlichen Geschehens ist die Zunahme der Plasmakonzentration von $\alpha$-Globulinen, Akute-Phase-Proteinen und Fibrinogen (Bruhn et al. 2011). Die entsprechende BSG-Beschleunigung tritt jedoch verzögert auf (frühestens nach 24 Stunden) und überdauert häufig das Abklingen eines Entzündungsprozesses um mehrere Tage (Bruhn et al. 2011). Die BSG ist ebenfalls ein diagnostisches Hilfsmittel für die RA und korreliert mit der Krankheitsaktivität (Joseph et al. 2013).

PA könnte somit durch die Erhöhung von inflammatorischen Zytokinen (wie IL-6) im Blut zu einem Anstieg der Serum-CRP- und -BSG-Level und damit zu einer Erhöhung der systemischen Entzündung bei RA beitragen (Golub et al. 2006). Andersherum könnten höhere CRP- und BSG-Spiegel als Reflexion einer aktiven RA wiederrum zu einem erhöhten Entzündungszustand bei PA beitragen (Susanto et al. 2013) (siehe Abbildung $3)$. 


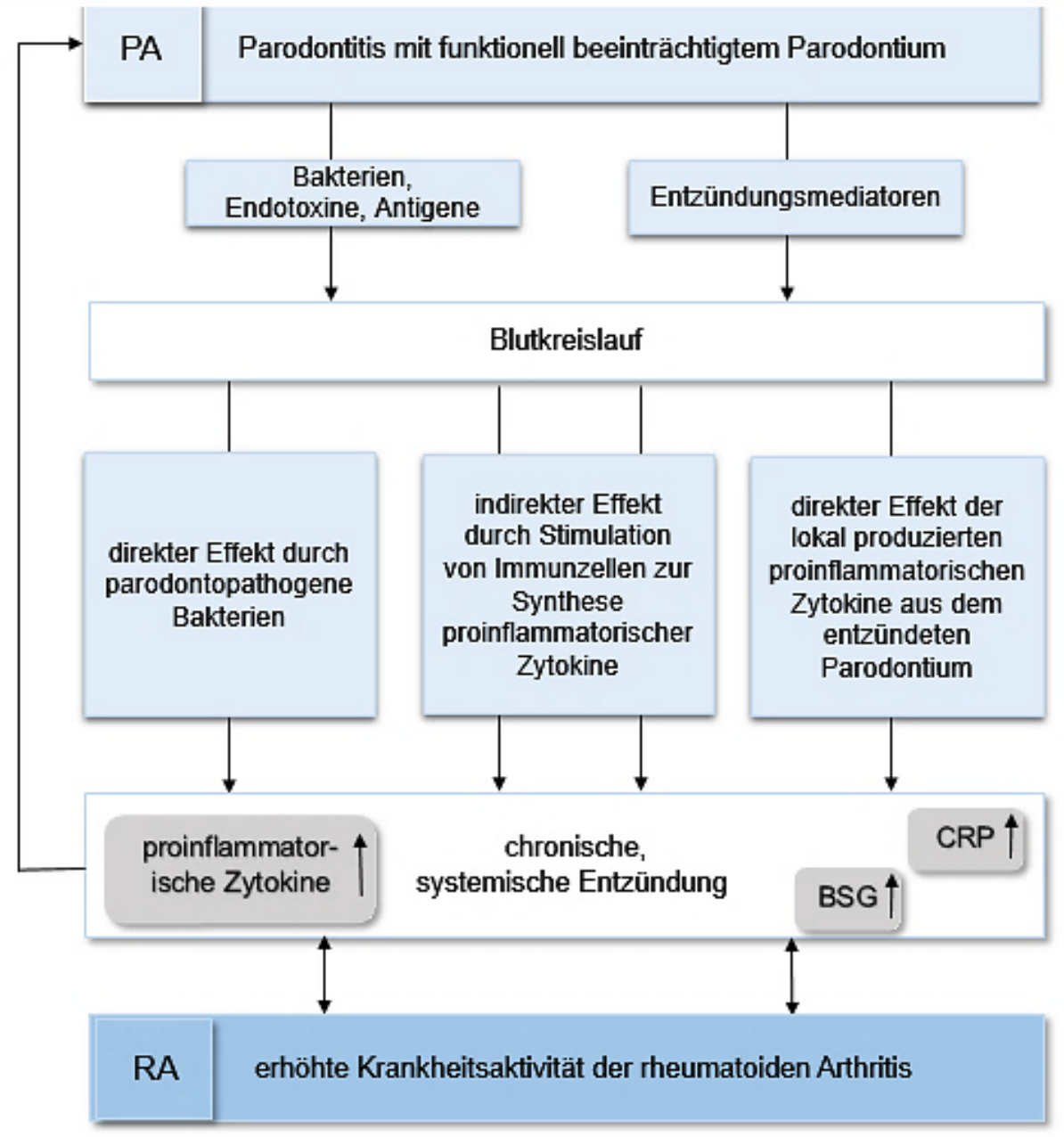

Abbildung 3: Assoziationen von systemischer Entzündung bei rheumatoider Arthrits (RA) und Parodontitis (PA) (CRP: C-reaktives Protein, BSG: Blutsenkungsgeschwindigkeit)

\subsection{Datenlage zu Assoziationen von systemischer Entzündung bei rheumatoider Arthritis und Parodontitis}

Zwar wiesen mehrere Studien eine geringe Evidenz für erhöhte CRP-Spiegel bei Patienten mit rheumatoider Arthritis und Parodontitis auf (Kaur et al. 2013), jedoch wurde gezeigt, dass eine Parodontaltherapie CRP-Spiegel bei Patienten mit RA reduzieren konnte (Susanto et al. 2013). Zudem haben zwei kleine randomisiert kontrollierte Studien herausgefunden, dass die PA-Behandlung bei Patienten mit RA einen positiven Effekt auf die BSG hat (Ribeiro et al. 2005) und zu einer Verbesserung des DAS28-Wertes führt (Al-Katma et al. 2007).

Andere Studien berichteten hingegen, dass die BSG bei Patienten mit rheumatoider Arthritis und Parodontitis nicht vom Parodontalstatus betroffen ist (Mercado et al. 2001; 
Pischon et al. 2008; Bıyıkoğlu et al. 2009). Auch Joseph et al. (2013) konnte keine signifikanten Assoziationen zwischen den mittleren BSG- und CRP-Werten und dem Schweregrad der Parodontitis bei Patienten mit RA feststellen. Dies könnte jedoch auf die Einnahme von Rheumamedikamenten zurückgeführt werden, die zu einer Abnahme der Krankheitsaktivität führen, da Nicht-RA-Patienten in der Studie eine positive Korrelation zwischen CRP-Spiegeln und CAL zeigten (Sjöström et al. 1989; Wolfe 1997). Somit bleibt die genaue Beziehung zwischen BSG- sowie CRP-Leveln und Parodontitis unklar und Langzeitstudien mit größeren Stichproben sind erforderlich (Joseph et al. 2013).

Auch die Präsenz des Rheumafaktors bei RA ist mit der Schwere der Erkrankung und einer Manifestation außerhalb der Gelenke assoziiert. Da diese aber nicht spezifisch für RA sind, wurde sie auch bei anderen chronischen Entzündungszuständen, einschließlich PA gefunden (Hirsch et al. 1989). Rheumafaktoren wurde in der Gingiva, in der subgingivalen Plaque und im Serum von Patienten mit PA nachgewiesen (Rosenstein et al. 2004). Seropositive Patienten mit PA zeigen erhöhte Titer von IgG- und IgM-Antikörpern gegen orale Mikroorganismen verglichen mit seronegativen Patienten mit PA, und ihr Rheumafaktor koagierte mit Epitopen der oralen Bakterien (Thé und Ebersole 1996).

Auch andere Studien zeigten, dass RA-Patienten mit PA signifikant RF-positiv waren und höhere Serum-ACPA- und -RF-Konzentrationen aufwiesen als ohne PA. Dabei waren diese Assoziationen unabhängig vom Vorhandensein supragingivaler Plaque (Dissick et al. 2010; Payne et al. 2015). Hingegen fanden Knaur et al. (2013) in einem systematischen Review keine Korrelation zwischen erhöhten Spiegeln von Anti-CCP-Antikörpern und der Anwesenheit von PA. Auch die Evidenz für einen Zusammenhang zwischen RF-Leveln und PA war gering. Trotzdem zeigten sich Schwankungen innerhalb der Studien, was weitere Untersuchungen notwendig macht (Kaur et al. 2013).

Dabei sollte die Heterogenität der RA-Patienten, insbesondere in Bezug auf ihre medikamentöse Therapie mit verschiedenen krankheitsmodifizierenden Antirheumatika, berücksichtigt werden. Sowohl die parodontale Entzündung als auch systemische entzündliche Marker könnten durch die verschiedenen Medikamente beeinflusst werden (Kobayashi et al. 2014a). 


\subsection{Medikamentöse Therapie der rheumatoiden Arthritis}

Das Ziel der medikamentösen Therapie ist es, durch eine frühzeitige, forcierte Intervention die Entzündung und deren Folgezustände einzudämmen und somit die Gelenkzerstörung zu verhindern (Fiehn et al. 2018). Zur Gelenkprotektion muss durch die medikamentöse Therapie eine Remission und damit eine umfassende Entzündungsund Beschwerdefreiheit erreicht werden (Felson et al. 2011). In Abhängigkeit von der Erkrankungsaktivität, dem Therapieerfolg und den Nebenwirkungen kommen verschiedene Substanzklassen zum Einsatz.

Als antientzündliche Basistherapeutika werden konventionelle synthetische (csDMARDs) und/oder biologische DMARDs (Biologika) eingesetzt (siehe Tabelle 5). In Phasen gesteigerter entzündlicher Aktivität können zur Symptomkontrolle zusätzlich nichtsteroidale Antirheumatika (NSAR), selektive Cyclooxygenase-2-Inhibitoren oder Glucocorticoide eingesetzt werden.

Der klinische Verlauf der Erkrankung bestimmt Auswahl, Kombination und Dosierung der Medikamente, ergänzt durch regelmäßige klinische, laborchemische und radiologische Verlaufskontrollen (Willburger et al. 2006). Der medikamentöse Therapiealgorithmus richtet sich dabei nach der S2e-Leitlinie der deutschen Gesellschaft für Rheumatologie (DGRh), die auf EULAR-Empfehlungen beruht (Fiehn et al. 2018).

\subsubsection{Konventionelle synthetische krankheitsmodifizierende Antirheumatika (csDMARDs)}

Die konventionell synthetisch hergestellten krankheitsmodifizierenden Antirheumatika bilden die pharmakologische Basis, da sie bei frühzeitigem Einsatz die therapeutische Wirksamkeit haben, eine entzündliche Gelenkschädigung zu verzögern oder zu verhindern und damit die Funktion der befallenen Gelenke zu erhalten (Mikuls und O'Dell 2000; Willburger et al. 2006). Als Wirkstoffe stehen unter andrem Methotrexat (MTX), Leflunomid und Sulfasalazin zur Verfügung.

MTX wird aufgrund seines Wirkungs-/Nebenwirkungsverhältnisses als das Mittel erster Wahl bei csDMARD-naiven Patienten mit früher RA angesehen und sollte frühestmöglich eingesetzt werden. Seine Wirksamkeit besteht als Mono- und Kombinationstherapeutikum. Außerdem wirkt es effektsteigernd bei einer Biologikatherapie (Pincus et al. 2003; Gaujoux-Viala et al. 2010; Nam et al. 2010). Ist der Einsatz von 
MTX als primäres DMARD nicht möglich, sollte ein anderes csDMARD (Leflunomid, Sulfasalazin) zum Einsatz kommen.

Wird das Therapieziel unter Monotherapie mit einem csDMARD nicht erreicht, sollte eine Kombination mehrerer csDMARDs eingesetzt werden. Bei hoher Krankheitsaktivität und ungünstigen Prognosefaktoren kann alternativ ein csDMARD mit einem Biologikum kombiniert werden. Eine Biologikatherapie sollte begonnen werden, wenn zwei csDMARDs (als Monotherapie oder in Kombination) wirkungslos bleiben (Fiehn et al. 2018).

\subsubsection{Biologische krankheitsmodifizierende Antirheumatika (Biologika)}

„Bei den Biologica handelt es sich um rekombinante Varianten natürlich vorkommender inhibitorischer Proteine, die selektiv mit Molekülen oder Rezeptoren interagieren, die bei der Modulation immunologischer oder inflammatorischer Prozesse beteiligt sind.“ (Willburger et al. 2006)

Bei der Therapie der RA beruht die Wirkung auf Hemmung des Tumornekrosefaktorsalpha (Anti-TNFa-Therapeutika: Adalimumab, Etanercept, Infliximab), Hemmung des IL-6-Signalweges (Tocilizumab), dem Einsatz von B-Zell-Antikörpern (Rituximab), der Hemmung der T-Zellaktivierung und weiteren.

Der Einsatz von Adalimumab, Etanercept und Tocilizumab ist in der Monotherapie möglich. Zur Verstärkung der Wirksamkeit wird jedoch bei den meisten Biologikern eine Kombinationstherapie mit MTX empfohlen (Nam et al. 2010).

Als erstes Biologikum wird häufig ein TNFa-Antagonist eingesetzt. Bei Therapieversagen oder nachlassender Wirkung kann ein Wechsel zu einem zweiten TNF $\alpha-H e m m e r$ sowie zu Rituximab oder Tocilizumab erfolgen. Kann das Therapieziel mit diesen Medikamenten nicht erreicht werden, sollte der Einsatz weiterer csDMARDs oder immunmodulierender Therapeutika eruiert werden. Bei kontinuierlicher Remission kann eine langsame Verringerung der DMARD-Therapie in Betracht gezogen werden (Schneider et al. 2011; Fiehn et al. 2018). 
Tabelle 5: Übersicht über die im Text aufgeführten Medikamente zur Therapie der rheumatoiden Arthritis (Willburger et al. 2006; Pfeil et al. 2018)

\begin{tabular}{|c|c|c|c|c|}
\hline 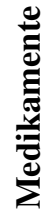 & $\begin{array}{l}\text { Biologische } \\
\text { Gruppe }\end{array}$ & $\begin{array}{l}\text { Wirkstoff/ } \\
\text { Handels- } \\
\text { name }\end{array}$ & \multicolumn{2}{|l|}{ Wirkung } \\
\hline & & $\begin{array}{l}\text { Methotrexat } \\
\text { Methotrexat }{ }^{\circledR}\end{array}$ & \multicolumn{2}{|c|}{$\begin{array}{l}\text { Folsäureantagonist, begrenzt die Proliferation/Aktivie- } \\
\text { rung von Lymphozyten }\end{array}$} \\
\hline 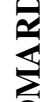 & & $\begin{array}{l}\text { Leflunomid } \\
\text { Arava }{ }^{\circledR}\end{array}$ & \multicolumn{2}{|c|}{$\begin{array}{l}\text { Hemmt das Enzym Dihydroorotat-Dehydrogenase, be- } \\
\text { grenzt die Lymphozytenproliferation/-aktivierung }\end{array}$} \\
\hline $\bar{\varepsilon}$ & & $\begin{array}{l}\text { Sulfasalazin } \\
\text { Azulfidine }{ }^{\circledR}\end{array}$ & \multicolumn{2}{|c|}{$\begin{array}{l}\text { Hemmt das Enzym Lipoxygenase, verhindert die Syn- } \\
\text { these proinflammatorischer Leukotriene und } \\
\text { Prostaglandine }\end{array}$} \\
\hline \multirow{5}{*}{$\frac{\pi}{0}$} & & $\begin{array}{l}\text { Adalimumab } \\
\text { Humira }{ }^{\circledR}\end{array}$ & $\begin{array}{l}\text { Anti-TNF } \alpha \text {-Antikörper, blockiert die } \\
\text { Rezeptorbindung von TNF } \alpha\end{array}$ & \multirow{3}{*}{$\begin{array}{l}\text { Hemmung der } \\
\text { TNF } \alpha- \\
\text { Signalgebung }\end{array}$} \\
\hline & $\begin{array}{l}\text { Anti-TNF } \alpha- \\
\text { Therapeutika }\end{array}$ & $\begin{array}{l}\text { Etanercept } \\
\text { Enbrel® }\end{array}$ & $\begin{array}{l}\text { TNF-Fc-Fusionsprotein, inhibiert die } \\
\text { Bindung an den membranständigen } \\
\text { TNF } \alpha \text {-Rezeptor }\end{array}$ & \\
\hline & & $\begin{array}{l}\text { Infliximab } \\
\text { Remicade } \AA\end{array}$ & $\begin{array}{l}\text { Anti-TNF } \alpha \text {-Antikörper gegen mem- } \\
\text { brangebundenes und lösliches TNF } \alpha\end{array}$ & \\
\hline & $\begin{array}{l}\text { Interleukin-6-Re- } \\
\text { zeptor-Antagonist }\end{array}$ & $\begin{array}{l}\text { Tocilizumab } \\
\text { RoActemra }{ }^{\circledR}\end{array}$ & \multicolumn{2}{|c|}{$\begin{array}{l}\text { Antikörper gegen den membrangebunden und löslichen } \\
\text { IL-6-Rezeptor, verhindert die IL-6-Signalgebung }\end{array}$} \\
\hline & $\begin{array}{l}\text { Anti-CD20-Anti- } \\
\text { körper }\end{array}$ & $\begin{array}{l}\text { Rituximab } \\
\text { Mabthera }{ }^{\circledR}\end{array}$ & \multicolumn{2}{|c|}{$\begin{array}{l}\text { Anti-CD20-Antikörper, depletieren B-Lymphozyten im } \\
\text { Blut }\end{array}$} \\
\hline
\end{tabular}

(csDMARDs: conventional synthetic disease modifying anti-rheumatic drugs, TNF $\alpha$ : Tumornekrosefaktoralpha, IL-6: Interleukin-6, CD20: B-Lymphozyten-Antigen) 


\section{Material und Methoden}

\subsection{Studiendesign}

Bei der vorliegenden Untersuchung handelt es sich um eine monozentrische, klinische Querschnittsstudie. Hierbei soll eine krankheits- und therapiebezogene Assoziation zwischen Parodontitis und rheumatoider Arthritis überprüft werden. Es wurde untersucht, ob und welchen Einfluss die Krankheitsaktivität sowie bestimmte Blutparameter auf den Schweregrad der parodontalen Erkrankung bei Patienten mit rheumatoider Arthritis haben.

Zudem wurde ermittelt, wie sich bestimmte immunsuppressive Medikamente und/oder deren Kombinationen auf den Schweregrad der Parodontitis und auf die Serumspiegel ausgewählter Zytokine (IL-6, IL-10) auswirken (siehe Abbildung 4).

Die Studie wurde von der Ethikkommission der medizinischen Fakultät der Georg-August-Universität Göttingen geprüft und bewilligt (Antragsnr. DOK_4_2014). Im Zeitraum von Juni 2013 bis August 2014 wurden die Patienten rekrutiert und untersucht. Dabei bezieht die vorliegende Untersuchung Patientendaten der Vorgängerstudien von Jan Schmickler (Schmickler et al. 2017) und Annegret Rupprecht (Ziebolz et al. 2018) mit ein. 


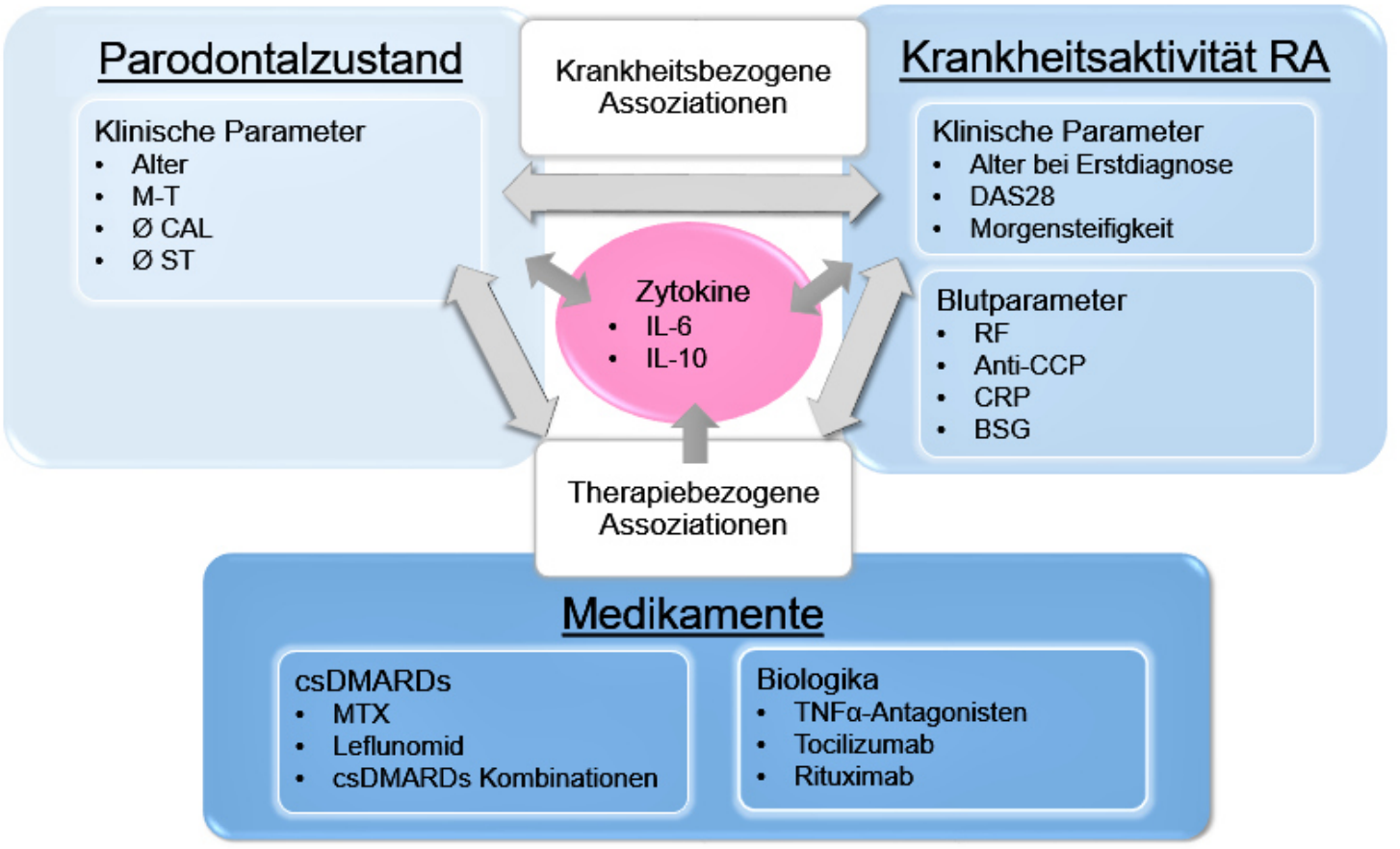

Abbildung 4: Übersicht der untersuchten Parameter und Abhängigkeiten in der vorliegenden Studie (M-T: Anzahl fehlender Zähne, CAL: klinischer Attachmentverlust, ST: Sondierungstiefe, RA: rheumatoide Arthritis, DAS28: disease activity score 28, RF: Rheumafaktor, Anti-CCP: Antikörper gegen cyclische citrullinierte Peptide, CRP: C-reaktives Protein, BSG: Blutsenkungsgeschwindigkeit, IL: Interleukin, csDMARDs: conventional synthetic disease modifying anti-rheumatic drugs, MTX: Methotrexat, TNF $\alpha$ : Tumornekrosefaktor-alpha)

\subsection{Patientenkollektiv}

Ausgewählt wurden 152 Patienten (125 weibliche, 27 männliche) der Abteilung Nephrologie und Rheumatologie der Universitätsmedizin Göttingen. Ausschlaggebend hierfür war eine diagnostizierte rheumatoide Arthritis nach den ACR/EULAR-Klassifikationskriterien (Aletaha et al. 2010) vor und/oder während medikamentöser Therapie.

Während ihres Klinikaufenthaltes (ambulant/teilstationär) wurden die Patienten mündlich und schriftlich über Inhalt und Ablauf der Studie aufgeklärt. Bei Interesse zur Teilnahme an der Studie erklärten sich die Patienten mit ihrer Unterschrift einverstanden, dass sie nach mindestens 24 Stunden Bedenkzeit zwecks Terminabsprache zur zahnärztlichen Untersuchung kontaktiert werden durften. Eine Absage bzw. ein Abbruch der Untersuchung war zu jedem Zeitpunkt ohne Angabe von Gründen möglich.

Aufgrund möglicher Interaktionen wurden Ausschlusskriterien definiert (siehe Tabelle 6) und von einem Untersucher in Form eines Anamnesegespräches und anhand klinischer Arztbriefe überprüft. 
Tabelle 6: Ausschlusskriterien der Studie

\begin{tabular}{|c|l|}
\hline & Ausschlusskriterien der Studie \\
\hline 1 & nicht durchführbare orale Untersuchung aufgrund eines schlechten Allgemeinzustandes \\
\hline 2 & $\begin{array}{l}\text { Patienten mit anderer Immunsuppression: Organtransplantierte, andere Autoimmunerkrankun- } \\
\text { gen (z. B. chronische Darmerkrankungen) }\end{array}$ \\
\hline 3 & Vorliegen von Hepatitis A, B, C, TBC, HIV \\
\hline 4 & Suchtkranke Patienten (z. B. Alkoholabhängigkeit) \\
\hline 5 & Vorliegen von Allgemeinerkrankungen: Diabetes mellitus, schwerkontrollierter Hypertonus \\
\hline 6 & Patienten mit Anfalls- oder Nervenleiden \\
\hline 7 & bestehende Schwangerschaft \\
\hline 8 & Patienten mit Niereninsuffizienz/Notwendigkeit einer Endokarditisprophylaxe \\
\hline 9 & $\begin{array}{l}\text { Patienten mit deutlich eingeschränktem Bewegungsapparat (fehlende Feinmotorik; entspre- } \\
\text { chend Funktionsklasse IV nach ACR-Klassifikation) }\end{array}$ \\
\hline 10 & Antibiotikaeinnahme vor < 3 Monate \\
\hline
\end{tabular}

(ACR: American College for Rheumatology)

\subsubsection{Pseudonymisierung}

Alle Patienten wurden entsprechend der Reihenfolge ihres Einschlusses in die Studie mit einem Studiencode nummeriert und die Datenblätter damit pseudonymisiert.

\subsection{Zahnärztliche Untersuchung}

Die zahnärztliche Untersuchung der Patienten wurde in der Poliklinik für Präventive Zahnmedizin, Parodontologie und Kariologie der Universitätsmedizin Göttingen von zwei erfahrenen und kalibrierten Zahnärzten (ZA Jan Schmickler oder Z ̈̈ Annegret Rupprecht) durchgeführt. Jede Untersuchung erfolgte unter standardisierten Umgebungsbedingungen.

\subsubsection{Fragebögen}

Um Informationen zum klinischen Ausgangszustand und zur Mundgesundheit des Patienten zu erhalten, füllte jeder Proband gemeinsam mit dem untersuchenden Zahnarzt folgende Fragebögen aus: 


\subsubsection{Anamnesebogen (siehe Anhang S. 76)}

In diesem Fragebogen wurden die Studienteilnehmer zu Allgemeinerkrankungen, bestehenden Allergien, regelmäßigen Medikamenteneinnahmen und zu ihrem Rauchverhalten befragt. Dabei wurde zwischen Rauchern (Patient hat zum Zeitpunkt der Befragung geraucht), Nichtrauchern und ehemaligen Rauchern (Patient hat seit fünf Jahren nicht mehr geraucht) unterschieden.

\subsubsection{Fragebogen Zahnärztliches Verhalten (siehe Anhang S. 78)}

Dieser Fragebogen gab Aufschluss über das Mundhygieneverhalten sowie die RegelmäBigkeit von zahnärztlichen Kontrollen vor allem nach Diagnosestellung der rheumatoiden Arthritis.

\subsubsection{Parodontitisfragebogen (siehe Anhang S. 81)}

Basierend auf einer Ja-/Nein-Entscheidung der Patienten wurde das Auftreten von Parodontitis-spezifischen Symptomen in den letzten zwölf Monaten erfragt.

\subsubsection{Klinisch-zahnmedizinische Untersuchung}

Im Anschluss wurde die klinisch zahnärztliche Untersuchung durchgeführt. Diese umfasste den zahnärztlichen Befund (DMF-T-Index) und die Erhebung eines ausführlichen Parodontalstatus zur Ermittlung von Sondierungstiefen und klinischem Attachmentverlust. Anhand der Untersuchungsergebnisse wurde die Art des Parodontalzustandes nach Page und Eke (2007) definiert.

\subsection{Parodontale Erkrankungslast}

Für die statistische Auswertung wurde der Schweregrad der Parodontitis durch vier Parameter definiert, die aus den Daten der zahnärztlichen Untersuchung gewonnen wurden. Diese umfassten die Anzahl fehlender Zähne (missing teeth, M-T), die durchschnittlichen Sondierungstiefen (Ø ST), den durchschnittlichen klinischen Attachmentverlust (Ø CAL) sowie den Parodontalzustand nach Page und Eke (2007). 


\subsubsection{Anzahl fehlender Zähne (missing teeth)}

Der DMF-T-Index wird zur Messung der Kariesinzidenz angewendet. Dabei summiert der Untersucher die kariösen $(\mathrm{D}=$ decayed $)$, extrahierten $(\mathrm{M}=$ missing $)$ sowie mit Füllungen $(\mathrm{F}=$ filled $)$ oder Kronen versorgten Zähne $(\mathrm{T}=$ teeth $)$. Da Weisheitszähne nicht berücksichtigt werden, kann der DMF-T einen Maximalwert von 28 annehmen (Lehmann et al. 2009). Zur erhöhten und differenzierten Aussagekraft kann der DMF-T in D-T, M$\mathrm{T}$ und F-T aufgeteilt werden. In Tabelle 7 wurden die Patienten anhand der Anzahl fehlender Zähne (M-T-Wert) in vier Gruppen eingeteilt.

Tabelle 7: Gruppeneinteilung der Patienten anhand der Anzahl fehlender Zähne (M-T)

\begin{tabular}{|l|l|}
\hline Gruppe & Definition \\
\hline M-T1 & $\leq 2$ fehlende Zähne \\
\hline M-T2 & $3-5$ fehlende Zähne \\
\hline M-T3 & $6-9$ fehlende Zähne \\
\hline M-T4 & $\geq 10$ fehlende Zähne \\
\hline
\end{tabular}

\subsubsection{Durchschnittliche Sondierungstiefe (Ø ST)}

Um die Sondierungstiefen (ST) der Zahnfleischtaschen zu erfassen, wurde an jedem Zahn eine Sechs-Punkt-Messung (mesio-vestibulär, vestibulär, disto-vestibulär, mesio-oral, oral, disto-oral) mit einer millimeterskalierten Parodontalsonde (PCP 15, HU-Friedy, Tutlingen, Deutschland) durchgeführt. Dabei wurde die Sonde an jedem Messpunkt in einem Winkel von $10-15^{\circ}$ in die Zahnfleischtasche eingeführt und die Tiefe in Millimetern angegeben.

Zur Berechnung der durchschnittlichen Sondierungstiefe wurde pro Zahn die höchste Sondierungstiefe gewählt. Diese wurde von allen Zähnen addiert und durch die Anzahl der vorhandenen Zähne geteilt. Die Einteilung erfolgte in vier Gruppen (siehe Tabelle 8). 
Tabelle 8: Gruppeneinteilung der Patienten anhand der durchschnittlichen Sondierungstiefen (Ø ST)

\begin{tabular}{|l|l|}
\hline Gruppe & Definition \\
\hline$\varnothing \mathrm{ST} 1$ & $\leq 3,48 \mathrm{~mm}$ \\
\hline$\varnothing \mathrm{ST} 2$ & $3,49-4,04 \mathrm{~mm}$ \\
\hline$\varnothing \mathrm{ST} 3$ & $4,05-4,51 \mathrm{~mm}$ \\
\hline$\varnothing \mathrm{ST} 4$ & $\geq 4,52 \mathrm{~mm}$ \\
\hline
\end{tabular}

\subsubsection{Durchschnittlicher klinischer Attachmentverlust (Ø CAL)}

Zur Bestimmung des klinischen Attachmentverlustes wurde an den oben genannten sechs Messpunkten die Distanz zwischen der Schmelz-Zement-Grenze und dem klinisch sondierbaren Boden der Zahnfleischtasche ermittelt.

Zur Berechnung des durchschnittlichen klinischen Attachmentverlustes wurde pro Zahn der höchste Wert gewählt. Dieser wurde von allen Zähnen addiert und durch die Anzahl der vorhandenen Zähne geteilt. Wie in Tabelle 9 dargestellt, erfolgte die Einteilung in vier Gruppen.

Tabelle 9: Gruppeneinteilung der Patienten anhand des durchschnittlichen klinischen Attachmentverlustes (Ø CAL)

\begin{tabular}{|l|l|}
\hline Gruppe & Definition \\
\hline$\varnothing \mathrm{CAL} 1$ & $\leq 3,71 \mathrm{~mm}$ \\
\hline$\varnothing \mathrm{CAL} 2$ & $3,72-4,36 \mathrm{~mm}$ \\
\hline$\varnothing \mathrm{CAL} 3$ & $4,37-5,00 \mathrm{~mm}$ \\
\hline$\varnothing \mathrm{CAL} 4$ & $5,01 \mathrm{~mm}$ \\
\hline
\end{tabular}

\subsubsection{Parodontalzustand nach Page und Eke (2007)}

Die Art des Parodontalzustandes wurde nach Page und Eke (2007) definiert. Anhand der Sondierungstiefen (ST) und dem klinischen Attachmentverlust (CAL) erfolgt die Einteilung in drei Schweregrade. Zur Übersichtlichkeit und statistischen Auswertung wurden diese zu drei Gruppen (PAR1 - 3) zusammengefasst (siehe Tabelle 10). 
Tabelle 10: Gruppeneinteilung der Patienten anhand des Parodontalzustandes (PAR) nach Page und Eke (2007)

\begin{tabular}{|l|l|l|}
\hline Gruppe & Einteilung der Krankheit & Klinische Definition \\
\hline PAR1 & keine/milde Parodontitis & weder schwere noch moderate Parodontitis \\
\hline PAR2 & moderate Parodontitis & $\begin{array}{l}\geq 2 \text { approximale Messstellen mit CAL } \geq 4 \mathrm{~mm} \\
\text { (nicht am selben Zahn) } \\
\text { oder } \\
\geq 2 \text { approximale Messstellen mit ST } \geq 5 \mathrm{~mm} \\
\text { (nicht am selben Zahn) }\end{array}$ \\
\hline PAR3 & schwere Parodontitis & $\begin{array}{l}\geq 2 \text { approximale Messstellen mit CAL } \geq 6 \mathrm{~mm} \\
\text { (nicht am selben Zahn) } \\
\text { und } \\
1 \text { approximale Messstelle mit ST } \geq 5 \mathrm{~mm} \\
\text { (nicht am selben Zahn) }\end{array}$ \\
\hline
\end{tabular}

(CAL: klinischer Attachmentverlust, ST: Sondierungstiefe)

\subsection{Allgemeinmedizinische Datenerfassung}

Es erfolgte eine Datenerfassung durch Auswertung der vorliegenden medizinischen Befund- und Behandlungsdokumentationen der Patientenakte im Archiv der Universitätsmedizin Göttingen.

\subsubsection{Klinisch-rheumatologische und serologische Parameter}

Aus den Patientenakten wurden die in Tabelle 11 aufgeführten klinisch-rheumatologischen Daten sowie die serologischen Parameter aus den aktuellsten Blutanalysen zur Bestimmung der Krankheitsaktivität der RA erhoben.

Zur Durchführbarkeit der statistischen Analyse wurden beim Rheumafaktor und AntiCCP für Werte $<10,1$ ein Durchschnittswert von 5 und für Werte > 340 ein Durchschnittswert von 350 angenommen. Für Werte von $<0,5$ wurde ein Durchschnittswert von 0,25 eingesetzt. 
Tabelle 11: Erhobene klinisch-rheumatologische sowie serologische Parameter zur Bestimmung der Krankheitsaktivität der rheumatoiden Arthritis

\begin{tabular}{|l|l|}
\hline Klinisch-rheumatologische Parameter & Serologische Parameter \\
\hline Datum der Erstdiagnose & Anti-CCP [U/ml] \\
\hline Aktuellster DAS28-Score [Wert, Datum] & Rheumafaktor [U/ml] \\
\hline Anzahl geschwollener Gelenke & CRP [mg/l] \\
\hline Anzahl druckdolenter Gelenke & BSG 1 Stunde Wartezeit [mm] \\
\hline Dauer der Morgensteifigkeit [min] & \\
\hline
\end{tabular}

(DAS28: disease activity score 28, Anti-CCP: Antikörper gegen cyclische citrullinierte Peptide, CRP: Creaktives Protein, BSG: Blutsenkungsgeschwindigkeit)

\subsubsection{Rheumamedikation}

In Tabelle 12 sind die aus den Patientenakten erfassten Medikamente zur Behandlung der rheumatoiden Arthritis aufgeführt.

Tabelle 12: Erfasste Medikamente zur Behandlung der rheumatoiden Arthritis

\begin{tabular}{|c|c|}
\hline Medikation & Präparat \\
\hline \multirow[t]{2}{*}{$\begin{array}{l}\text { Medikamente zur } \\
\text { Symptomkontrolle }\end{array}$} & $\begin{array}{l}\text { Nichtsteroidale Antirheumatika } \\
\text { (Ibuprofen, Diclofenac, Naproxen, Celecoxib) }\end{array}$ \\
\hline & Glucocorticoide (Prednisolon) \\
\hline \multirow{3}{*}{$\begin{array}{l}\text { Konventionelle synthetische } \\
\text { krankheitsmodifizierende } \\
\text { Antirheumatika } \\
\text { (conventional synthetic disease } \\
\text { modifying anti-rheumatic drugs } \\
\text { - csDMARDs) }\end{array}$} & MTX (Methotrexat ${ }^{\circledR}$ ) \\
\hline & Leflunomid (Arava $\left.{ }^{\circledR}\right)$ \\
\hline & $\begin{array}{l}\text { csDMARDs Kombinationen: } \\
\text { zeitgleiche Einnahme mindestens zwei dieser Medikamente: MTX } \\
\left.\left.\text { (Methotrexat }{ }^{\circledR}\right) \text {, Leflunomid (Arava }{ }^{\circledR}\right) \text {, Sulfasalazin (Azulfidine }{ }^{\circledR} \text { ) }\end{array}$ \\
\hline \multirow{3}{*}{$\begin{array}{l}\text { Biologische krankheitsmodifi- } \\
\text { zierende Antirheumatika } \\
\text { (biologic disease modifying anti- } \\
\text { rheumatic drugs - Biologika) }\end{array}$} & $\begin{array}{l}\text { Anti-TNF } \alpha \text {-Therapeutika: } \\
\left.\text { Infliximab (Remicade }{ }^{\circledR}\right) \text { oder Etanercept (Enbrel }{ }^{\circledR} \text { ) oder Ada- } \\
\left.\text { limumab (Humira }{ }^{\circledR}\right) \text { als Monotherapie oder in Kombination mit } \\
\text { MTX }\end{array}$ \\
\hline & $\begin{array}{l}\left.\text { Tocilizumab (RoActemra }{ }^{\circledR}\right) \text { als Monotherapie oder in Kombination } \\
\text { mit MTX }\end{array}$ \\
\hline & Rituximab (Mabthera $\left.{ }^{\circledR}\right)$ in Kombination mit MTX \\
\hline
\end{tabular}

(TNFa: Tumornekrosefaktor-alpha) 
Bei der Dokumentation der Dauer der Medikamenteneinnahme wurde zwischen Vortherapie und aktueller Therapie unterschieden.

Zur Erfassung der aktuellen Medikation wurde aus der Patientenakte entnommen, welche Medikamente der Patient zum Zeitpunkt der zahnärztlichen Untersuchung einnahm und wie lange die Einnahme bereits erfolgte. Die Angabe erfolgte in Monaten. Dabei musste eine Mindesteinnahmezeit von drei Monaten gewährleistet sein. Als Vortherapie galten alle eingenommenen Medikamente, die vor der aktuellen Medikation eingenommen wurden. Die Angabe erfolgte in Monaten.

Zudem wurde die Gesamtdauer der Einnahme von csDMARDs ermittelt, indem die Einnahmedauer aller csDMARDs (Vortherapie + aktuelle Therapie) addiert wurde. Die Angabe erfolgte in Monaten. Ebenso wurde die Gesamteinnahmedauer aller Biologika durch Addition der Einnahmedauer aller Biologika (Vortherapie + aktuelle Therapie) errechnet.

\subsection{Blutabnahme}

Zusätzlich zur zahnärztlichen Untersuchung erfolgte eine Blutabnahme (Vollblut und Citratblut) bei den Patienten. Die Proben wurden innerhalb von 24 Stunden im Labor der Abteilung Nephrologie und Rheumatologie der Universitätsmedizin Göttingen (Lagerung bei Raumtemperatur) bearbeitet.

\subsubsection{Blutprobenbearbeitung}

Das entnommene Vollblut (S-Monovette ${ }^{\circledR}$ 7,5 ml, Serum mit Gerinnungsaktivator der Firma Sarstedt AG \& Co, Nümbrecht, Deutschland) wurde mit Gegengewicht bei $2000 \mathrm{U} / \mathrm{min}$ für acht Minuten bei $20^{\circ} \mathrm{C}$ zentrifugiert (Allegra ${ }^{\mathrm{TM}} \mathrm{X}-12 \mathrm{R}$ Centrifuge der Firma Beckman Coulter, Kalifornien, USA). Anschließend wurde das überstehende Serum in ein Cryoröhrchen (Cryoröhrchen 4 ml, Carl Roth GmbH + Co. KG, Karlsruhe, Deutschland) abpipettiert. Das Röhrchen wurde beschriftet (Name, Datum, Kennnummer) und zur weiteren Diagnostik bei $-20^{\circ} \mathrm{C}$ (Gefrierschrank Liebherr Mediline, Biberach an der Riß, Deutschland) eingefroren.

Das Citratblut (S-Monovette ${ }^{\circledR}$ 4,3 ml, Citrat 3,2 \% (1:10), der Firma Sarstedt AG \& Co, Nümbrecht, Deutschland) wurde zusammen mit $40 \mathrm{ml}$ Lysepuffer (RCLB-red cell lysis 
buffer) in ein Gefäß (Röhrchen $50 \mathrm{ml}$ der Firma Sarstedt AG \& Co, Nümbrecht, Deutschland) gegeben. Nach zehnminütiger Wartezeit wurde dieses für acht Minuten bei $2000 \mathrm{U} / \mathrm{min}$ zentrifugiert (Zentrifuge Allegra ${ }^{\mathrm{TM}}$ X-12R Centrifuge der Firma Beckman Coulter, Kalifornien, USA). Im Anschluss wurde der Überstand verworfen, das Zellpellet durch vortexen (Vortex Genie ${ }^{\mathrm{TM}}$, Bender \& Hobein, Zurich, Schweiz) gelöst und erneut in $40 \mathrm{ml}$ Lysepuffer resuspendiert.

Nach zehnminütiger Wartezeit wurde bei gleicher Einstellung erneut zentrifugiert und hinterher der Überstand verworfen. Anschließend wurde das Zellpellet mit einem Milliliter Lysepuffer in eine Pipette (Pipette 100-1000 $\mu$, Eppendorf AG, Hamburg, Deutschland) aufgenommen und in ein Regiergefäß (Reagiergefäß 1,5 ml, Sarstedt AG \& Co, Nümbrecht, Deutschland) umgefüllt. Dieses wurde für fünf Minuten bei $3000 \mathrm{U} / \mathrm{min}$ zentrifugiert (Eppendorf Centrifuge 5415 C, Eppendorf AG, Hamburg, Deutschland). Der Überstand wurde mit einer Pipette abgenommen und verworfen, während das Zellpellet im Reagiergefäß bei $-20^{\circ} \mathrm{C}$ eingefroren wurde (Gefrierschrank Liebherr Mediline, Biberach an der Riß, Deutschland).

In den Tabellen 13, 14 und 15 sind alle verwendeten Geräte, Verbrauchsmaterialien und Chemikalien aufgeführt.

Tabelle 13: Liste der verwendeten Geräte zur Bearbeitung der Blutproben

\begin{tabular}{|l|l|l|}
\hline Produktname & Hersteller & Details \\
\hline $\begin{array}{l}\text { Zentrifuge Allegra } \\
\text { Centrifuge }\end{array}$ & $\begin{array}{l}\text { Beckman Coulter, Brea, Kalifornien, } \\
\text { USA }\end{array}$ & Serien-Nr. ALV05K32 \\
\hline $\begin{array}{l}\text { Pipette Eppendorf Reference } \\
2,100-1000 \mu 1\end{array}$ & Eppendorf AG, Hamburg, Deutschland & Katalog-Nr. 4924000088 \\
\hline $\begin{array}{l}\text { Vortex Genie } \\
\text { Model K-550-GE }\end{array}$ & Bender \& Hobein AG, Zurich, Schweiz & Serien-Nr. Z8676 \\
\hline $\begin{array}{l}\text { Eppendorf Centrifuge 5415 C } \\
\text { Eefrierschrank Liebherr }\end{array}$ & $\begin{array}{l}\text { Liebherr-International Deutschland } \\
\text { Gedline }\end{array}$ & \\
\hline
\end{tabular}


Tabelle 14: Liste der verwendeten Verbrauchsmaterialien zur Bearbeitung der Blutproben

\begin{tabular}{|c|c|c|}
\hline Produktname & Hersteller & Details \\
\hline $\begin{array}{l}\text { S-Monovette }{ }^{\circledR} 7,5 \mathrm{ml} \text {, Serum mit } \\
\text { Gerinnungsaktivator, } 92 \times 15 \mathrm{~mm} \text {, } \\
\text { weiß }\end{array}$ & $\begin{array}{l}\text { Sarstedt AG \& Co, } \\
\text { Nümbrecht, Deutschland }\end{array}$ & Bestellnummer: 01.1601 \\
\hline $\begin{array}{l}\text { S-Monovette }{ }^{\circledR} 4,3 \mathrm{ml} \text {, Citrat } 3,2 \% \\
(1: 10), 75 \times 13 \mathrm{~mm} \text {, grün }\end{array}$ & $\begin{array}{l}\text { Sarstedt AG \& Co, } \\
\text { Nümbrecht, Deutschland }\end{array}$ & Bestellnummer 04.1922 \\
\hline $\begin{array}{l}\text { Cryoröhrchen, mit Außengewinde, } \\
\text { Dichtung, Länge } 78 \mathrm{~mm}, 4 \mathrm{ml}\end{array}$ & $\begin{array}{l}\text { Carl Roth GmbH + Co. KG, } \\
\text { Karlsruhe, Deutschland }\end{array}$ & Bestellnummer E318.1 \\
\hline Röhre $50 \mathrm{ml}, 114 \times 28 \mathrm{~mm}, \mathrm{PP}$ & $\begin{array}{l}\text { Sarstedt AG \& Co, } \\
\text { Nümbrecht, Deutschland }\end{array}$ & $\begin{array}{l}\text { Bestellnummer: } 62.547 .254 \\
\text { Artikelnummer: } 547254\end{array}$ \\
\hline Reagiergefäß 1,5 ml & $\begin{array}{l}\text { Sarstedt AG \& Co, } \\
\text { Nümbrecht, Deutschland }\end{array}$ & $\begin{array}{l}\text { Artikelnummer: } 690001 \\
\text { Bestellnummer: } 72.690 .001\end{array}$ \\
\hline Saphire Pipettenspitze $1250 \mu \mathrm{l}$ & $\begin{array}{l}\text { Greiner Bio-One GmbH, } \\
\text { Kremsmünster, Österreich }\end{array}$ & Artikelnummer 750254 \\
\hline Duran Laborflasche $500 \mathrm{ml}$ & $\begin{array}{l}\text { DWK Life Sciences GmbH, } \\
\text { Wertheim, Deutschland }\end{array}$ & Bestellnummer 21801445 \\
\hline
\end{tabular}

Tabelle 15: Liste der verwendeten Chemikalien zur Bearbeitung der Blutproben

\begin{tabular}{|l|l|l|}
\hline Produktname & Hersteller & Details \\
\hline Aqua bidest & Carl Roth GmbH + Co. KG, Karlsruhe, Deutschland & 3478.1 \\
\hline Tris & Carl Roth GmbH + Co. KG, Karlsruhe, Deutschland & 4855.2 \\
\hline $\mathrm{MgCl}$ & Merck KGaA, Darmstadt, Deutschland & 1.05 .832 .1000 \\
\hline $\mathrm{NaCl}$ & Carl Roth GmbH + Co. KG, Karlsruhe, Deutschland & 9265.2 \\
\hline $\begin{array}{l}\text { RCLB } \\
\text { (red cell lysis buffer) }\end{array}$ & $\begin{array}{l}100 \mathrm{ml} \text { Aqua bidest } \\
6,05 \mathrm{~g} \mathrm{Tris} \\
5,07 \mathrm{mg} \mathrm{MgCl} \\
2,9 \mathrm{~g} \mathrm{NaCl}\end{array}$ & $\begin{array}{l}50 \text {-fach konzentriert, } \\
\text { pH-Wert 7,6 }\end{array}$ \\
\hline
\end{tabular}

(Aqua bidest: bidestilliertes Wasser, Tris: Tris(hydroxymethyl)aminomethan, $\mathrm{MgCl}$ : Magnesiumchlorid, $\mathrm{NaCl}$ : Natriumchlorid)

\subsection{ELISA-Test}

Um zu überprüfen, welche Medikamente die Zytokinspiegel von IL-6 und IL-10 im Blut beeinflussen, wurden die Patienten entsprechend ihrer aktuellen Medikation in sieben Gruppen (A - G) eingeteilt (Tabelle 16). Aus jeder Medikamentengruppe wurden 11 - 13 Patienten ausgewählt, bei denen die Konzentration der genannten Zytokine im Blut mit 
Hilfe eines Sandwich-ELISA (enzyme-linked immunosorbent assay) bestimmt wurde. Auswahlkriterien waren eine möglichst lange Einnahmedauer des Medikamentes sowie ein möglichst geringer Zeitunterschied zwischen zahnärztlicher Untersuchung und Blutabnahme.

Tabelle 16: Einteilung der Medikamentengruppen für den ELISA-Test

\begin{tabular}{|c|c|c|}
\hline Gruppe & Medikament & Patientenzahl \\
\hline A & Nichtsteroidale Antirheumatika und/oder Glucocorticoide & $\mathrm{n}=13$ \\
\hline $\mathrm{B}$ & MTX (Methotrexat $\left.{ }^{\circledR}\right)$ & $\mathrm{n}=11$ \\
\hline $\mathrm{C}$ & Leflunomid (Arava $\left.{ }^{\circledR}\right)$ & $\mathrm{n}=11$ \\
\hline $\mathrm{D}$ & $\begin{array}{l}\text { Anti-TNF } \alpha \text {-Therapeutika: } \\
\left.\text { Infliximab (Remicade } \AA \text { ) oder Etanercept (Enbrel }{ }^{\circledR}\right) \text { oder Adalimumab } \\
\left.\text { (Humira }{ }^{\circledR}\right) \text { als Monotherapie oder in Kombination mit MTX }\end{array}$ & $\mathrm{n}=11$ \\
\hline $\mathrm{E}$ & $\begin{array}{l}\left.\text { Tocilizumab (RoActemra }{ }^{\circledR}\right) \\
\text { als Monotherapie oder in Kombination mit MTX }\end{array}$ & $\mathrm{n}=12$ \\
\hline $\mathrm{F}$ & $\begin{array}{l}\text { Rituximab (Mabthera }{ }^{\circledR} \text { ) } \\
\text { in Kombination mit MTX }\end{array}$ & $\mathrm{n}=11$ \\
\hline $\mathrm{G}$ & $\begin{array}{l}\text { csDMARDs Kombinationen: } \\
\text { zeitgleiche Einnahme mindestens zwei dieser Medikamente: MTX (Me- } \\
\left.\left.\text { thotrexat }{ }^{\circledR}\right) \text {, Leflunomid (Arava }{ }^{\circledR}\right) \text {, Sulfasalazin }\left(\text { Azulfidine }{ }^{\circledR}\right)\end{array}$ & $\mathrm{n}=11$ \\
\hline
\end{tabular}

(TNF $\alpha$ : Tumornekrosefaktor-alpha, csDMARDs: conventional synthetic disease modifying anti-rheumatic drugs)

Die ELISA-Tests wurden von einer MTA der Abteilung Nephrologie und Rheumatologie der Universitätsmedizin Göttingen mittels kommerziell erhältlicher Testkits der Firma R\&D Systems (Minneapolis, Minnesota, USA) nach dem vorgegebenen Versuchsprotokoll durchgeführt und ausgewertet.

Im Folgenden soll das Verfahren eines Sandwichs-ELISA exemplarisch beschrieben werden. Ein ELISA-Test dient zur Detektion sowie zur Quantifizierung bestimmter Antigene. Beim Sandwich-ELISA werden zwei Antikörper verwendet, die beide spezifisch an das nachzuweisende Antigen binden.

Dazu wird eine Mikrotiterplatte mit monoklonalen Antikörpern beschichtet, die spezifisch für das nachzuweisende Antigen sind. Bei Zugabe von Standards und Proben wird nach einer entsprechenden Inkubationszeit das nachzuweisende Antigen durch den immobilisierten Antikörper gebunden. Nach Ablauf der Inkubationszeit wird die Mikrotiterplatte gewaschen, wodurch alle ungebunden Substanzen entfernt werden. 
Anschließend wird ein enzymgebundener polyklonaler Antikörper hinzugefügt, der ebenfalls spezifisch für das Antigen ist, dieses aber an einem anderen Epitop bindet. Erneut erfolgt ein Waschvorgang, um ungebundenes Antikörper-Enzym-Reagenz zu entfernen. Anschließend wird ein Substrat hinzugegeben, das vom Enzym zu einem Reaktionsprodukt umgesetzt wird, woraufhin sich ein Farbumschlag ergibt. Dabei entwickelt sich die Farbe proportional zur Menge an gebundenem Antigen. Die Farbentwicklung wird nach 20 Minuten gestoppt und die Intensität der Farbe (optische Dichte) innerhalb von 30 Minuten mit einem Mikroplattenleser bei $450 \mathrm{~nm}$ gemessen.

Die Standardreihe mit bekannter Antigenkonzentration ermöglicht die Erstellung einer Kalibrierungskurve für die emittierte Intensität und damit einen quantitativen Nachweis. Zur Positiv- und Negativkontrolle wurden vom Hersteller vorgegebene Standards in einer Verdünnungsreihe angelegt und bei der Messung miterfasst.

In den Tabellen 17 und 18 sind die Immunoasseys sowie verwendete Geräte, Verbrauchsmaterialien und Chemikalien aufgeführt.

Tabelle 17: Liste der verwendeten Immunoasseys zur Bestimmung der Konzentration von Interleukin-6 (IL-6) und Interleukin-10 (IL-10) im Blut

\begin{tabular}{|l|l|l|}
\hline Produktname & Hersteller & Katalognummer \\
\hline Human IL-6 Quantikine Elisa Kit & $\begin{array}{l}\text { R\&D Systems, } \\
\text { Minneapolis, Minnesota, USA }\end{array}$ & D6050 \\
\hline Human IL-10 Quantikine Elisa Kit & $\begin{array}{l}\text { R\&D Systems, } \\
\text { Minneapolis, Minnesota, USA }\end{array}$ & D1000B \\
\hline
\end{tabular}


Tabelle 18: Geräte, Verbrauchsmaterialien und Chemikalien für den ELISA-Test

\begin{tabular}{|c|c|c|}
\hline Produktname & Hersteller & Details \\
\hline Eppendorf Pipetten & $\begin{array}{l}\text { Eppendorf AG, Hamburg, } \\
\text { Deutschland }\end{array}$ & \\
\hline $\begin{array}{l}\text { Eppendorf Research }{ }^{\circledR} \text { plus, } 8 \text {-Kanal, } \\
\text { variabel, inkl. epT.I.P.S. }{ }^{\circledR} \text {-Box, } \\
0,5-10 \mu 1 \text {, mittelgrau }\end{array}$ & $\begin{array}{l}\text { Eppendorf AG, Hamburg, } \\
\text { Deutschland }\end{array}$ & Katalog-Nr. 3125000028 \\
\hline $\begin{array}{l}\text { Eppendorf Research }{ }^{\circledR} \text { plus, } 8 \text {-Kanal, } \\
\text { variabel, inkl. epT.I.P.S. }{ }^{\circledR} \text {-Box, } \\
10-100 \mu 1 \text {, gelb }\end{array}$ & $\begin{array}{l}\text { Eppendorf AG, Hamburg, } \\
\text { Deutschland }\end{array}$ & Katalog-Nr. 3125000036 \\
\hline diverse Pipettenspitzen & $\begin{array}{l}\text { Greiner Bio-One GmbH, } \\
\text { Kremsmünster, Österreich }\end{array}$ & \\
\hline Reagiergefäß $1,5 \mathrm{ml}$ & $\begin{array}{l}\text { Sarstedt AG \& Co, Nümbrecht, } \\
\text { Deutschland }\end{array}$ & $\begin{array}{l}\text { Artikelnummer: } 690001 \\
\text { Bestellnummer: } 72.690 .001\end{array}$ \\
\hline Vortex Genie ${ }^{\mathrm{TM}}$ Model K-550-GE & $\begin{array}{l}\text { Bender \& Hobein AG, Zurich, } \\
\text { Schweiz }\end{array}$ & Serien-Nr. Z8676 \\
\hline $\begin{array}{l}\text { Teca Sunrise }{ }^{\mathrm{TM}} \text { absorbance micro- } \\
\text { plate reader }\end{array}$ & $\begin{array}{l}\text { Tecan Group Ltd., Männedorf, } \\
\text { Schweiz }\end{array}$ & \\
\hline
\end{tabular}

\subsection{Auswertung der Ergebnisse und statistische Methodik}

Alle erhobenen Daten wurden in codierter Form im Tabellenkalkulationsprogramm Microsoft Excel 2013 (Microsoft Cooperation, Redmond, USA) aufgeführt und archiviert.

Die statistische Auswertung erfolgte mit Hilfe des Programms SPSS (Version 24.0 für Windows, SPSS Inc., USA) von Frau Dr. Kottmann (Clinical Research Organisation, Hamm, Deutschland).

Es wurde zunächst die Normalverteilung der metrischen Daten mit Hilfe des Kolmogorow-Smirnow-Tests überprüft. Da die getesteten Variablen überwiegend keine Normalverteilung aufwiesen (Kolmogorow-Smirnow-Test: $\mathrm{p}<0,05$ ), wurden im Folgenden durchgehend nichtparametrische Tests angewandt. Handelte es sich dabei um mehr als zwei unabhängige, nicht normalverteilte Stichproben, wurde der H-Test nach Kruskal und Wallis eingesetzt. Eine Signifikanz bestand für alle statistischen Tests bei einem pWert $<0,05$, wobei immer eine zweiseitige Signifikanzprüfung erfolgte. P-Werte, die knapp über 0,05 lagen ( $\mathrm{p}=0,06$ oder 0,07 ), waren somit nicht signifikant, jedoch konnte hier von einem deutlichen Trend gesprochen werden. 
Die Verteilung der metrischen Daten wurde graphisch durch Boxplots dargestellt. Dabei wurden mit der Box der Median sowie die 25. - 75. Perzentile dargestellt, während die T-Balken dem kleinsten und größten Wert entsprachen. Werte, die zwischen $1 \frac{1}{2}-3$ Boxlängen außerhalb der Box lagen, wurden als Ausreißer bezeichnet und in den Grafiken als Kreise dargestellt. Lagen die Werte mehr als 3 Boxenlängen außerhalb, handelte es sich um Extremwerte, die als Kreuze aufgetragen wurden.

Die kategorisierten bzw. nominalen Daten wurden als absolute und relative Häufigkeiten angegeben. 


\section{Ergebnisse}

\subsection{Allgemeine Datenerfassung}

\subsubsection{Die Studienpopulation}

Die Studienpopulation bestand aus 152 Patienten im Alter von 36 bis 80 Jahren. Davon waren 27 Patienten männlich und 125 weiblich. Das Durchschnittsalter aller Probanden zum Zeitpunkt der Untersuchung betrug 59,55 \pm 9,82 Jahre. Unter den Patienten befanden sich $38(25,0 \%)$ Raucher, 34 (22,37\%) ehemalige Raucher und 80 (52,63\%) Nichtraucher (siehe Tabelle 19).

Tabelle 19: Alter und Rauchgewohnheiten der Studienpopulation

\begin{tabular}{|l|l|l|l|l|l|}
\hline & \multicolumn{2}{|c|}{$\begin{array}{c}\text { Alter } \\
\text { (in Jahren) }\end{array}$} & \multicolumn{3}{c|}{$\begin{array}{c}\text { Rauchgewohnheiten } \\
\text { n (\%) }\end{array}$} \\
\hline & Min. & Max. & Raucher & ehemalige Raucher & Nichtraucher \\
\hline $\begin{array}{l}\text { männlich } \\
(\mathrm{n}=27)\end{array}$ & 40 & 78 & 6 & 10 & 11 \\
\hline weiblich & 36 & 80 & $(22,22 \%)$ & $(37,04 \%)$ & $(40,74 \%)$ \\
\hline $\mathrm{n}=125)$ & & 32 & 24 & 69 \\
total & MW $\mathrm{n}=152)$ & $59,55 \pm 9,82,59,5$ & $(25,60 \%)$ & $(19,20 \%)$ & $(55,20 \%)$ \\
\hline
\end{tabular}

(MW: Mittelwert, SA: Standardabweichung)

\subsubsection{Rheumatologische Daten}

Die Tabellen 20 und 21 geben einen Überblick über die Patientencharakteristik bezüglich klinisch-rheumatologischer Parameter sowie der Blutparameter. Da die erfassten Daten aus den Akten nicht bei allen Patienten vollständig waren, variiert die Anzahl der Patienten (n). Etwa die Hälfte der Patienten war seronegativ für Rheumafaktor $(55,9 \%)$ und Anti-CCP $(48,7 \%)$ bei durchschnittlich mittlerer Krankheitsaktivität (DAS28 $3,22 \pm 4,01$ ) und einer durchschnittlichen Erkrankungsdauer von 85,07 \pm 266 Monaten. 
Tabelle 20: Klinisch-rheumatologische Parameter der Studienpopulation

\begin{tabular}{|l|l|l|l|l|}
\hline Klinisch-rheumatologische Parameter & $\begin{array}{c}\text { Patientenzahl } \\
(\boldsymbol{\%})\end{array}$ & $\begin{array}{c}\text { MW } \mathbf{f} \text { SA, } \\
\text { Median }\end{array}$ & Min. & Max. \\
\hline Dauer der Erkrankung (Monate) & $\mathrm{n}=150(98,68)$ & $85,07 \pm 266,267$ & 1 & 533 \\
\hline $\begin{array}{l}\text { Alter zum Zeitpunkt der Erstdiagnose } \\
\text { (Jahre) }\end{array}$ & $\mathrm{n}=151(99,34)$ & $50,28 \pm 11,86,50,96$ & 11 & 76 \\
\hline Krankheitsaktivität (DAS28) & $\mathrm{n}=150(98,68)$ & $3,51 \pm 1,4,3,41$ & 0,55 & 7,24 \\
\hline Anzahl geschwollener Gelenke & $\mathrm{n}=151(99,34)$ & $3,22 \pm 4,01,2,00$ & 0 & 22 \\
\hline Anzahl druckdolenter Gelenke & $\mathrm{n}=151(99,34)$ & $6,40 \pm 6,75,4,00$ & 0 & 29 \\
\hline Morgensteifigkeit (min) & $\mathrm{n}=147(96,71)$ & $39,23 \pm 47,75,30,00$ & 0 & 240 \\
\hline
\end{tabular}

(MW: Mittelwert, SA: Standardabweichung, DAS28: disease activity score 28)

Tabelle 21: Blutparameter der Studienpopulation

\begin{tabular}{|c|c|c|c|}
\hline Blutparameter & $\begin{array}{c}\text { Patientenzahl } \\
(\%)\end{array}$ & $\mathbf{M W} \pm \mathbf{S A}$, Median & $\begin{array}{l}\text { Normwerte im menschlichen } \\
\text { Blut für Erwachsene }\end{array}$ \\
\hline Rheumafaktor [U/ml] & $\mathrm{n}=146(96,05)$ & $90,85 \pm 250,60,10,10$ & $<15,9 \mathrm{U} / \mathrm{ml}$ \\
\hline Seronegativ & $\mathrm{n}=85(55,92)$ & & \\
\hline Seropositiv & $\mathrm{n}=61(40,13)$ & & \\
\hline Anti-CCP [U/ml] & $\mathrm{n}=144(94,74)$ & $98,00 \pm 160,60,6,50$ & $<5 \mathrm{U} / \mathrm{ml}$ \\
\hline Seronegativ & $\mathrm{n}=74(48,68)$ & & \\
\hline Seropositiv & $\mathrm{n}=70(46,05)$ & & \\
\hline $\mathrm{CRP}[\mathrm{mg} / \mathrm{l}]$ & $\mathrm{n}=152(100)$ & $6,20 \pm 14,47,2,40$ & $<5 \mathrm{mg} / \mathrm{l}$ \\
\hline $\begin{array}{l}\text { BSG } \\
\text { [mm } 1 \text { Std Wartezeit] }\end{array}$ & $\mathrm{n}=151(99,34)$ & $13,21 \pm 12,49,10,00$ & $\begin{array}{l}\text { Männer max. } 22 \mathrm{~mm} \text {, } \\
\text { Frauen max. } 28 \mathrm{~mm}\end{array}$ \\
\hline
\end{tabular}

(MW: Mittelwert, SA: Standardabweichung, Anti-CCP: Antikörper gegen cyclische citrullinierte Peptide, CRP: C-reaktives Protein, BSG: Blutsenkungsgeschwindigkeit)

\subsubsection{Rheumamedikamente}

In Tabelle 22 ist die Medikation zum Zeitpunkt der Untersuchung (aktuelle Medikation) aufgeführt. Die Hälfte der Patienten (50\%) nahm csDMARDs ein und etwa ein Drittel der Patienten (39,47 \%) wurde mit Biologika behandelt. Nur wenige Patienten (10,53\%) wurden ausschließlich mit nichtsteroidalen Antirheumatika und/oder Glucocorticoiden therapiert. Die Tabelle gibt zudem einen Überblick, wie viele Patienten der Studienpopulation insgesamt die aufgeführten Medikamente (aktuelle Therapie und Vortherapie) eingenommen haben und wie lange die Einnahmedauer bestand. 
Tabelle 22: Rheumamedikation der Studienpopulation

\begin{tabular}{|c|c|c|c|c|}
\hline & \multirow[t]{2}{*}{ RA-Medikamente } & \multirow{2}{*}{$\begin{array}{c}\text { Aktuelle } \\
\text { Therapie } \\
\begin{array}{c}\text { Patientenzahl } \\
(\%)\end{array}\end{array}$} & \multicolumn{2}{|c|}{$\begin{array}{c}\text { Gesamteinnahmedauer } \\
\text { (in Monaten) } \\
\text { Aktuelle Therapie + Vortherapie }\end{array}$} \\
\hline & & & $\begin{array}{l}\text { Patientenzahl } \\
(\%)\end{array}$ & $\mathrm{MW} \pm \mathrm{SA}$, Median \\
\hline & $\begin{array}{l}\text { Nichtsteroidale Antirheumatika } \\
\text { und/oder Glucocorticoide }\end{array}$ & $\mathrm{n}=16(10,53)$ & & \\
\hline \multirow{4}{*}{ 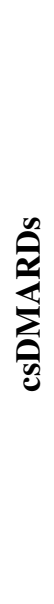 } & $\begin{array}{l}\text { MTX } \\
\left.\text { (Methotrexat }{ }^{\circledR}\right)\end{array}$ & $\mathrm{n}=42(27,63)$ & $\mathrm{n}=132(86,84)$ & $46,45 \pm 59,15,27,00$ \\
\hline & $\begin{array}{l}\text { Leflunomid } \\
\left(\text { Arava }{ }^{\circledR}\right)\end{array}$ & $\mathrm{n}=15(9,87)$ & $\mathrm{n}=73(48,03)$ & $27,96 \pm 32,56,16,00$ \\
\hline & $\begin{array}{l}\text { csDMARDs Kombinationen } \\
\text { zeitgleiche Einnahme mindestens } \\
\text { zwei dieser Medikamente: MTX } \\
\left(\text { Methotrexat }{ }^{\circledR}\right) \text {, Leflunomid (A- } \\
\left.\text { rava }{ }^{\circledR}\right) \text {, Sulfasalazin (Azulfidine }{ }^{\circledR} \text { ) }\end{array}$ & $\mathrm{n}=19(12,50)$ & $\mathrm{n}=47(30,92)$ & $35,57 \pm 46,44,23,00$ \\
\hline & \multicolumn{2}{|c|}{$\begin{array}{l}\text { Gesamtdauer der Einnahme von csDMARDs } \\
\text { (aktuelle Therapie + Vortherapie) }\end{array}$} & $\mathrm{n}=148(97,37)$ & $66,52 \pm 77,75,43,00$ \\
\hline \multirow{4}{*}{$\frac{\pi}{\frac{\pi}{0}}$} & $\begin{array}{l}\text { Anti-TNF } \alpha \text {-Therapeutika } \\
\left.\text { Infliximab (Remicade }{ }^{\circledR}\right) \text { oder Eta- } \\
\left.\text { nercept (Enbrel }{ }^{\circledR}\right) \text { oder } \\
\left.\text { Adalimumab (Humira }{ }^{\circledR}\right) \text { als Mo- } \\
\text { notherapie oder in Kombination } \\
\text { mit MTX }\end{array}$ & $\mathrm{n}=28(18,42)$ & $\mathrm{n}=57(37,50)$ & $38,32 \pm 34,61,30,00$ \\
\hline & $\begin{array}{l}\text { Tocilizumab } \\
\left.\text { (RoActemra }{ }^{\circledR}\right) \text { als Monotherapie } \\
\text { oder in Kombination mit MTX }\end{array}$ & $\mathrm{n}=13(8,55)$ & $\mathrm{n}=17(11,18)$ & $22,47 \pm 18,74,13,00$ \\
\hline & $\begin{array}{l}\text { Rituximab } \\
\left.\text { (Mabthera }{ }^{\circledR}\right) \text { in Kombination mit } \\
\text { MTX }\end{array}$ & $\mathrm{n}=19(12,50)$ & $\mathrm{n}=30(19,74)$ & $44,82 \pm 32,46,38,00$ \\
\hline & \multicolumn{2}{|c|}{$\begin{array}{l}\text { Gesamtdauer der Einnahme von Biologika } \\
\text { (aktuelle Therapie + Vortherapie) }\end{array}$} & $\mathrm{n}=71(46,71)$ & $20,87 \pm 18,00,13,00$ \\
\hline
\end{tabular}

(MW: Mittelwert, SA: Standardabweichung, RA: rheumatoide Arthritis, csDMARDs: conventional synthetic disease modifying anti-rheumatic drugs, TNF $\alpha$ : Tumornekrosefaktor-alpha) 


\subsection{Ergebnisse der zahnärztlichen Untersuchung}

Die Ergebnisse des zahnärztlichen Befundes sind in Tabelle 23 dargestellt. Der mittlere DMF-T-Index der Probanden lag bei 19,7 \pm 3. Im Durchschnitt wies die Studienpopulation 0,37 \pm 0 kariöse $(\mathrm{D}-\mathrm{T})$ sowie 13,3 \pm 5,5 mit Füllungen oder Kronen versorgte Zähne auf (F-T). Im Mittel fehlten 6,28 \pm 2,5 Zähne (M-T). Insgesamt hatten 112 Patienten (73,68 \%) mehr als 20 Zähne. Kein Patient war zahnlos.

Tabelle 23: Dentale Befunde der Studienpopulation

\begin{tabular}{|l|l|l|l|l|}
\hline & \multicolumn{1}{|c|}{ DMFT } & \multicolumn{1}{|c|}{ D-T } & \multicolumn{1}{c|}{ M-T } & \multicolumn{1}{c|}{ F-T } \\
\hline MW \pm SA, Median $(\mathrm{n}=152)$ & $19,70 \pm 3,14$ & $0,37 \pm 0,0$ & $6,28 \pm 2,5,5,5$ & $13,30 \pm 5,5,8,5$ \\
\hline Min. & 2 & 0 & 0 & 2 \\
\hline Max. & 31 & 7 & 26 & 26 \\
\hline
\end{tabular}

(MW: Mittelwert, SA: Standardabweichung, DMFT: Index zur Messung der Kariesinzidenz, D-T: kariöse Zähne, M-T: fehlende Zähne, F-T: mit Füllungen oder Kronen versorgte Zähne)

\subsubsection{Parodontale Erkrankungslast}

Annähernd alle Patienten der Studienpopulation wiesen nach den Kriterien von Page und Eke (2007) eine schwere $(55,26 \%)$ oder moderate $(42,76 \%)$ Parodontitis auf. Im Mittel fehlten 6,28 \pm 2,5 Zähne (M-T). Der durchschnittliche klinische Attachmentverlust (Ø CAL) lag bei 4,55 $\pm 0,28 \mathrm{~mm}$ und die durchschnittliche Sondierungstiefe ( $\varnothing \mathrm{ST}$ ) betrug 4,14 $\pm 0,4 \mathrm{~mm}$. Tabelle 24 stellt die klinischen Untersuchungsergebnisse zusammenfassend dar. 
Tabelle 24: Patientenverteilung in den einzelnen Gruppen der vier parodontalen Parameter

\begin{tabular}{|c|c|c|c|}
\hline Parodontaler Parameter & Gruppe & Klinische Definition & Patientenzahl (\%) \\
\hline \multirow{3}{*}{$\begin{array}{l}\text { Parodontalzustand nach Page und Eke } \\
(2007) \\
\text { (PAR) }\end{array}$} & PAR1 & mild/gesund & $\mathrm{n}=3(1,97)$ \\
\hline & PAR2 & modert & $\mathrm{n}=65(42,76)$ \\
\hline & PAR3 & schwer & $\mathrm{n}=84(55,26)$ \\
\hline \multirow{4}{*}{$\begin{array}{l}\text { Anzahl fehlender Zähne } \\
(\mathrm{M}-\mathrm{T})\end{array}$} & M-T1 & $\leq 2$ fehlende Zähne & $\mathrm{n}=43(28,29)$ \\
\hline & M-T2 & 3 - 5 fehlende Zähne & $\mathrm{n}=44(28,95)$ \\
\hline & M-T3 & 6 - 9 fehlende Zähne & $\mathrm{n}=33(21,71)$ \\
\hline & M-T4 & $\geq 10$ fehlende Zähne & $\mathrm{n}=32(21,05)$ \\
\hline \multirow{4}{*}{$\begin{array}{l}\text { Durchschnittlicher klinischer Attach- } \\
\text { mentverlust } \\
(\varnothing \mathrm{CAL})\end{array}$} & $\varnothing \mathrm{CAL} 1$ & $\leq 3,71 \mathrm{~mm} \varnothing \mathrm{CAL}$ & $\mathrm{n}=39(25,66)$ \\
\hline & $\varnothing \mathrm{CAL} 2$ & 3,72 - 4,36 mm ØCAL & $\mathrm{n}=37(24,34)$ \\
\hline & $\varnothing$ CAL3 & $4,37-5,00 \mathrm{~mm} \emptyset \mathrm{CAL}$ & $\mathrm{n}=41(26,97)$ \\
\hline & $\varnothing \mathrm{CAL} 4$ & $\geq 5,01 \mathrm{~mm} \varnothing \mathrm{CAL}$ & $\mathrm{n}=35(23,03)$ \\
\hline \multirow{4}{*}{$\begin{array}{l}\text { Durchschnittliche Sondierungstiefe } \\
\text { (Ø ST) }\end{array}$} & $\varnothing \mathrm{ST} 1$ & $\leq 3,48 \mathrm{~mm} \emptyset \mathrm{ST}$ & $\mathrm{n}=38(25,00)$ \\
\hline & $\emptyset \mathrm{ST} 2$ & $3,49-4,04 \mathrm{~mm} \varnothing \mathrm{ST}$ & $\mathrm{n}=38(25,00)$ \\
\hline & $\varnothing \mathrm{ST} 3$ & $4,05-4,51 \mathrm{~mm} \varnothing \mathrm{ST}$ & $\mathrm{n}=38(25,00)$ \\
\hline & $\varnothing \mathrm{ST} 4$ & $\geq 4,52 \mathrm{~mm} \varnothing \mathrm{ST}$ & $\mathrm{n}=38(25,00)$ \\
\hline
\end{tabular}

\subsection{Ergebnisse deskriptiver anamnestischer Erhebungen}

Nachfolgend werden die Ergebnisse von ausgewählten Fragen aus dem Fragebogen zum zahnärztlichen Verhalten sowie dem Parodontitisfragebogen vorgestellt.

\subsubsection{Fragebogen zum zahnärztlichen Verhalten (siehe Anhang S. 78)}

\subsubsection{Zeitpunkt und Grund des letzten Zahnarztbesuches}

Abbildung 5 zeigt graphisch die Zeitpunkte des letzten Zahnarztbesuches und Abbildung 6 zeigt die Gründe dafür. Mehr als zwei Drittel (70,2 \%) der Patienten waren in den vergangenen sechs Monaten beim Zahnarzt. Über ein Drittel der Patienten (38,2 \%) suchten den Zahnarzt zur Kontrolluntersuchung auf, während ein Viertel der Patienten (27,0 \%) im Rahmen der laufenden Behandlung vorstellig wurden. 


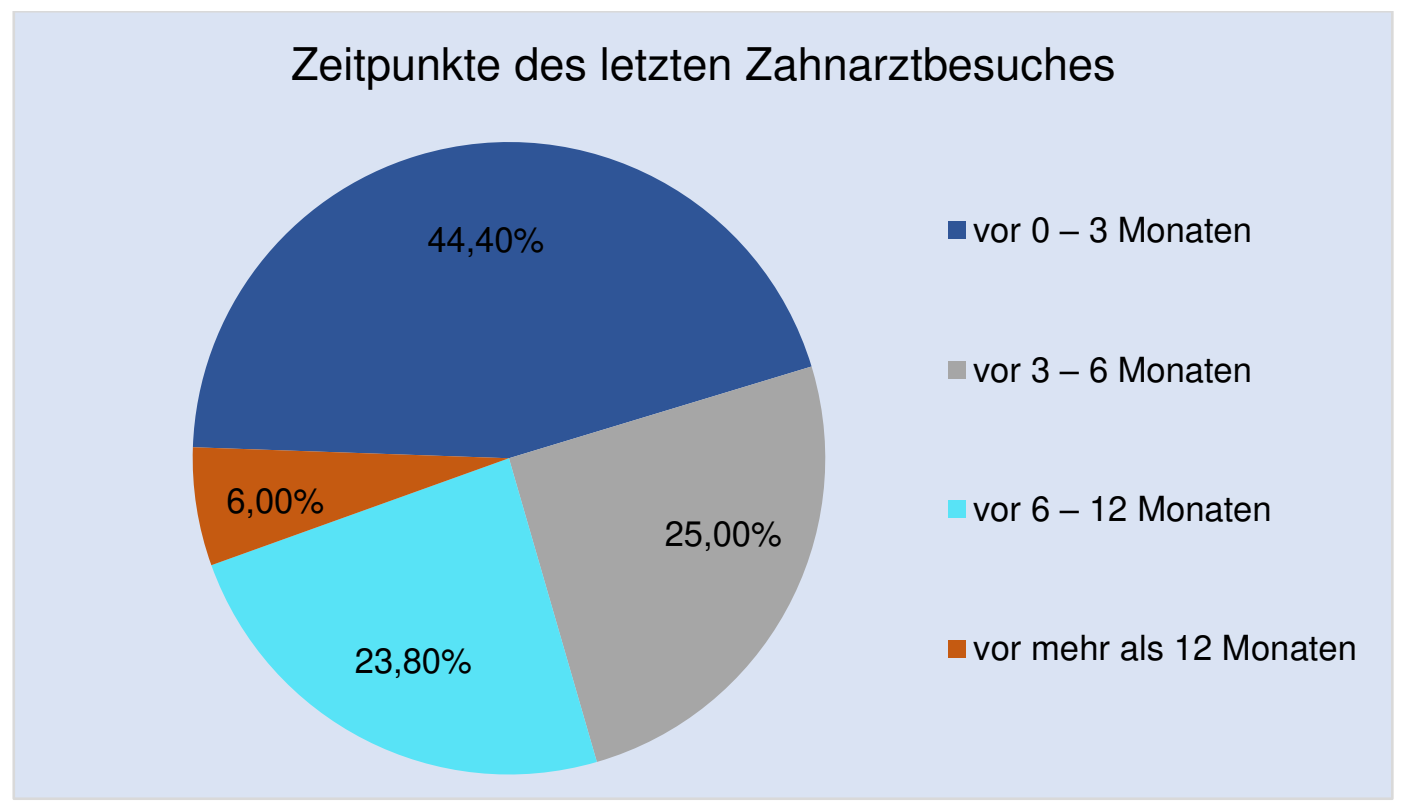

Abbildung 5: Zeitpunkte des letzten Zahnarztbesuches mit Angabe der prozentualen Verteilung innerhalb der Studienpopulation (siehe Anhang S. 78)

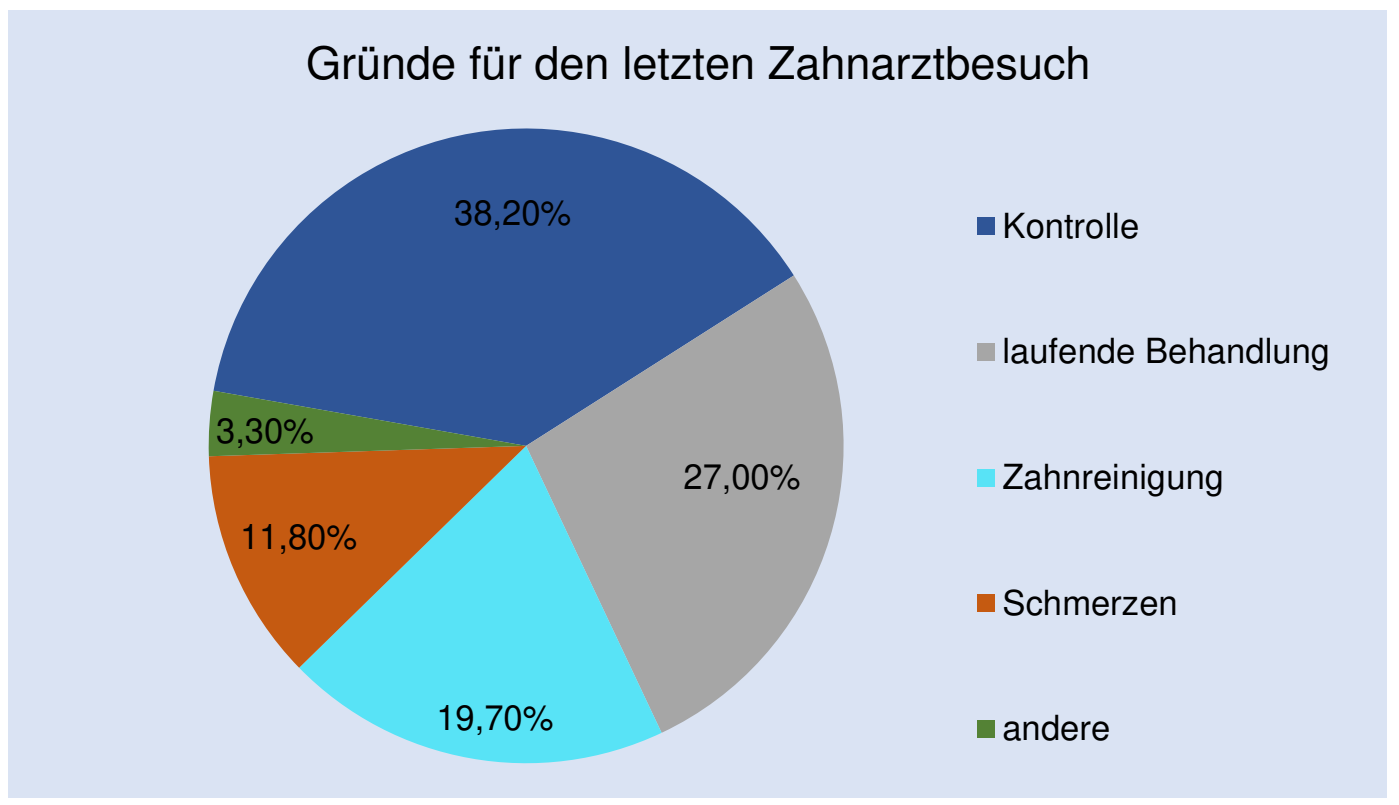

Abbildung 6: Gründe für den letzten Zahnarztbesuch mit Angabe der prozentualen Verteilung innerhalb der Studienpopulation (siehe Anhang S. 78)

\subsubsection{Zusammenhang von Parodontitis und rheumatoider Arthritis}

Nur wenige Patienten (7,2\%) wurden nach der Diagnose der rheumatoiden Arthritis zum Zahnarzt geschickt. Bei zwei Drittel $(68,4 \%)$ der Patienten war dem Zahnarzt bekannt, dass eine Erkrankung an rheumatoider Arthritis besteht. Aber mehr als drei Viertel 
$(79,6 \%)$ der Patienten waren nicht darüber aufgeklärt, dass ein Zusammenhang zwischen rheumatoider Arthritis und Parodontitis besteht. Ähnlich viele $(81,6 \%)$ Patienten waren nicht darüber aufgeklärt, dass sie aufgrund ihrer Erkrankung an rheumatoider Arthritis als Risikopatient gelten. Bei informierten Patienten erfolgte die Aufklärung in beiden Fällen überwiegend durch den Zahnarzt sowie den Rheumatologen (siehe Abbildung 7).

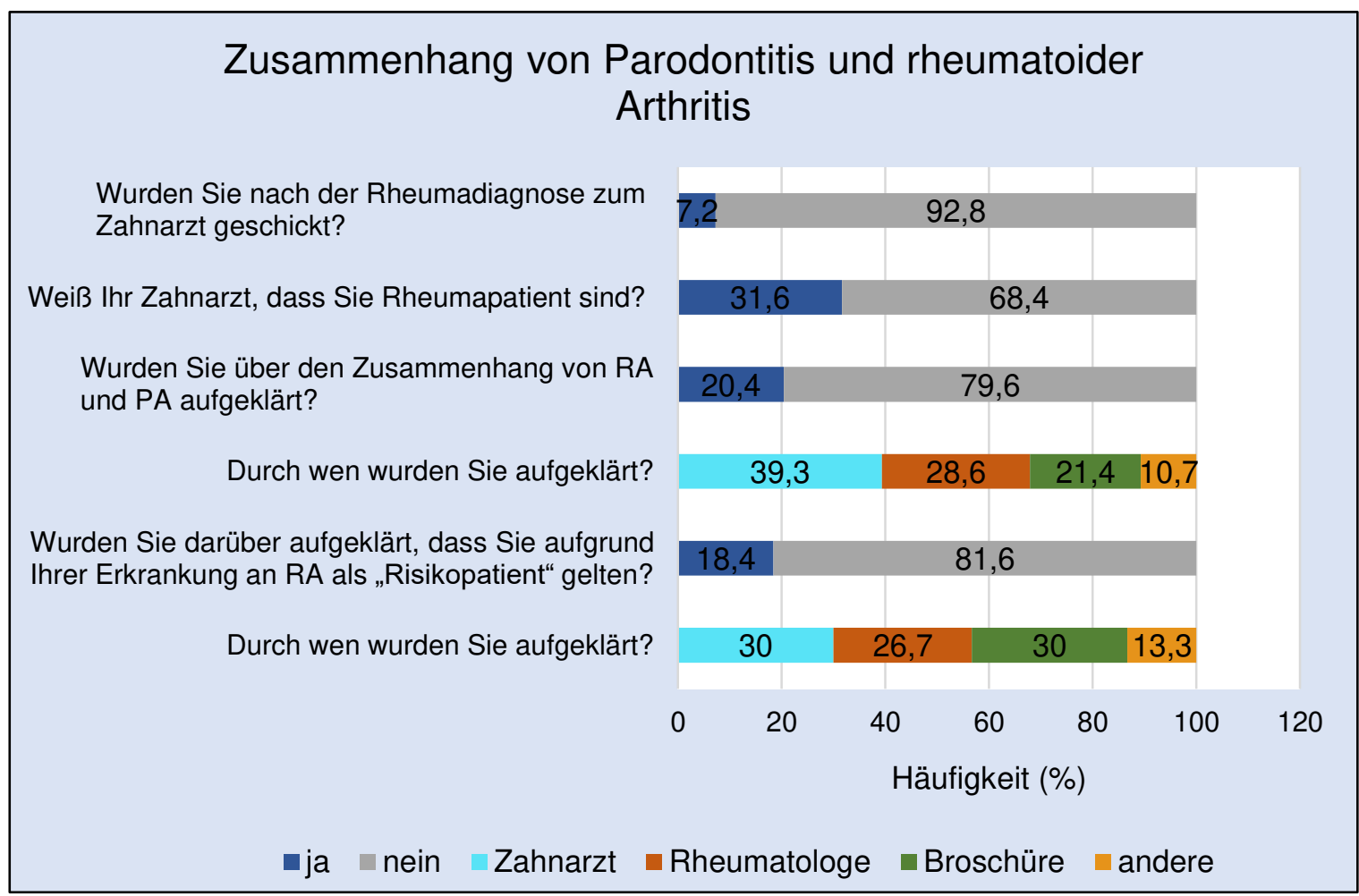

Abbildung 7: Antworten der Studienpopulation auf Fragen zum Zusammenhang von Parodontitis (PA) und rheumatoider Arthritis (RA) aus dem Fragebogen „Zahnärztliches Verhalten“ (siehe Anhang S. 78)

\subsubsection{Zahnärztliche Maßnahmen im Rahmen einer Zahnsanierung}

Bei fast allen Patienten $(91,9 \%)$ erfolgten bereits zahnärztliche Maßnahmen (siehe Abbildung 8), am häufigsten die Zahnentfernung (72,4\%). Auffällig war, dass eine PABehandlung bei weniger als einem Drittel $(28,9 \%)$ der Patienten durchgeführt wurde. 


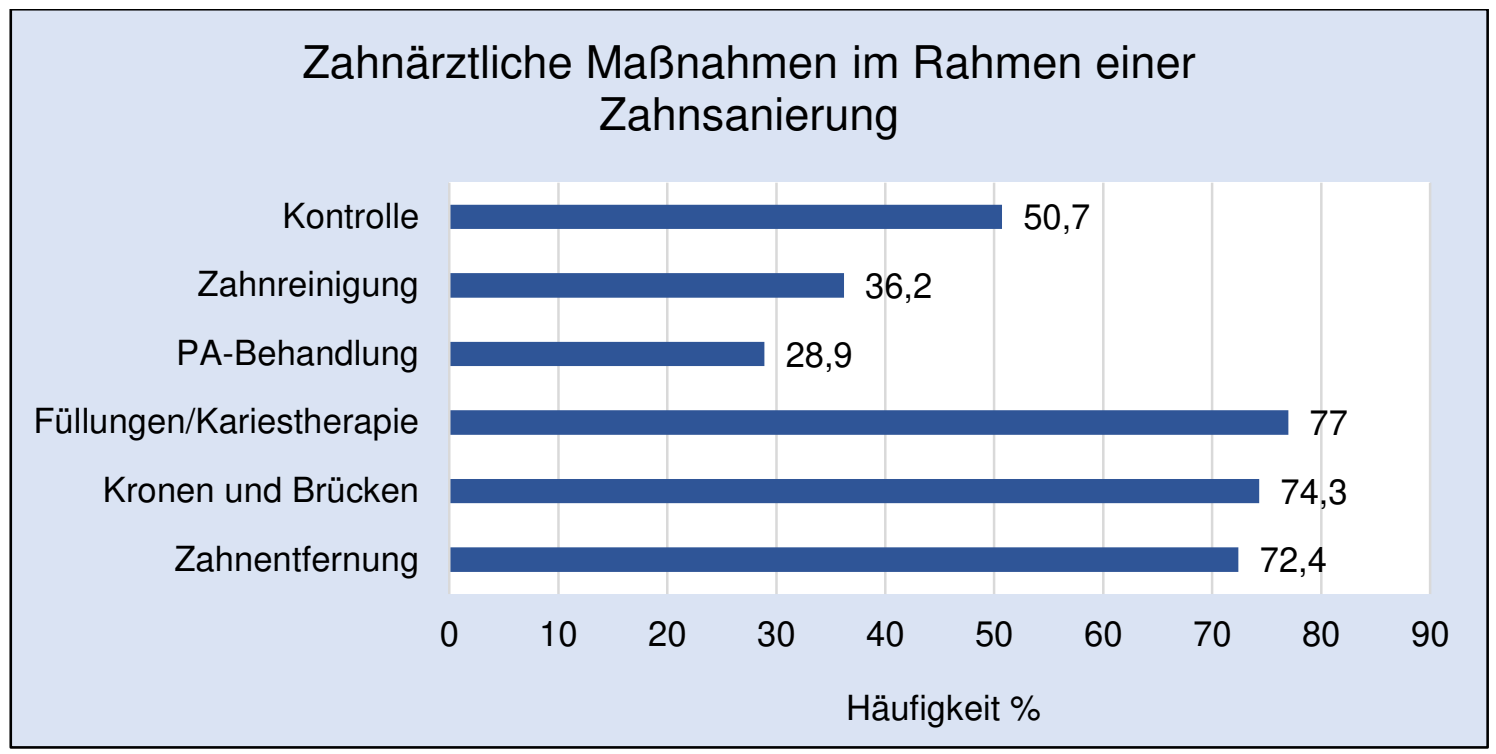

Abbildung 8: Prozentuale Verteilung der zahnärztlichen Maßnahmen, die bei den Patienten der Studienpopulation im Rahmen einer Zahnsanierung durchgeführt wurden (siehe Anhang S. 78) (PA: Parodontitis)

\subsubsection{Mundhygiene}

Mehr als die Hälfte der Patienten (59,6 \%) fühlte sich gut über Mundhygiene aufgeklärt und fast ein Viertel der Patienten (22,5\%) putzte Zähne bzw. Zahnersatz überdurchschnittlich oft (> 2/d). Obwohl die meisten Patienten (88,8 \%) aufgrund der rheumatoiden Arthritis Einschränkungen in der täglichen Bewegungsfähigkeit hatten, fühlten sich weniger als die Hälfte der Patienten (40,1\%) auch in der täglichen Mundhygiene eingeschränkt (Abbildung 9). 


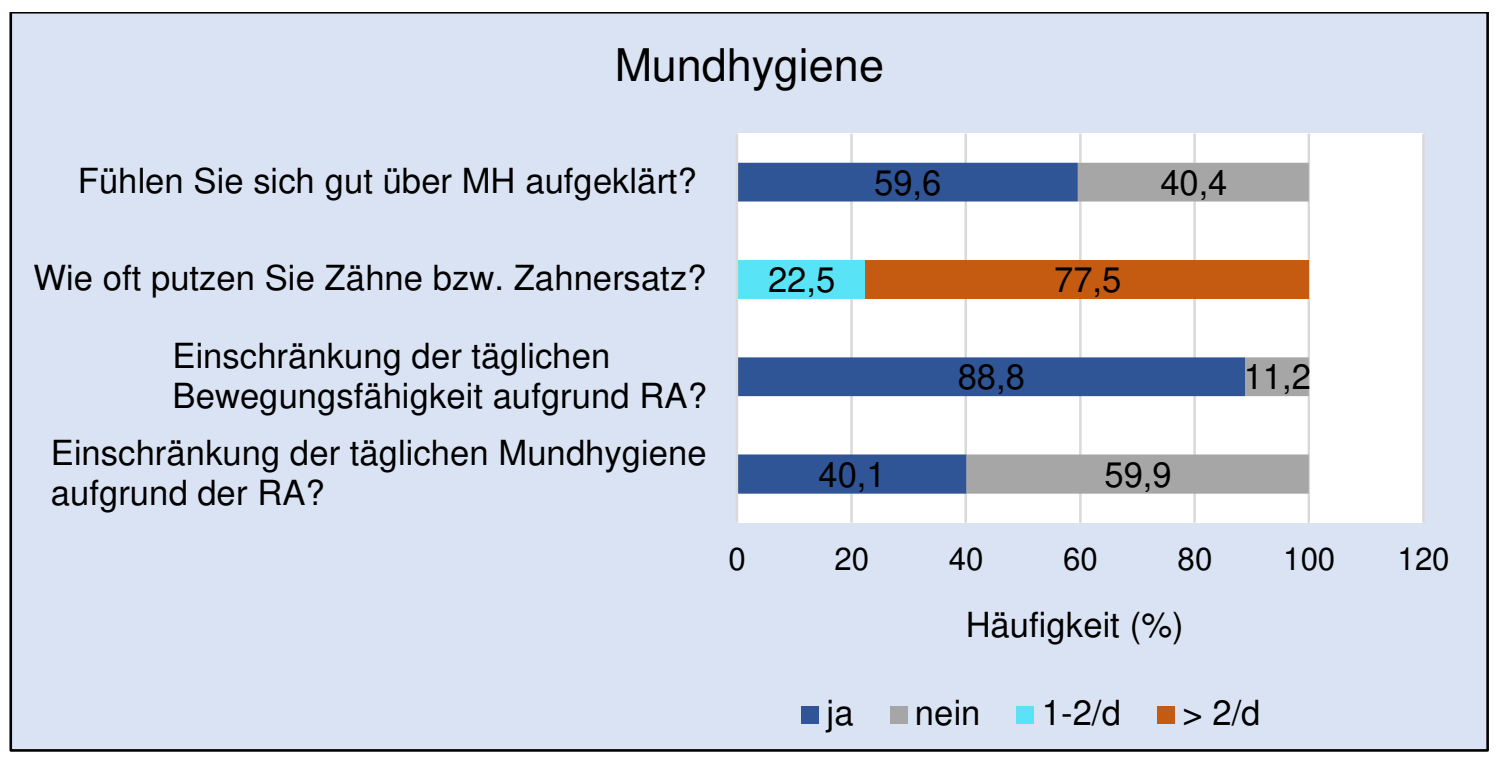

Abbildung 9: Antworten der Studienpopulation auf Fragen zur Mundhygiene (MH) aus dem Fragebogen „Zahnärztliches Verhalten“ (siehe Anhang S. 78) (RA: rheumatoide Arthritis)

\subsubsection{Parodontitisfragebogen (siehe Anhang S. 81)}

In Abbildung 10 sind die Häufigkeitsverteilungen der bejahten Fragen des Parodontitisfragebogens graphisch dargestellt. Den Patienten fielen selbst Veränderungen des Parodontalzustandes auf, vor allem Zahnfleischbluten (52,6\%) und zurückgehendes Zahnfleisch (50\%). Außerdem litt knapp die Hälfte der Patienten an empfindlichem Zahnfleisch (44,7 \%) oder Zahnüberempfindlichkeit (44,7 \%). Ein Großteil der Patienten $(89,5 \%)$ ging regelmäßig zur Kontrolle, weniger als die Hälfte $(45,4 \%)$ ließ regelmäßig eine professionelle Zahnreinigung (PZR) durchführen und nur wenige Patienten $(14,5 \%)$ wurden vorab mit einer PA-Behandlung therapiert. 


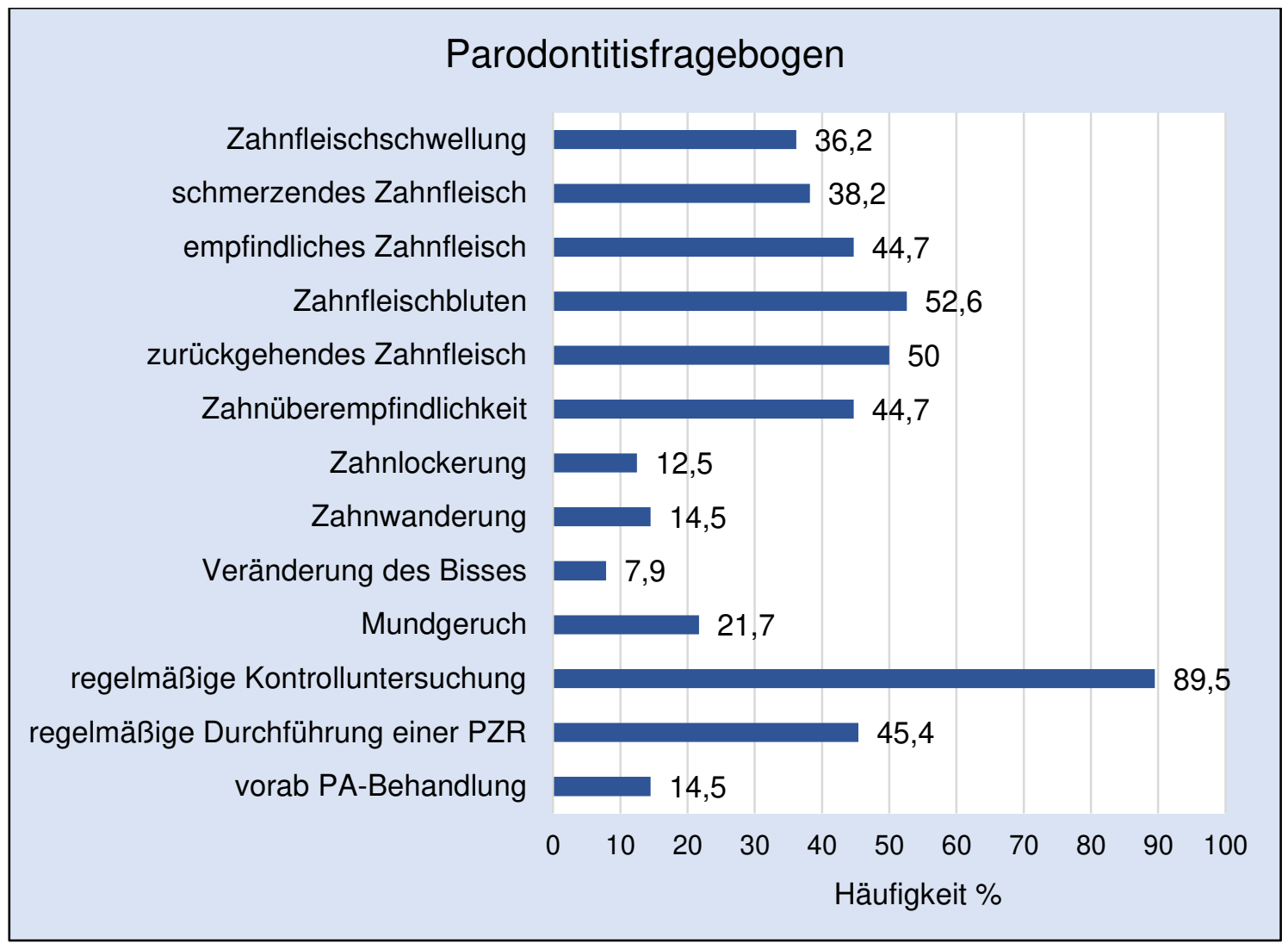

Abbildung 10: Prozentuale Verteilung der bejahten Fragen des Parodontitisfragebogens (siehe Anhang S. 81). Neben der Häufigkeit des Auftretens der aufgeführten Parodontitis-spezifischen Symptome innerhalb der Studienpopulation wird auch die Häufigkeit der Durchführung von drei Therapieoptionen dargestellt (PZR: professionelle Zahnreinigung, PA: Parodontitis)

\subsection{Assoziationen zwischen dem Schweregrad der Parodontalerkrankung und rheumatologischen Parametern}

Tabelle 25 gibt eine Übersicht über die Assoziationen zwischen dem Schweregrad der Parodontalerkrankung, definiert durch die vier parodontalen Parameter, und rheumatologischen Kenngrößen. Die mit Sternchen (*) markierten Werte geben an, dass ein signifikanter Zusammenhang besteht $(\mathrm{p} \leq 0,05)$. 
Tabelle 25: Assoziationen zwischen parodontalen und klinisch-rheumatologischen Parametern sowie Blutparametern mit Angabe der entsprechenden p-Werte

\begin{tabular}{|c|c|c|c|c|c|}
\hline \multicolumn{2}{|c|}{ Rheumatologische Parameter } & 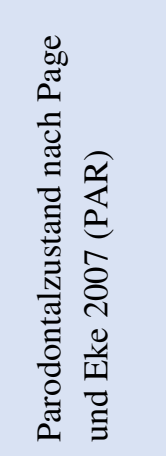 & 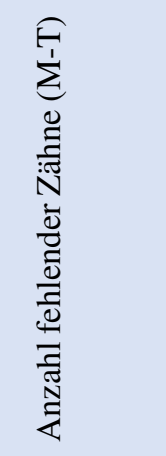 & 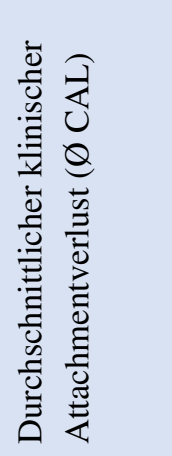 & 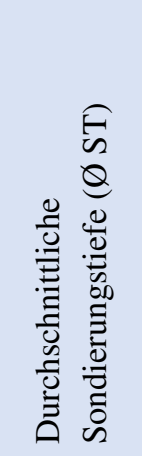 \\
\hline \multirow{3}{*}{$\begin{array}{l}\text { klinisch-rheumato- } \\
\text { logische Parameter }\end{array}$} & Alter bei Erstdiagnose & $\mathrm{p}=0,272$ & $\mathrm{p}=0,037 *$ & $\mathrm{p}=0,162$ & $\mathrm{p}=0,062$ \\
\hline & DAS28 & $\mathrm{p}=0,460$ & $\mathrm{p}=0,004^{*}$ & $\mathrm{p}=0,386$ & $\mathrm{p}=0,810$ \\
\hline & Morgensteifigkeit & $\mathrm{p}=0,465$ & $\mathrm{p}=0,477$ & $\mathrm{p}=0,048 *$ & $\mathrm{p}=0,712$ \\
\hline \multirow{4}{*}{ Blutparameter } & Rheumafaktor & $\mathrm{p}=0,007 *$ & $\mathrm{p}=0,775$ & $\mathrm{p}=0,023 *$ & $\mathrm{p}=0,090$ \\
\hline & Anti-CCP & $\mathrm{p}=0,237$ & $\mathrm{p}=0,642$ & $\mathrm{p}=0,141$ & $\mathrm{p}=0,488$ \\
\hline & CRP & $\mathrm{p}=0,099$ & $\mathrm{p}=0,450$ & $\mathrm{p}=0,397$ & $\mathrm{p}=0,445$ \\
\hline & BSG (1 Std. Wartezeit) & $\mathrm{p}=0,082$ & $\mathrm{p}=0,319$ & $\mathrm{p}=0,024^{*}$ & $\mathrm{p}=0,101$ \\
\hline
\end{tabular}

Signifikante Zusammenhänge $(\mathrm{p} \leq 0,05)$ sind mit Sternchen $(*)$ hervorgehoben. (DAS28: disease activity score 28, Anti-CCP: Antikörper gegen cyclische citrullinierte Proteine, CRP: C-reaktives Protein, BSG: Blutsenkungsgeschwindigkeit)

\subsubsection{Klinisch rheumatologische Parameter}

Der DAS28 kombiniert die Informationen über geschwollene und druckschmerzhafte Gelenke, das Akute-Phase-Protein (CRP oder BSG) und den allgemeinen Gesundheitszustand miteinander und gibt so einen beständigen Maßstab für den Entzündungszustand (Fransen und van Riel 2005). Auch die Dauer der Morgensteifigkeit spiegelt die Krankheitsaktivität wider.

\subsubsection{Einflussfaktor Alter bei Erstdiagnose}

Je älter die Patienten zum Zeitpunkt der Erstdiagnose waren, desto mehr verlorengegangene Zähne wiesen sie auf ( $\mathrm{p}=0,037)$ (siehe Abbildung 11). Zudem war ein deutlicher Trend zu erkennen, dass ein höheres Alter bei Erstdiagnose mit einer höheren durchschnittlichen Sondierungstiefe korrelierte $(\mathrm{p}=0,062)$. 


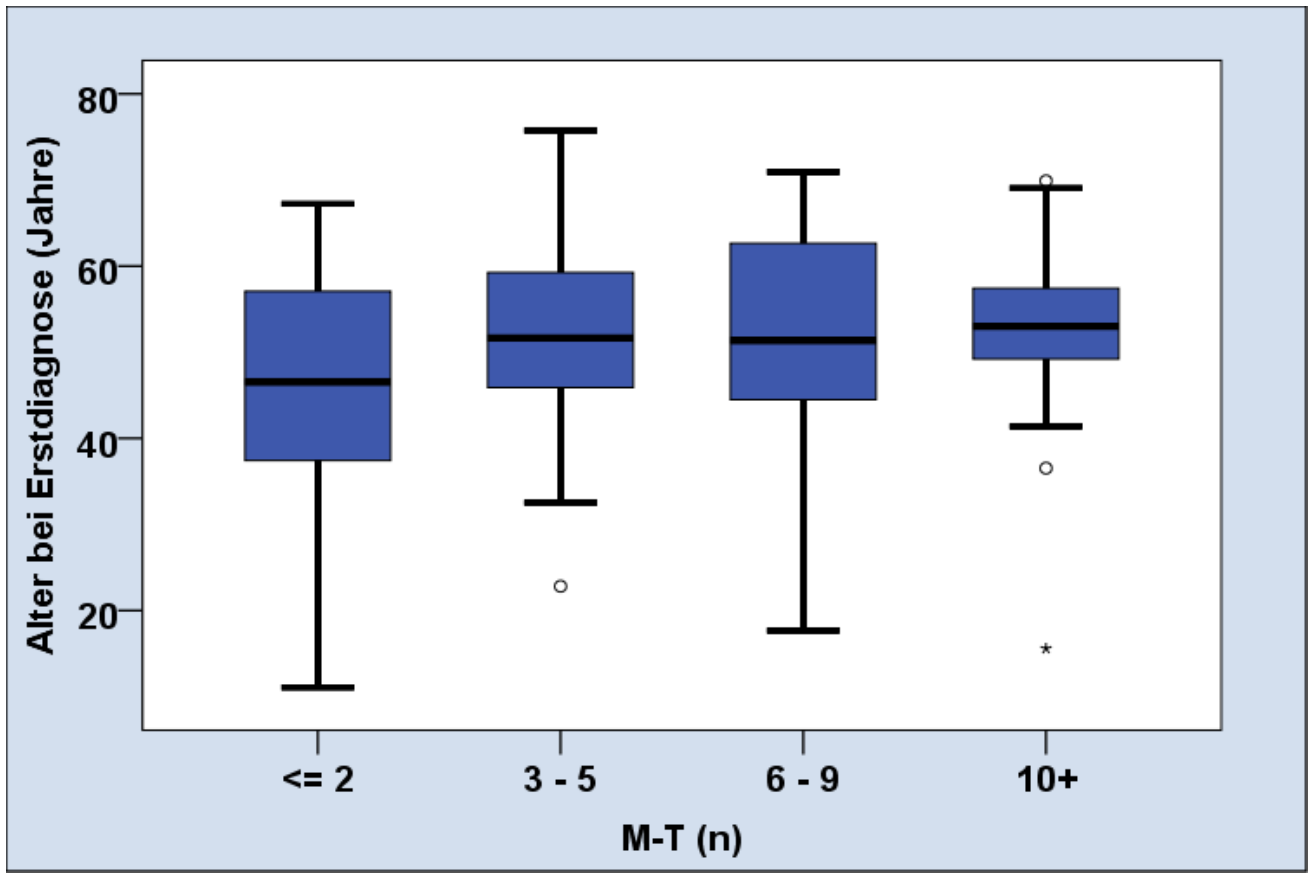

Abbildung 11: Darstellung des Alters bei Erstdiagnose bei unterschiedlicher Anzahl fehlender Zähne $(\mathrm{M}-\mathrm{T})$

\subsubsection{Einflussfaktor DAS28}

Patienten, die einen höheren DAS28-Wert aufwiesen, hatten ebenfalls signifikant mehr fehlende Zähne $(\mathrm{p}=0,004)$, wie in Abbildung 12 graphisch dargestellt wird.

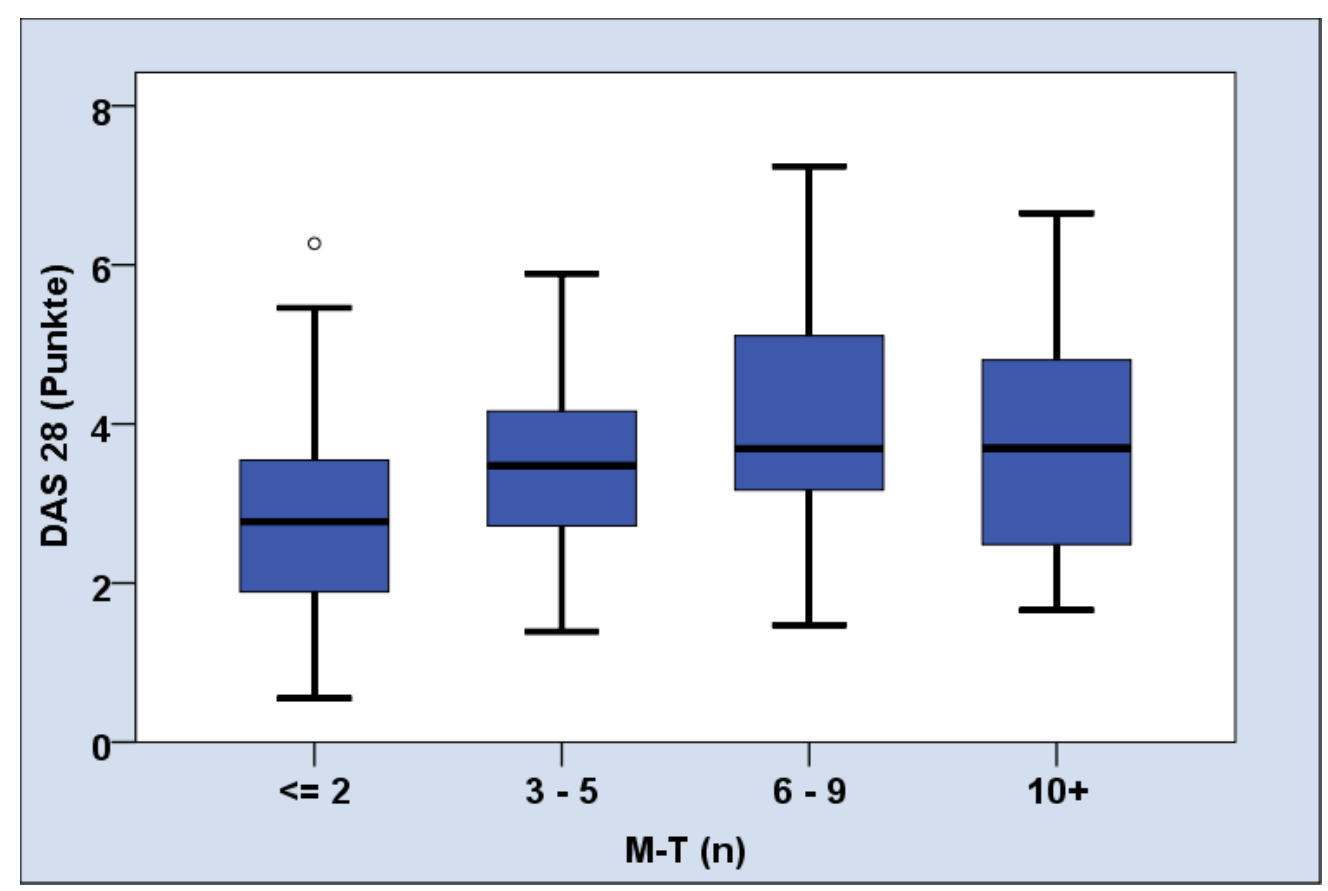

Abbildung 12: Darstellung der DAS28-Werte (disease activity score 28) bei unterschiedlicher Anzahl fehlender Zähne (M-T) 


\subsubsection{Einflussfaktor Morgensteifigkeit}

Es zeigte sich ein signifikanter Zusammenhang zwischen der Dauer der Morgensteifigkeit und dem durchschnittlichen klinischen Attachmentverlust ( $p=0,048)$, wobei eine längere Dauer der Morgensteifigkeit mit einem niedrigeren durchschnittlichen Attachmentverlust korrelierte (siehe Abbildung 13).

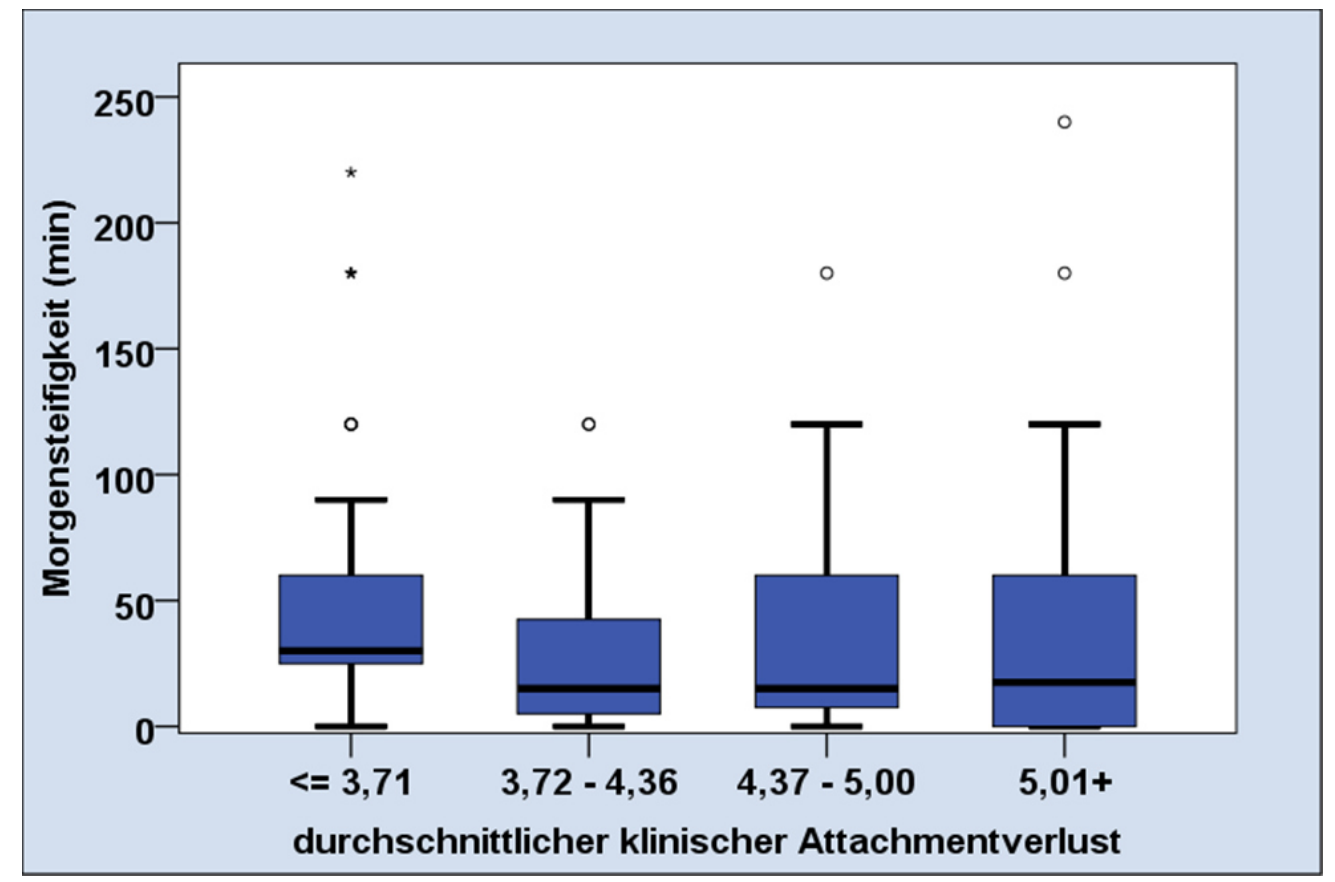

Abbildung 13: Darstellung der Dauer der Morgensteifigkeit bei unterschiedlichem durchschnittlichen klinischen Attachmentverlust (Ø CAL)

\subsubsection{Blutparameter}

Untersuchungen auf Rheumafaktoren und Antikörper gegen cyclische citrullinierte Peptide werden zur Erhärtung der Diagnose einer rheumatoiden Arthritis durchgeführt (Schneider et al. 2011). Hingegen sind die Blutsenkungsgeschwindigkeit und das C-reaktive Protein unspezifische serologische Entzündungszeichen, die bei Patienten mit einer etablierten RA die Krankheitsaktivität widerspiegeln (Sokka und Pincus 2009).

\subsubsection{Einflussfaktor Rheumafaktor}

Mit steigendem Schweregrad der Parodontitis nahm die Konzentration von Rheumafaktor im Blut signifikant $(\mathrm{p}=0,007) \mathrm{zu}$ (siehe Abbildung 14). Ebenfalls statistisch signifikant war der Zusammenhang zwischen der Konzentration von Rheumafaktor im Blut und dem 
durchschnittlichen klinischen Attachmentverlust, wie in Abbildung $15 \mathrm{zu}$ sehen ist. Je höher die Konzentration von Rheumafaktor im Blut war, desto höher war auch der durchschnittliche klinische Attachmentverlust $(\mathrm{p}=0,023)$.

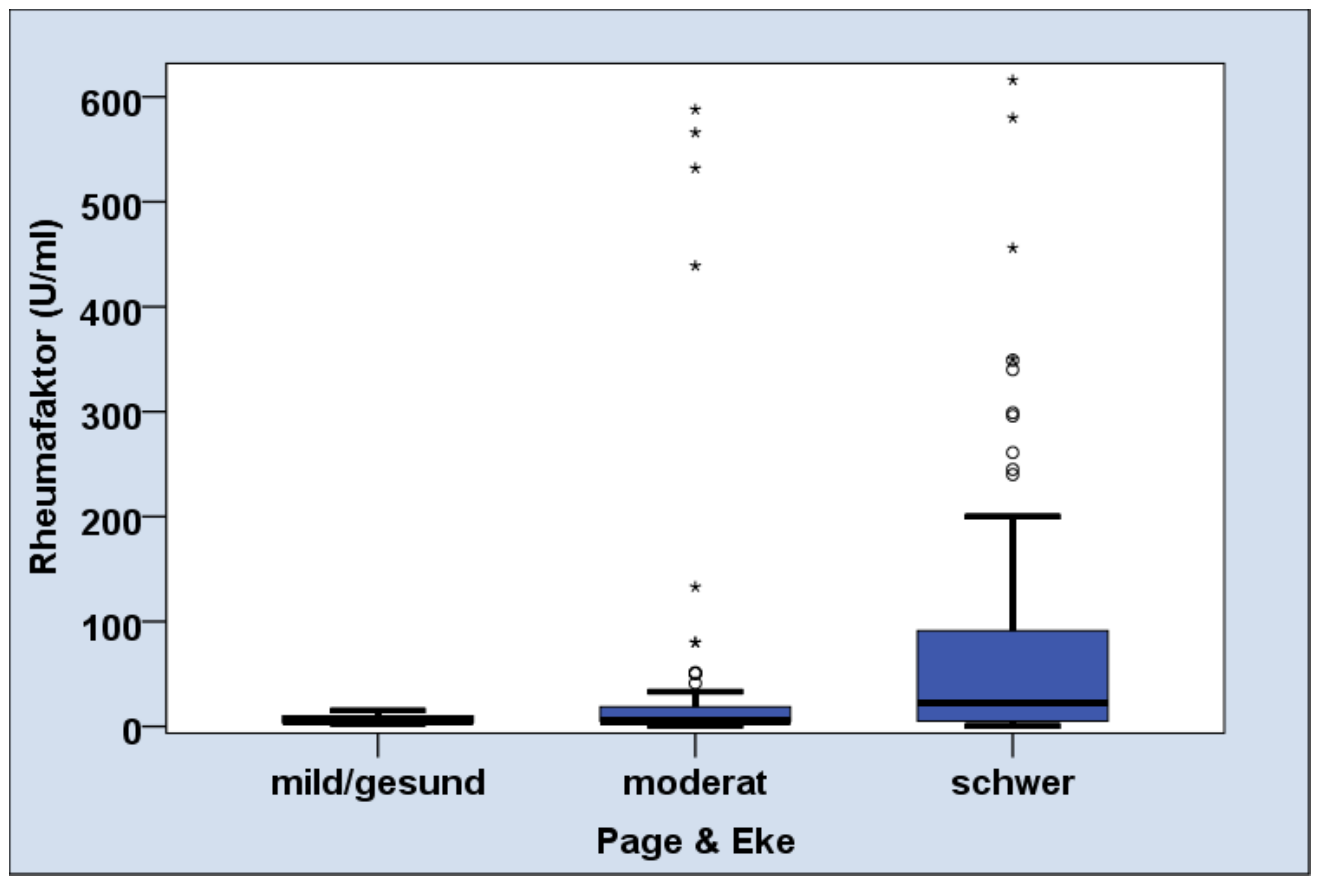

Abbildung 14: Darstellung der Konzentration des Rheumafaktors im Blut bei unterschiedlichem Schweregrad der Parodontitis nach Page und Eke (2007)

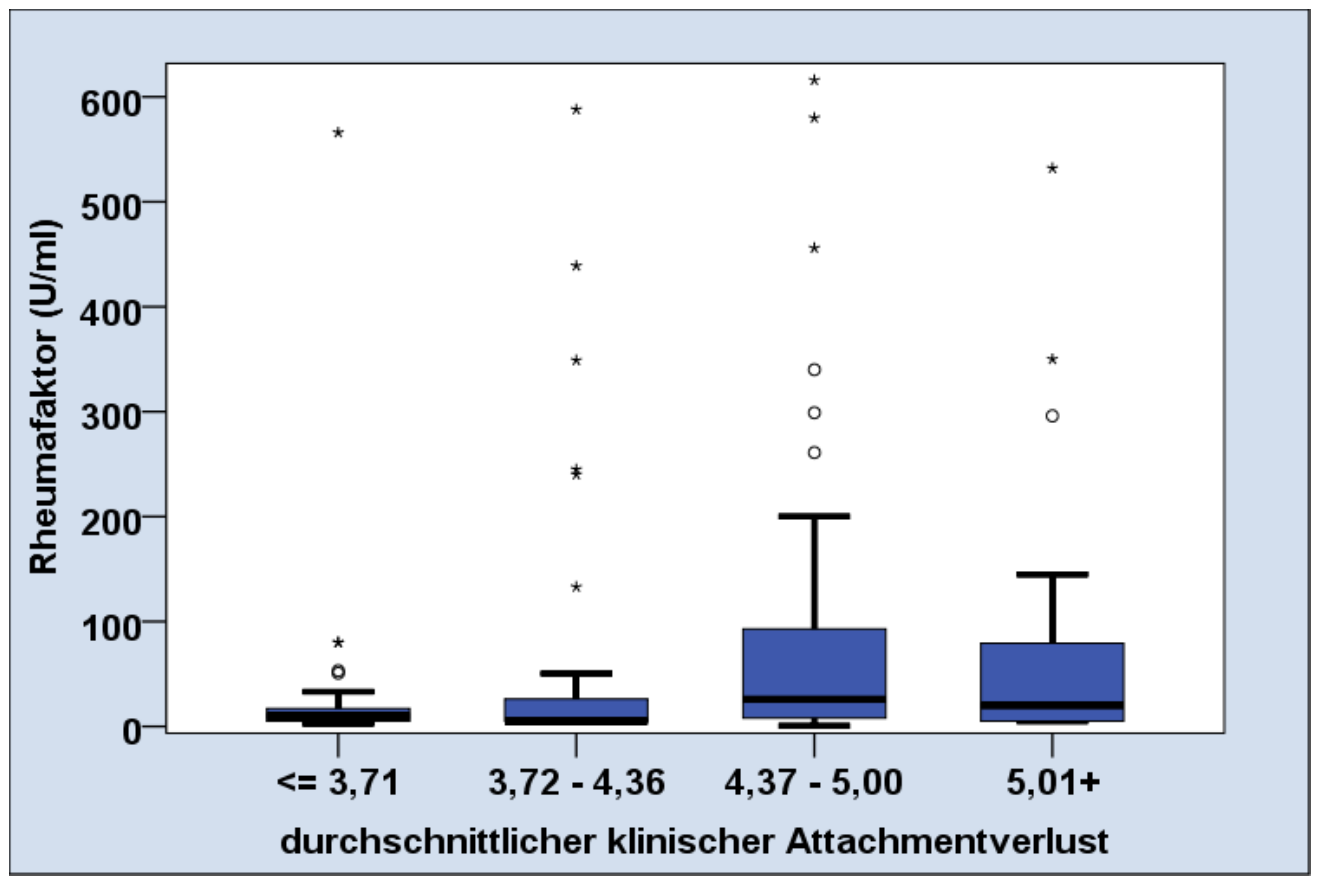

Abbildung 15: Darstellung der Konzentration des Rheumafaktors im Blut bei unterschiedlichem durchschnittlichen klinischen Attachmentverlust (Ø CAL) 


\subsubsection{Einflussfaktoren Anti-CCP und CRP}

Es bestand keine signifikante Interaktion zwischen der Konzentration von Anti-CCP oder CRP im Blut und einem der vier parodontalen Parameter.

\subsubsection{Einflussfaktor BSG}

Es bestand ein signifikanter Zusammenhang $(\mathrm{p}=0,024)$ zwischen der BSG nach einer Stunde Wartezeit und dem durchschnittlichen klinischen Attachmentverlust, wobei eine erhöhte BSG mit einem erhöhten durchschnittlichen klinischen Attachmentverlust korrelierte (siehe Abbildung 16).

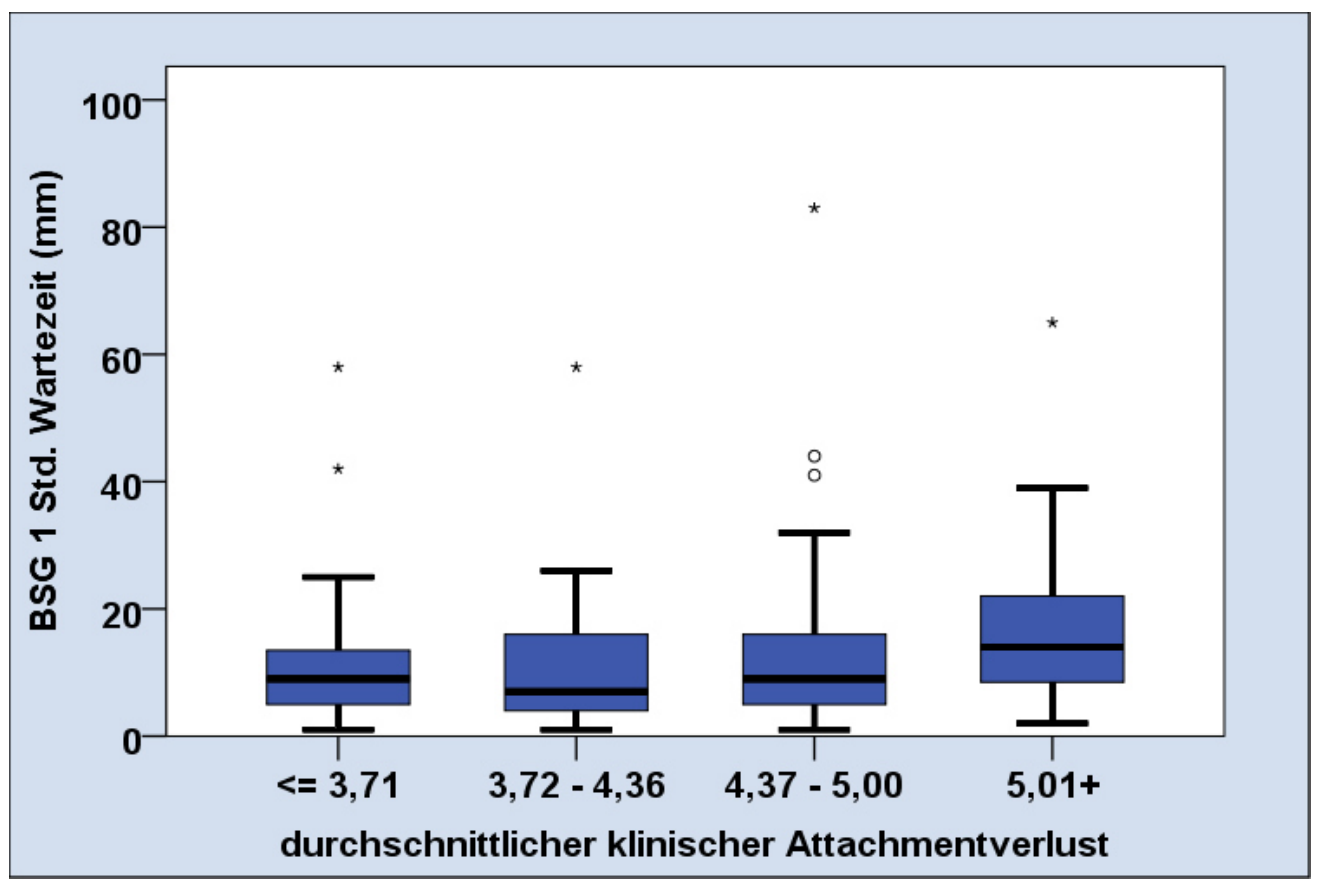

Abbildung 16: Darstellung der Blutsenkungsgeschwindigkeit (BSG) nach einer Stunde Wartezeit bei unterschiedlichem durchschnittlichen Attachmentverlust (Ø CAL) 


\subsection{Assoziationen zwischen dem Schweregrad der Parodontalerkrankung und der Einnahmedauer der Rheumamedikamente}

Bei keinem der aufgeführten Medikamente (MTX, Leflunomid, Kombinationen von csDMARDs, Anti-TNF $\alpha$-Therapeutika, Tocilizumab, Rituximab) konnte eine signifikante Interaktion zwischen der Dauer der Einnahme (aktuelle Therapie) und einem der vier parodontalen Parameter (Parodontalzustand nach Page und Eke 2007, M-T, Ø CAL, Ø ST) nachgewiesen werden.

Auch die Gesamtdauer der Einnahme von csDMARDs (MTX + Leflunomid + csDMARDs Kombinationen, aktuelle Therapie + Vortherapie) hatte keinen signifikanten Einfluss.

Lediglich bei der Gesamtdauer der Einnahme von Biologika (Anti-TNF $\alpha$-Therapeutika + Tocilizumab + Rituximab, aktuelle Therapie + Vortherapie) zeigte sich ein deutlicher Trend ( $\mathrm{p}=0,078)$ zu niedrigeren durchschnittlichen Sondierungstiefen bei längerer Gesamteinnahmedauer von Biologika, jedoch ohne statistische Signifikanz. Ein Einfluss auf die anderen drei parodontalen Parameter bestand nicht. Die Ergebnisse der statistischen Analysen sind in Tabelle 26 mit den entsprechenden p-Werten aufgeführt. 
Tabelle 26: Assoziationen zwischen den vier parodontalen Parametern und der Einnahmedauer von Rheumamedikamenten mit Angabe der entsprechenden p-Werte

\begin{tabular}{|c|c|c|c|c|c|}
\hline Parodontaler Par & ameter & 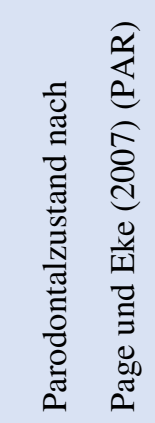 & 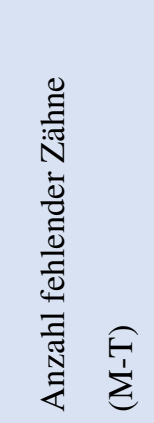 & 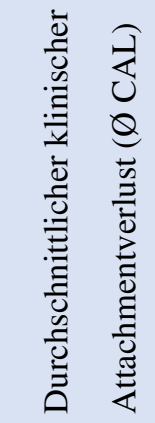 & 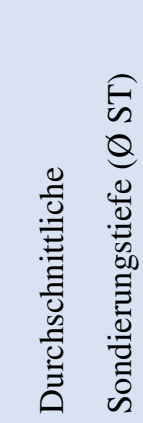 \\
\hline $\begin{array}{l}\text { MTX } \\
\text { (Methotrexat } \AA)\end{array}$ & $\mathrm{n}=132$ & $\mathrm{p}=0,819$ & $\mathrm{p}=0,173$ & $\mathrm{p}=0,259$ & $\mathrm{p}=0,612$ \\
\hline $\begin{array}{l}\text { Leflunomid } \\
\left(\text { Arava }{ }^{\circledR}\right)\end{array}$ & $\mathrm{n}=73$ & $\mathrm{p}=0,492$ & $p=0,660$ & $\mathrm{p}=0,987$ & $p=0,429$ \\
\hline $\begin{array}{l}\text { csDMARDs Kombinationen } \\
\text { zeitgleiche Einnahme mindestens zwei } \\
\text { dieser Medikamente: MTX (Methotr- } \\
\text { exat }(\AA) \text {, Leflunomid (Arava }(), \\
\text { Sulfasalazin (Azulfidine }(\text { ) }\end{array}$ & $\mathrm{n}=47$ & $\mathrm{p}=0,103$ & $\mathrm{p}=0,694$ & $p=0,645$ & $\mathrm{p}=0,902$ \\
\hline $\begin{array}{l}\text { Anti-TNFo-Therapeutika } \\
\text { Infliximab (Remicade } ®) \text { oder Etanercept } \\
\left(\text { Enbrel } \AA \text { ) oder Adalimumab (Humira }{ }^{\circledR}\right) \\
\text { als Monotherapie oder in Kombination } \\
\text { mit MTX }\end{array}$ & $\mathrm{n}=57$ & $\mathrm{p}=0,713$ & $\mathrm{p}=0,677$ & $\mathrm{p}=0,754$ & $\mathrm{p}=0,238$ \\
\hline $\begin{array}{l}\text { Tocilizumab } \\
\left(\text { RoActemra }{ }^{\circledR}\right) \text { als Monotherapie oder in } \\
\text { Kombination mit MTX }\end{array}$ & $\mathrm{n}=17$ & $\mathrm{p}=0,211$ & $\mathrm{p}=0,938$ & $\mathrm{p}=0,300$ & $\mathrm{p}=0,894$ \\
\hline $\begin{array}{l}\text { Rituximab } \\
\left(\text { Mabthera }{ }^{\circledR}\right) \text { in Kombination mit MTX }\end{array}$ & $\mathrm{n}=30$ & $\mathrm{p}=0,234$ & $\mathrm{p}=0,658$ & $p=0,757$ & $\mathrm{p}=0,525$ \\
\hline $\begin{array}{l}\text { Gesamtdauer Einnahme csDMARDs } \\
\text { (MTX + Leflunomid + csDMARDs Kom- } \\
\text { binationen, aktuelle Therapie + } \\
\text { Vortherapie) }\end{array}$ & $\mathrm{n}=148$ & $\mathrm{p}=0,539$ & $\mathrm{p}=0,095$ & $p=0,119$ & $\mathrm{p}=0,657$ \\
\hline $\begin{array}{l}\text { Gesamtdauer Einnahme Biologika } \\
\text { (Anti-TNF } \alpha \text {-Therapeutika + Tocilizumab } \\
+ \text { Rituximab, aktuelle Therapie + Vorthe- } \\
\text { rapie) }\end{array}$ & $\mathrm{n}=71$ & $\mathrm{p}=0,711$ & $\mathrm{p}=0,648$ & $\mathrm{p}=0,328$ & $\mathrm{p}=0,078$ \\
\hline
\end{tabular}

(csDMARDs: conventional synthetic disease modifying anti-rheumatic drugs, TNF $\alpha$ : Tumornekrosefaktoralpha) 


\subsection{Assoziationen zwischen Medikamenteneinnahme und Zytokinspiegeln im Blut}

Biologika und csDMARDs wirken immunsuppressiv durch Hemmung der T- und BLymphozyten sowie der Interleukin-abhängigen Signalübertragung, was zu Änderungen der Zytokinspiegel im Blut führt.

Daher wurden in einer Subanalyse bei 80 RA-Patienten (w: 65, m: 15; mittleres Alter 64,59 \pm 2,24 Jahre) die Serumkonzentrationen der Zytokine IL-6 und IL-10 in Abhängigkeit von der medikamentösen Therapie mit nichtsteroidalen Antirheumatika und/oder Glucocorticoiden, MTX, Leflunomid, Anti-TNF $\alpha$-Therapeutika, Tocilizumab, Rituximab sowie csDMARDs Kombinationen mittels ELISA quantifiziert. Tabelle 27 stellt die Serumkonzentrationen von IL-6 und IL-10 unter dem Einfluss der aufgeführten Rheumamedikamente dar.

Tabelle 27: Übersicht über die Konzentrationen von Interleukin-6 (IL-6) und Interleukin-10 (IL-10) im Blut unter dem Einfluss unterschiedlicher Rheumamedikation

\begin{tabular}{|c|c|c|c|c|}
\hline \multicolumn{2}{|r|}{ Medikamentengruppe } & \multirow{2}{*}{$\begin{array}{l}\text { Patien- } \\
\text { tenzahl }\end{array}$} & IL-6 [pg/ml] & IL-10 [pg/ml] \\
\hline & & & $\mathrm{MW} \pm \mathrm{SA}$, Median & $\mathrm{MW} \pm \mathrm{SA}$, Median \\
\hline A & $\begin{array}{l}\text { Nichtsteroidale Antirheumatika } \\
\text { und/ oder Glucocorticoide }\end{array}$ & $\mathrm{n}=13$ & $13,23 \pm 17,91,7,00$ & $96,54 \pm 241,62,7,00$ \\
\hline B & MTX (Methotrexat ${ }^{\circledR}$ ) & $\mathrm{n}=11$ & $12,73 \pm 21,40,7,00$ & $5,45 \pm 5,84,4,00$ \\
\hline $\mathrm{C}$ & Leflunomid (Arava $\left.{ }^{\circledR}\right)$ & $\mathrm{n}=11$ & $38,64 \pm 105,76,5,00$ & $4,18 \pm 2,23,4,00$ \\
\hline $\mathrm{D}$ & $\begin{array}{l}\text { Anti-TNF } \alpha \text {-Therapeutika } \\
\left.\text { Infliximab (Remicade }{ }^{\circledR}\right) \text { oder Eta- } \\
\text { nercept }\left(\text { Enbrel }{ }^{\circledR}\right) \text { oder Adalimumab } \\
\left(\text { Humira }{ }^{\circledR}\right) \text { als Monotherapie oder in } \\
\text { Kombination mit MTX }\end{array}$ & $\mathrm{n}=11$ & $5,82 \pm 5,02,4,00$ & $29,45 \pm 67,60,8,00$ \\
\hline $\mathrm{E}$ & $\begin{array}{l}\text { Tocilizumab }\left(\text { RoActemra }{ }^{\circledR}\right) \text { als } \\
\text { Monotherapie oder in Kombination } \\
\text { mit MTX }\end{array}$ & $\mathrm{n}=12$ & $127,67 \pm 169,23,64,00$ & $22,75 \pm 34,33,13,00$ \\
\hline $\mathrm{F}$ & $\begin{array}{l}\left.\text { Rituximab (Mabthera }{ }^{\circledR}\right) \text { in Kombi- } \\
\text { nation mit MTX }\end{array}$ & $\mathrm{n}=11$ & $9,18 \pm 7,81,5,00$ & $21,36 \pm 48,36,8,00$ \\
\hline $\mathrm{G}$ & $\begin{array}{l}\text { csDMARDs Kombinationen } \\
\text { zeitgleiche Einnahme mindestens } \\
\text { zwei dieser Medikamente: MTX } \\
\left.\text { (Methotrexat }{ }^{\circledR}\right) \text {, Leflunomid (A- } \\
\left.\text { rava }{ }^{\circledR}\right) \text {, Sulfasalazin (Azulfidine }{ }^{\circledR} \text { ) }\end{array}$ & $\mathrm{n}=11$ & $25,45 \pm 61,17,4,00$ & $18,09 \pm 35,78,7,00$ \\
\hline
\end{tabular}

(MW: Mittelwert, SA: Standardabweichung, TNF $\alpha$ : Tumornekrosefaktor-alpha, csDMARDs: conventional synthetic disease modifying anti-rheumatic drugs) 
Es bestand kein signifikanter Zusammenhang zwischen der Einnahme der aufgeführten Medikamente und der Konzentration von IL-10 im Blut. Hingegen war die Konzentration von IL-6 im Blut bei Gruppe E (Tocilizumab) signifikant erhöht ( $p=0,005)$, wie Abbildung 17 veranschaulicht.

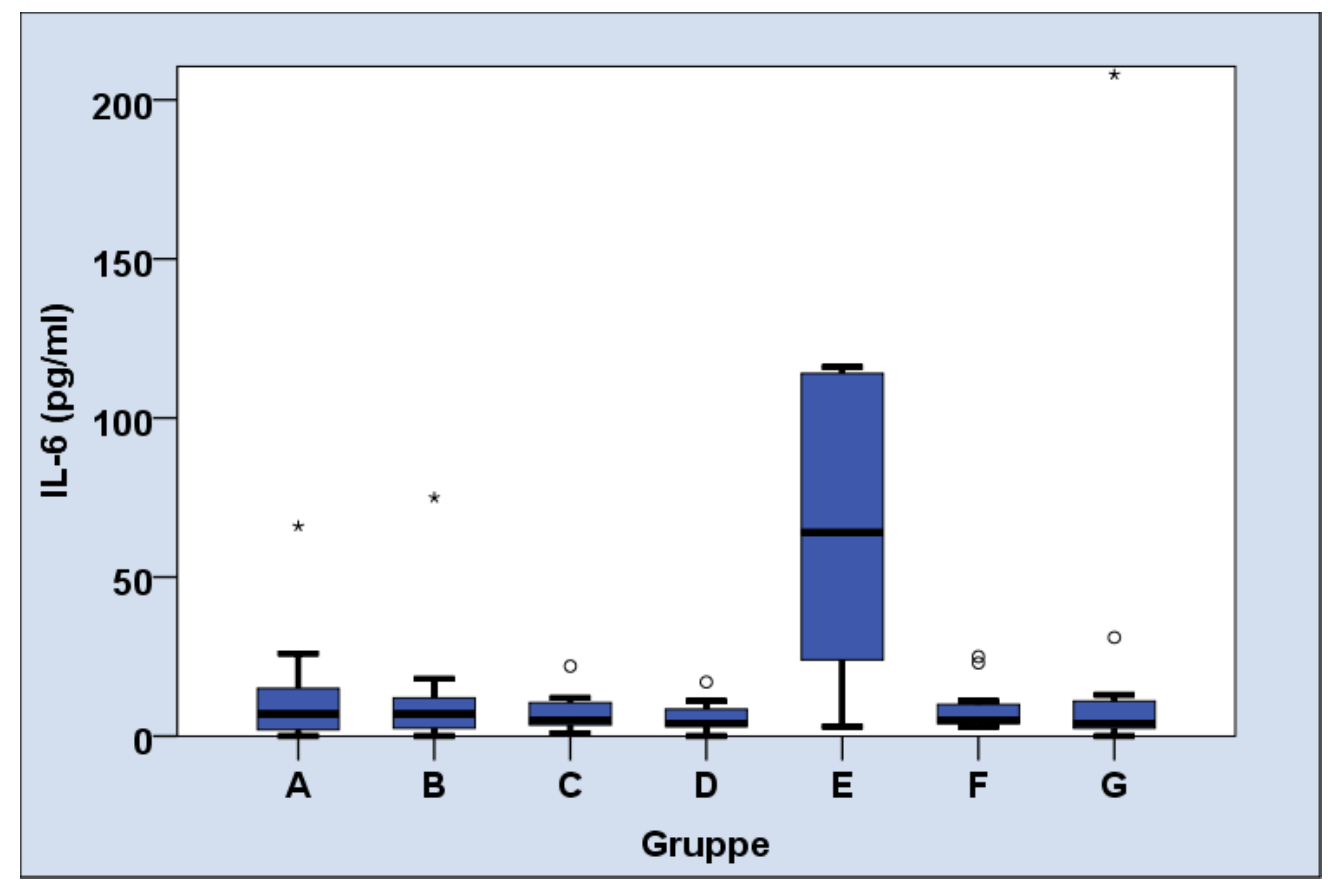

Abbildung 17: Darstellung der Konzentration von Interleukin-6 (IL-6) im Blut bei den verschiedenen Medikamentengruppen

$\mathrm{A}=$ Nichtsteroidale Antirheumatika und/oder Glucocorticoide

$\mathrm{B}=\operatorname{MTX}\left(\right.$ Methotrexat $\left.{ }^{\circledR}\right)$

$\mathrm{C}=$ Leflunomid $\left(\right.$ Arava $\left.{ }^{\circledR}\right)$

$\mathrm{D}=$ Anti-TNF $\alpha-\left(\right.$ Tumornekrosefaktor-alpha) Therapeutika: Infliximab (Remicade $\left.{ }^{\circledR}\right)$ oder Etanercept (Enbrel ${ }^{\circledR}$ ) oder Adalimumab (Humira ${ }^{\circledR}$ ) als Monotherapie oder in Kombination mit MTX

$\mathrm{E}=$ Tocilizumab $\left(\right.$ RoActemra $\left.^{\circledR}\right)$ als Monotherapie oder in Kombination mit MTX

$\mathrm{F}=$ Rituximab $\left(\right.$ Mabthera $\left.{ }^{\circledR}\right)$ in Kombination mit MTX

$\mathrm{G}=$ csDMARDs- (conventional synthetic disease modifying anti-rheumatic drugs) Kombinationen: zeitgleiche Einnahme mindestens zwei dieser Medikamente: MTX (Methotrexat ${ }^{\circledR}$ ), Leflunomid (Arava ${ }^{\circledR}$ ), Sulfasalazin (Azulfidine ${ }^{\circledR}$ ) 


\subsection{Zusammenfassung der wichtigsten Ergebnisse}

In Tabelle 28 sind die wichtigsten Ergebnisse der vorliegenden Studie zusammengefasst. Diese betreffen die Assoziationen zwischen dem Schweregrad der Parodontalerkrankung und rheumatologischen Parametern sowie jene zwischen dem Schweregrad der Parodontalerkrankung und der Einnahmedauer der Rheumamedikamente. Des Weiteren sind die Ergebnisse bezüglich der Assoziationen zwischen Medikamenteneinnahme und Zytokinspiegeln im Blut aufgeführt.

Tabelle 28: Zusammenfassung der wichtigsten Ergebnisse der Studie

\begin{tabular}{|c|c|}
\hline Assoziierte Parameter & Ergebnisse \\
\hline \multirow{2}{*}{$\begin{array}{l}\text { Assoziationen zwischen dem } \\
\text { Schweregrad der Parodontaler- } \\
\text { krankung und } \\
\text { rheumatologischen Parametern }\end{array}$} & $\begin{array}{l}\text { Klinisch-rheumatologische Parameter: } \\
\text { Patienten mit vermehrtem Zahnverlust waren durchschnittlich älter } \\
\text { und hatten einen höheren mittleren DAS28. Eine längere Dauer der } \\
\text { Morgensteifigkeit korrelierte mit einem niedrigeren } \emptyset \text { CAL }\end{array}$ \\
\hline & $\begin{array}{l}\text { Serologische Parameter: } \\
\text { Mit steigendem Schweregrad der Parodontitis (PA-Zustand nach Page } \\
\text { und Eke 2007) nahm die Konzentration von Rheumafaktor im Blut } \\
\text { zu. Sowohl ein erhöhter 1h-BSG-Wert, als auch eine erhöhte Kon- } \\
\text { zentration von Rheumafaktor im Blut korrelierte mit vermehrtem } \\
\varnothing \text { CAL. Zusammenhänge mit der Konzentration von Anti-CCP oder } \\
\text { CRP im Blut blieben ohne Signifikanz }\end{array}$ \\
\hline \multirow{2}{*}{$\begin{array}{lrr}\text { Assoziationen } & \text { zwischen dem } \\
\text { Schweregrad der } & \text { Parodontaler- } \\
\text { krankung } & \text { und } & \text { der } \\
\text { Einnahmedauer } & \text { der } & \text { Rheuma- } \\
\text { medikamente } & & \end{array}$} & $\begin{array}{l}\text { csDMARDs: } \\
\text { Die Einnahmedauer isolierter csDMARDs oder die Gesamtthera- } \\
\text { piedauer mit csDMARDs (inkl. Kombinationen) war nicht signifikant } \\
\text { mit den parodontalen Zielparametern (M-T, } \varnothing \text { CAL, } \varnothing \text { ST, Parodon- } \\
\text { talzustand nach Page und Eke 2007) assoziiert }\end{array}$ \\
\hline & $\begin{array}{l}\text { Biologika: } \\
\text { Es zeigte sich ein deutlicher Trend zu niedrigeren durchschnittlichen } \\
\text { Sondierungstiefen bei längerer Gesamteinnahmedauer von Biologika } \\
\text { (TNF } \alpha \text {-Antagonisten + Tocilizumab + Rituximab, aktuelle Therapie } \\
+ \text { Vortherapie), jedoch ohne statistische Signifikanz }\end{array}$ \\
\hline $\begin{array}{l}\text { Assoziationen zwischen Medi- } \\
\text { kamenteneinnahme und } \\
\text { Zytokinspiegeln im Blut }\end{array}$ & $\begin{array}{l}\text { Die Einnahme von Tocilizumab korrelierte mit einer erhöhten Kon- } \\
\text { zentration von IL- } 6 \text { im Blut, die Einnahme der anderen Medikamente } \\
\text { hatte keinen signifikanten Einfluss auf die Serumkonzentrationen von } \\
\text { IL- } 6 \text { oder IL-10 }\end{array}$ \\
\hline
\end{tabular}

(DAS28: disease activity score 28, CAL: klinischer Attachmentverlust, PA: Parodontitis, BSG: Blutsenkungsgeschwindigkeit, Anti-CCP: Antikörper gegen cyclische citrullinierte Peptide, CRP: C-reaktives Protein, csDMARDs: conventional synthetic disease modifying anti-rheumatic drugs, M-T: missing teeth, ST: Sondierungstiefen, TNF $\alpha$ : Tumornekrosefaktor-alpha, IL-6: Interleukin-6, IL-10: Interleukin-10) 
Abbildung 18 gibt eine abschließende Übersicht über die Ergebnisse und Assoziationen der vorliegenden Studie.

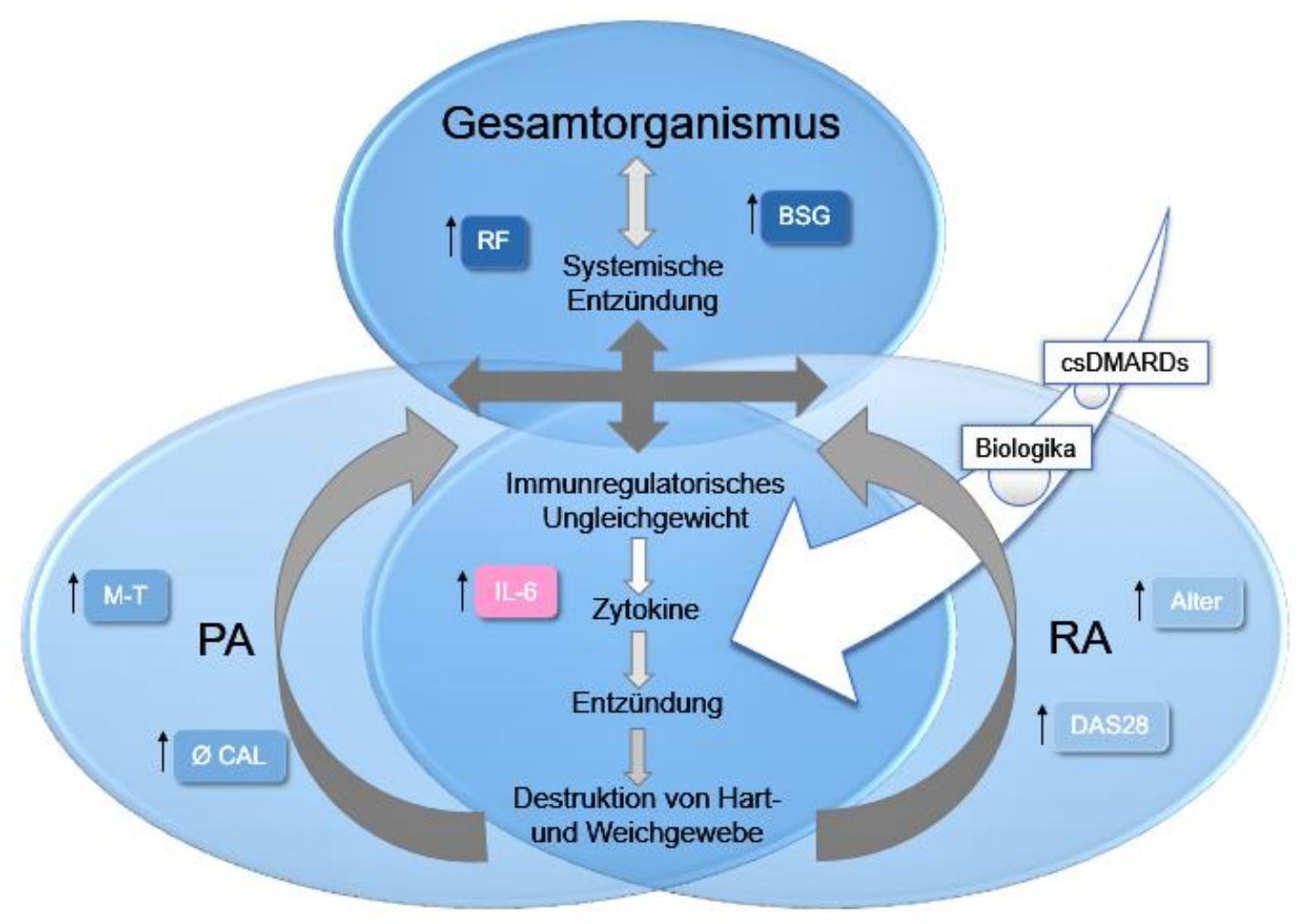

Abbildung 18: Übersicht über die Ergebnisse und Assoziationen der vorliegenden Studie

(RA: rheumatoide Arthritis, PA: Parodontitis, M-T: Anzahl fehlender Zähne, CAL: klinischer Attachmentverlust, DAS28: disease activity score 28, RF: Rheumafaktor, BSG: Blutsenkungsgeschwindigkeit, csDMARDs: conventional synthetic disease modifying anti-rheumatic drugs, IL-6: Interleukin-6) 


\section{Diskussion}

Ziel der vorliegenden klinischen Querschnittsstudie war es, bei Patienten mit rheumatoider Arthritis Parameter der Krankheitsaktivität (klinisch und serologisch) in Abhängigkeit von objektivierbaren Parametern des Parodontalzustandes zu erfassen, um die Assoziationen der beiden Erkrankungen spezifizieren zu können. Des Weiteren wurde der Einfluss immunsuppressiv wirkender Rheumamedikamente auf den Parodontitisschweregrad und auf die Serumspiegel definierter immunmodulatorischer Zytokine untersucht.

\subsection{Studiendesign}

Die parodontalen und mikrobiologischen Befunde der Gesamtkohorte sowie der Einfluss der Rheumamedikation auf die Bakterienpopulation wurden in zwei Vorgängerstudien dieser Arbeitsgruppe analysiert und diskutiert (Schmickler et al. 2017; Ziebolz et al. 2018). Entsprechend konzentrierte sich die vorliegende Untersuchung auf die Patienten mit RA.

Bei diesen Probanden bestand eine nach den ACR/EULAR-Klassifikationskriterien von Aletaha et al. (2010) sicher diagnostizierte rheumatoide Arthritis. Unter den StudienteilnehmernInnen waren 27 männliche und 125 weibliche Patienten, in Übereinstimmung mit epidemiologischen Daten anderer Studien. Somit ergab sich eine Kohorte von 152 Patienten im Alter von 36 bis 80 Jahren. Die evaluierte RA-Population war repräsentativ, was die Aussagekraft der Ergebnisse unterstreicht.

Unter den Patienten befanden sich 38 (25,0 \%) Raucher, 34 (22,37 \%) ehemalige Raucher und $80(52,63 \%)$ Nichtraucher. Zwar ist die Anzahl der Raucher in der vorliegenden Untersuchung gering, trotzdem sollte dies als Confounder berücksichtigt werden. Denn Zigarettenrauchen gilt als ein wichtiger Risikofaktor für die Entwicklung und Progression sowohl von RA (Lundström et al. 2009; Di Giuseppe et al. 2014; Lee et al. 2014) als auch von PA (Razali et al. 2005; Bergström 2006; Saxer et al. 2007). Für zukünftige Untersuchungen ist zu empfehlen, eine Studie ausschließlich mit nichtrauchenden Patienten bzw. Rauchern durchzuführen und das Rauchverhalten genau zu evaluieren. 
Es wurde eine sehr ausführliche parodontale Befundung vorgenommen. Die Messungen des klinischen Attachmentverlustes und der Sondierungstiefen wurden an sechs Messstellen eines jeden Zahnes durchgeführt (mesio-vestibulär, vestibulär, disto-vestibulär, disto-oral, oral, mesio-oral). Die Auswertung der Befunde erfolgte nach den Kriterien von Page und Eke (2007). Zudem wurde der DMFT-Index erhoben.

Die Prävalenz von Parodontitis in der Studienkohorte war sehr hoch, in Übereinstimmung mit anderen Studien (Mercado et al. 2001; Bartold et al. 2005; Pischon et al. 2008; Martinez-Martinez et al. 2009; Abdelsalam et al. 2011; Wolff et al. 2014; Lee et al. 2015; Äyräväinen et al. 2017). Annähernd alle Patienten der Studienpopulation wiesen nach den genannten Kriterien eine schwere $(55,26 \%)$ oder moderate $(42,76 \%)$ Parodontitis auf. Im Mittel fehlten 6,28 \pm 2,5 Zähne (M-T). Der durchschnittliche klinische Attachmentverlust ( $\varnothing \mathrm{CAL}$ ) lag bei 4,55 $\pm 0,28 \mathrm{~mm}$ und die durchschnittliche Sondierungstiefe (Ø ST) betrug 4,14 $\pm 0,4 \mathrm{~mm}$. Die Studienpopulation war somit auch in Bezug auf parodontale Parameter repräsentativ. Zudem bestätigen die Ergebnisse die aktuelle Datenlage (de Pablo et al. 2009; Kaur et al. 2013; Payne et al. 2015; Potempa et al. 2017).

Die erfassten parodontalen Parameter beschreiben die Schwere der Parodontitis zum Zeitpunkt der zahnärztlichen Untersuchung. Die Befragung zum zahnärztlichen Verhalten sowie zu parodontitisspezifischen Symptomen bot zudem eine gute Basis und stützte die Interpretationen der Ergebnisse. Trotzdem muss berücksichtigt werden, dass die Antworten zum Teil subjektive Empfindungen widerspiegeln. Zusätzlich hätte der BOP (bleeding on probing) erhoben werden können, um genauere Aussagen zum Entzündungszustand des Parodonts zum Zeitpunkt der zahnärztlichen Untersuchung treffen zu können. Außerdem hätten die Chronizität der Parodontitis sowie bereits erfolgte Behandlungen stärker Berücksichtigung finden können.

Die ermittelten Blutparameter (RF, Anti-CCP, CRP, BSG) wurden den aktuellsten Blutanalysen der Patientenakte entnommen. Dabei ergab sich teilweise ein Zeitunterschied zum Zeitpunkt der zahnärztlichen Untersuchung von bis zu drei Monaten, was die Aussagekraft der Zusammenhänge zwischen den Blutparametern und parodontalen Parametern reduziert.

Um den Einfluss der Rheumamedikation (csDMARDs, Biologika) zu evaluieren, wurden sieben Medikamentengruppen definiert (NSAR und/oder Glucocorticoide, MTX, Leflunomid, csDMARDs Kombinationen, Anti-TNF $\alpha$-Therapeutika, Tocilizumab, 
Rituximab). Die Dauer der Medikation wurde anhand der Dokumentation in der Patientenakte detailliert erfasst, wobei zwischen der Dauer der Einnahme der aktuellen Medikation und der Dauer der Einnahme früherer Medikamente (Vortherapie) unterschieden wurde. Es wurden Monotherapien als auch Kombinationen von Immunsuppressiva berücksichtigt. Entsprechend ihrer aktuellen Medikation wurden die Patienten evaluiert. Somit wurden Patienten in unterschiedlichen Erkrankungs- bzw. Therapiestadien erfasst. Die Studienpopulation zeigte daher ein sehr heterogenes Bild bezüglich der durchschnittlichen Erkrankungsdauer (85,07 \pm 266 Monate) und der durchschnittlichen mittleren Krankheitsaktivität (DAS28 3,22 \pm 4,01). In dieser Studie wurde der Einfluss zusätzlich eingenommener Medikamente, wie z. B. antihypertensiver Präparate, Statine oder Medikamente gegen Osteoporose, die ebenfalls einen Einfluss auf die Mundgesundheit/parodontale Situation haben können, nicht berücksichtigt.

Zudem wurden zwei Zytokine (IL-6, IL-10) ausgewählt, die sowohl in der Pathophysiologie von RA als auch PA eine entscheidende Rolle spielen (Graves et al. 2011). Es handelt sich jedoch um komplexe und heterogene Erkrankungen, die durch eine Vielzahl von Immunzellen und Zytokinen beeinflusst werden. Bei der Interpretation der Ergebnisse muss daher berücksichtigt werden, dass die benannten Zytokine nur einen Auszug aus dem komplexen Netzwerk potentiell relevanter Zytokine darstellen.

Um die Assoziationen zu untersuchen, wurden aus jeder Medikamentengruppe mindestens elf Patienten ausgewählt, bei denen die Konzentration der benannten Zytokine im Blut mit Hilfe eines Sandwich-ELISA bestimmt wurde. Auswahlkriterien waren eine möglichst lange Einnahmedauer des Medikamentes sowie ein möglichst geringer Zeitunterschied zwischen zahnärztlicher Untersuchung und Blutabnahme. Durch die Selektion der Patienten sollte die Aussagekraft der Ergebnisse gesteigert werden. Die geringe Patientenzahl dieser Subgruppen könnte jedoch auch kritisch betrachtet werden und die Aussagekraft einschränken.

Da es sich um eine klinische Querschnittsstudie handelt, muss bei allen erhobenen Parametern berücksichtigt werden, dass lediglich eine Momentaufnahme resultiert. Assoziationen zwischen verschiedenen Größen können dadurch aufgezeigt werden. Es ist jedoch nicht möglich, Aussagen über kausale Zusammenhänge zu treffen. Es muss bei der Interpretation der Ergebnisse berïcksichtigt werden, dass die Patienten zum Teil eine sehr lange Krankheitsgeschichte aufweisen und aufgrund der Schwere der Symptome und/oder der Erkrankungsdauer bereits eine Vielzahl verschiedener RA-Medikamente 
und/oder Medikamentenkombinationen eingenommen haben, mit dem Ziel, die Krankheitsaktivität zu reduzieren. Daher waren sowohl die erhobenen Blutparameter als auch die parodontalen Parameter von der Medikation beeinflusst, was Zusammenhänge maskieren könnte.

Zudem ist es schwierig, die erzielten Ergebnisse mit anderen Studien zu vergleichen, da eine Standardisierung für die Klassifikationen und Schwere beider Erkrankungen fehlt. Außerdem mangelt es vielen Studien an Informationen über die medikamentöse Therapie und die Dauer der Einnahme sowie zusätzlichen Confoundern. Dies erschwert eine Interpretation der aktuellen Studienergebnisse.

\subsection{Assoziationen zwischen dem Schweregrad der Parodontalerkrankung und rheumatologischen Parametern}

In der vorliegenden Untersuchung wurde überprüft, ob der Parodontitisschweregrad im Zusammenhang mit der Erkrankungsaktivität bei rheumatoider Arthritis steht. Als ein objektiver parodontaler Parameter wurde die Anzahl fehlender Zähne (M-T) herangezogen. Die Patienten der Studienpopulation wiesen durchschnittlich 6,28 \pm 2,5 fehlende Zähne auf. Zudem waren die Patienten mit vermehrtem Zahnverlust durchschnittlich älter $(50,28 \pm 11,86$ Jahre; $p=0,037)$ und hatten einen höheren mittleren DAS28 $(3,51 \pm 1,4$; $p=0,004)$. Zahlreiche Studien belegen ebenfalls einen vermehrten Zahnverlust bei Patienten mit rheumatoider Arthritis im Vergleich zu gesunden Probanden bei ähnlichen Werten (Pischon et al. 2008; Garib und Qaradaxi 2011; Ziebolz et al. 2011; Joseph et al. 2013).

Da Zahnverlust die Folge eines multifaktoriellen Prozesses ist, sind vor allem bei RAPatienten viele Gründe denkbar. Ein oft genanntes Argument ist die eingeschränkte Mundhygienefähigkeit aufgrund von Bewegungseinschränkungen, vor allem der Hände, die mit der Erkrankung einhergehen. Viele Studien zeigten mehr Plaque bei Patienten mit RA im Vergleich zu gesunden Kontrollgruppen (Page und Kornman 1997; Chapple et al. 2007; D’Aiuto et al. 2007; de Paula Ishi et al. 2008; Pischon et al. 2008; Biyıkoğlu et al. 2009; Mirrielees et al. 2010; Susanto et al. 2013). Eine erhöhte Ansammlung von Zahnbelag kann zu Karies aber auch zu Parodontitis führen, und beide Erkrankungen können ursächlich für Zahnverlust sein. Die anhaltend hohe Akkumulation von bakterieller Plaque könnte die erhöhte Prävalenz für PA im Zusammenhang mit der RA erklären (de 
Pablo et al. 2009). Hingegen konnten Pischon et al. (2008) zeigen, dass unter Berücksichtigung von demografischen Faktoren sowie Lifestil-Faktoren Mundhygiene zwar ein wichtiger Faktor ist, jedoch nur zu 13,4 \% die Assoziation von RA und PA erklären kann. Auch Esen et al. (2012) konnten zeigen, dass die manuelle Behinderung Mundhygienemaßnahmen nicht beeinträchtig. Zwar wurden in der vorliegenden Untersuchung keine Mundhygieneindizes erhoben, die Probanden wurden jedoch zu ihrem Mundhygieneverhalten befragt. Die Mehrheit der Patienten der Studienpopulation gab an, dass sie sich gut über Mundhygiene aufgeklärt fühlen $(59,6 \%)$ und überdurchschnittlich oft ihre Zähne putzen $(22,5 \%)$. Trotz Einschränkungen in der täglichen Bewegungsfähigkeit $(88,8 \%)$ fühlten sie sich bei der Mundhygiene nicht manuell eingeschränkt (40,1\%).

Bezüglich des Zusammenhangs mit dem Alter muss berücksichtigt werden, dass die Parodontitisprävalenz mit zunehmendem Lebensalter ansteigt (Institut der Deutschen Zahnärzte 2016). Als Ursache werden die über Jahre bestehenden entzündlichen Belastungen mit zunehmenden Gewebetraumata sowie altersabhängige Umstellungen im Immun- und Entzündungszustand des Wirtes angesehen (Hajishengallis 2014). Franceschi et al. (2000) beschreiben unter dem Begriff „Inflamm-Aging“ einen chronischen Entzündungsprozess als Altersphänomen, mit Zunahme von proinfammatorischen Zytokinen (besonders IL-6) und vermehrter Aktivierung von Entzündungszellen. Hingegen konnten Kim et al. (2019) zeigen, dass RA auch bei jungen Erwachsenen mit vermehrtem Zahnverlust assoziiert ist.

Xerostomie ist ebenfalls einer der häufigsten klinischen Befunde bei Patienten mit RA. Diese kann zum einen medikamentös bedingt sein, zum anderen aber auch aufgrund eines sekundären Sjörgen-Syndroms vorliegen. Es wird angenommen, dass die Abnahme des Speichelflusses mit der Schwere und Dauer der RA korreliert (Nagler et al. 2003). Durch die herabgesetzte Speicheldrüsenfunktion und die verminderte Speichelflussrate kann eine Akkumulation von Plaque erleichtert werden, was die Kariesprävalenz erhöht, aber auch Erkrankungen des Parodonts positiv beeinflussen kann (Silvestre-Rangil et al. 2016). Das Vorliegen einer Xerostomie wurde bei der Studienpopulation nicht erfragt, sollte jedoch in künftigen Studien aufgegriffen werden.

Hinzu kommen nichtbiologische Prozesse, welche Berücksichtigung finden müssen. Denn auch die allgemeine Krankheitslast und die enorme Beeinträchtigung des täglichen Lebens könnte einen Einfluss auf das Gesundheitsverhalten des Patienten, aber auch auf zahnärztliche Behandlungsoptionen haben (de Pablo et al. 2009; Mühlberg et al. 2017). So könnte der Zahnarzt bei Patienten mit RA aufgrund ihrer gesundheitlichen Belastung 
eine Zahnextraktion gegenüber einer umfangreichen konservierenden und prothetischen Behandlung favorisieren. Allerdings wurden diese Möglichkeiten noch nicht systematisch untersucht (de Pablo et al. 2009) und auch in dieser Studie nur deskriptiv erfragt. Mehr als zwei Drittel (70,2 \%) der Patienten der Studienpopulation waren in den vergangenen sechs Monaten beim Zahnarzt. Nur wenige Patienten (7,2\%) wurden nach der Diagnose der rheumatoiden Arthritis zum Zahnarzt geschickt. Bei zwei Drittel $(68,4 \%)$ der Patienten war dem Zahnarzt bekannt, dass eine Erkrankung an rheumatoider Arthritis besteht. Aber mehr als drei Viertel (79,6 \%) der Patienten waren nicht darüber aufgeklärt, dass ein Zusammenhang zwischen rheumatoider Arthritis und Parodontitis besteht. Ähnlich viele $(81,6 \%)$ Patienten waren nicht informiert, dass sie aufgrund ihrer Erkrankung an rheumatoider Arthritis als Risikopatient in der zahnärztlichen Praxis gelten. Die Patienten gaben an, dass bei 72,4\% eine Zahnextraktion im Rahmen einer Zahnsanierung durchgeführt wurde. Eine PA-Therapie hingegen nur bei 28,9\%. Auch wenn der Einfluss der genannten Faktoren spekulativ bleibt, scheint der iatrogene Einfluss und die Aufklärung der Patienten einen entscheidenden Einfluss auf die Mundgesundheit zu haben.

Als ein weiterer objektiver Parameter der Parodontitis wurde der klinische Attachmentverlust betrachtet. Zusammen mit der Messung der Sondierungstiefen gehört dieser zum Goldstandard hinsichtlich einer Beurteilung des parodontalen Gesundheitsstatus (Joseph et al. 2013). Der klinische Attachmentverlust berechnet sich aus der Summe von parodontaler Taschentiefe und gingivaler Rezession und drückt den Abstand von der ursprünglichen Position des Zahnfleisches zum verbleibenden Alveolarknochen aus. In zahlreichen Studien wurde ein vermehrter klinischer Attachmentverlust bei Patienten mit RA im Vergleich zu gesunden Kontrollgruppen ermittelt (Havemose-Poulsen et al. 2007; Pischon et al. 2008; Abdelsalam et al. 2011; Kaur et al. 2013). Erneut konnte Mundhygiene diese Assoziation nur teilweise erklären (Pischon et al. 2008).

Bei der vorliegenden Untersuchung zeigte sich ein signifikanter Zusammenhang zwischen der Dauer der Morgensteifigkeit $(39,23 \pm 47,75 \mathrm{~min} ; \mathrm{p}=0,048)$ und dem durchschnittlichen klinischen Attachmentverlust, wobei eine längere Dauer der Morgensteifigkeit mit einem niedrigeren durchschnittlichen Attachmentverlust korrelierte. Da die Dauer der Morgensteifigkeit auch als Aktivitätsparameter der RA angesehen wird, ist dieses Ergebnis überraschend und inkonsistent zur oben beschriebenen Korrelation von reduzierter Zahnanzahl und erhöhten DAS28-Werten. Auch in anderen Studien konnten signifikant höhere DAS28-Scores bei Patienten mit schwerer Parodontitis nachgewiesen werden (Payne et al. 2015). Aufgrund der Subjektivität des Parameters 
„Morgensteifigkeit“ könnte hier eine reduzierte Aussagekraft in Betracht gezogen werden.

Zudem bestand ein signifikanter Zusammenhang zwischen der BSG nach einer Stunde Wartezeit und dem durchschnittlichen klinischen Attachmentverlust $(13,21 \pm 12,49 \mathrm{~mm} / 1 \mathrm{~h} ; \mathrm{p}=0,024)$, wobei eine erhöhte BSG mit einem erhöhten durchschnittlichen klinischen Attachmentverlust korrelierte. Das Ergebnis zeigt sich konsistent mit den Untersuchungen von Romero-Sanchez et al. (2017), die eine signifikante Assoziation von BSG und erhöhten Sondierungstiefen nachweisen konnten. Wiederum sind andere Studien zu dem Ergebnis gekommen, dass die BSG nicht vom Parodontalstatus betroffen ist (Mercado et al. 2001; Bıyıkoğlu et al. 2009; Prakash et al. 2012).

Die Bestimmung der Blutsenkungsgeschwindigkeit wird verwendet, um das Vorhandensein von systemischer Entzündung zu belegen. „Die BSG hat den Vorteil, für entzündliche Veränderungen sensibel und im individuellen Krankheitsverlauf empfindlich für Änderungen der Entzündungsaktivität zu sein.“ (Hartung und Seelig 2007). Die BSG kann daher zur Verlaufskontrolle der Krankheitsaktivität bei RA herangezogen werden. Es besteht jedoch eine geringere Spezifität im Vergleich zum CRP. Da hier keine signifikante Korrelation gefunden wurde, ist die Aussagekraft des Ergebnisses möglicherweise reduziert.

Ebenfalls statistisch signifikant war der Zusammenhang zwischen der Konzentration des Rheumafaktors im Blut und dem durchschnittlichem klinischen Attachmentverlust. Je höher die Konzentration des Rheumafaktors im Blut war, desto höher war auch der durchschnittliche klinische Attachmentverlust (90,85 \pm 250,60 U/ml; $\mathrm{p}=0,023)$. Dieses Ergebnis ist konträr zu bisherigen Studien, die eine Assoziation zwischen RF und PA nicht ausreichend belegen konnten (de Pablo et al. 2009; Kaur et al. 2013).

Der Rheumafaktor ist ein unspezifischer Antikörper, der bei der Diagnose von rheumatoider Arthritis verwendet wird. Jedoch sind nicht alle Personen mit rheumatoider Arthritis Rheumafaktor-positiv (Nishimura et al. 2007). Bei der Studienpopulation wiesen 40,13\% der Patienten einen positiven RF-Titer auf. In der Regel sind die RF-Titer unabhängig vom Krankheits- und Therapieverlauf. RA-Patienten mit extraartikularen Manifestationen und rasch progredienter Gelenkdestruktion haben allerdings häufiger hochtitrige Rheumafaktoren (Hartung und Seelig 2007). Da eine geringere Krankheitsspezifität besteht, wurde vorgeschlagen, dass RF hauptsächlich dazu dienen, die Entzündungsreaktionen sowohl im rheumatoiden Gelenk als auch bei der Läsion bei PA zu verstärken, anstatt eine direkte Rolle bei der Pathogenese von Krankheiten zu spielen 
(Mikuls et al. 2009). Diese Annahme wird durch eine signifikante Zunahme der Konzentration von RF im Blut bei steigendem Schwergrad der PA in der vorliegenden Untersuchung bestätigt ( $\mathrm{p}=0,007)$. Dabei hatten $42,76 \%$ der Patienten der Studienpopulation eine moderate und 55,26 \% eine schwere PA nach den Kriterien von Page und Eke (2007). Auch Dissick et al. 2010 konnten eine erhöhte Prävalenz von moderater zu schwerer PA bei Patienten mit seropositiven Titern für RF und Anti-CCP nachweisen.

Hingegen wurde bei der vorliegenden Untersuchung kein signifikanter Zusammenhang zwischen der Konzentration von Anti-CCP oder CRP im Blut und einem der vier parodontalen Parameter gefunden, in Übereinstimmung mit den Ergebnissen von Knaur et al. (2013). Der Mangel an erhöhten CRP-Serumspiegeln bei Probanden mit RA und Parodontitis könnte auf die Wirkungen der immunsuppressiven RA-Medikamente zurückgeführt werden (Pischon et al. 2008; Bıyıkoğlu et al. 2009; Dissick et al. 2010; Ziebolz et al. 2011).

Der parodontale Parameter „durchschnittliche Sondierungstiefe“ war ebenfalls nicht mit klinischen-rheumatologischen oder Blutparametern assoziiert. Die Sondierungstiefe ist der Abstand vom Zahnfleischrand zur Basis des gingivalen Sulkus oder der Parodontaltasche (Page und Eke 2007). Da sowohl CAL- als auch ST-Messungen für die Beurteilung des Parodontalzustandes erforderlich sind, müssen auch die Ergebnisse für den klinischen Attachmentverlust kritisch betrachtet werden. Denn obwohl CAL als ein genaueres Maß wie die Sondierungstiefe angesehen wird und als Goldstandard für die Schwere und Progression der Krankheit akzeptiert wird, können sich ohne Berücksichtigung der Sondierungstiefen falsch positive Werte ergeben. Die Verwendung von CAL allein könnte fälschlicherweise parodontal gesunde Seiten einbeziehen, die aufgrund nicht entzündlicher gingivaler Rezessionen Attachmentverlust aufweisen. Außerdem kommt es auch nach einer erfolgreichen Behandlung einer Parodontitis nicht zu einer Rückkehr der Gingiva zum Ausgangszustand, sodass Attachmentverlust detektierbar bleibt. Wird ein Krankheitsverlauf somit ausschließlich anhand von CAL bewertet, ergibt sich eine geringe bis mäßige Spezifität (Page und Eke 2007).

Hingegen würde die alleinige Verwendung der Sondierungstiefen vermutlich zu einer Unterschätzung der Prävalenz führen, vor allem bei älteren Menschen, die Rezessionen aufweisen. Die Definition des Schweregrades der Parodontitis erfordert somit mindestens eine approximale Messstelle mit einer Sondierungstiefe $\geq 5 \mathrm{~mm}$. (Page und Eke 2007). 
Zusammenfassend lässt sich sagen, dass die Ergebnisse auf eine Assoziation zwischen erhöhter Krankheitsaktivität und reduzierter Zahngesundheit sowie schlechterer parodontaler Gesundheit bei RA hindeuten. Gleichwohl lässt sich diese Annahme nicht für alle Aktivitätsparameter konsistent bestätigen (Morgensteifigkeit, CRP). Es bleibt zu evaluieren, welche Analyte hier besonders stark prädiktiv sind. Dabei muss berücksichtigt werden, dass es sich größtenteils um medikamentös behandelte Patienten handelt, was zu einer Abnahme der Krankheitsaktivität führt und Zusammenhänge maskieren könnte. Trotzdem reduzieren wahrscheinlich die meisten Medikamente, die zur Behandlung einer RA eingesetzt werden, das Risiko eine PA zu entwickeln bzw. ihre Progression, als die Krankheit oder deren Progression ungünstig zu beeinflussen (Howell 1993; Howell und Williams 1993; Pers et al. 2008; Pischon et al. 2008).

\subsection{Assoziationen zwischen dem Schweregrad der Parodontalerkrankung und der Einnahmedauer der Rheumamedikamente}

Rheumatoide Arthritis und Parodontitis weisen viele Ähnlichkeiten in der Pathophysiologie und der klinischen Progression auf, die auf denselben zugrundeliegenden Entzündungswegen beruhen. Die Entwicklung neuer Antirheumatika, einschließlich csDMARDs und Biologika, die auf spezifische molekulare Faktoren in der Entzündungskaskade abzielen, bietet das Potenzial, das Fortschreiten der RA zu verlangsamen oder zu stoppen (Curtis und Singh 2011). Dies deutet darauf hin, dass die medikamentöse Behandlung auch das Fortschreiten von destruktiven parodontalen Erkrankungen verringern kann (Han und Reynolds 2012). Daher war ein weiteres Ziel der Studie, den Einfluss der immunsuppressiv wirkenden Rheumamedikamente auf den Parodontitisschweregrad zu überprüfen. Es wurden sowohl konventionelle synthetische DMARDs (Methotrexat, Leflunomid, Sulfasalazin) als auch biologische DMARDs untersucht. $\mathrm{Zu}$ diesen zählten Anti-TNFa-Therapeutika (Etanercept, Infliximab, Adalimumab), IL-6- (Tocilizumab) und B-Zell-Antikörper (Rituximab).

In zahlreichen Studien wurde nachgewiesen, dass biologische DMARDs nicht nur die RA-Aktivität verringern, sondern auch systemische Entzündung lindern, was indirekt auch zur Verbesserung der parodontalen Entzündung beitragen kann. Die Studien zeigten, dass die klinische Wirksamkeit von Anti-TNFa-Therapeutika, Rituximab und 
Tocilizumab mit einer Senkung der Serumspiegel von RF, Anti-CCP-Antikörpern und Entzündungsmediatoren einschließlich BSG und CRP sowie einer Abnahme des DAS28 assoziiert sind (Atzeni et al. 2005; Nishimoto et al. 2007; Smolen et al. 2008; Nishimoto et al. 2009; Emery et al. 2010; Tak et al. 2011; Greenberg et al. 2012; Tak et al. 2012; Herenius et al. 2013; Nishimoto et al. 2014; Kobayashi et al. 2015).

Zudem wurden Studien durchgeführt, die eine direkte Wirkung der Medikamente auf Parodontitis untersucht haben, wobei diese Untersuchungen sich ebenfalls größtenteils auf biologische DMARDs konzentrierten.

Für MTX konnte kein Einfluss auf die entzündliche Immunantwort oder den parodontalen Status nachgewiesen werden (Verzeletti et al. 2007; Pers et al. 2008).

$\mathrm{TNF} \alpha$-Inhibitoren blockieren oder antagonisieren die Wirkungen von $\mathrm{TNF} \alpha$, das als Hauptregulator der Entzündungsreaktion sowohl bei RA (Feldmann und Maini 2003) als auch bei PA (Bartold et al. 2010) angesehen wird. Zahlreiche Studien konnten eine therapeutische Wirksamkeit der TNF $\alpha$-Hemmung (mit Infliximab, Etanercept, Adalimumab) auf Parodontitis zeigen (Pers et al. 2008; Mayer et al. 2009; Mayer et al. 2013; Üstün et al. 2013; Kobayashi et al. 2014b). Eine Verbesserung klinisch-parodontaler Parameter (BOP, ST, CAL) und eine Reduktion der TNF $\alpha$-Level im gingivalen cervikalen Fluid (GCF) wurden beschrieben. Ortiz et al. (2009) berichteten hingegen, dass eine Anti-TNF $\alpha$-Therapie (mit Adalimumab) ohne parodontale Behandlung keinen signifikanten Effekt auf den parodontalen Zustand hatte. Nur im Zusammenhang mit einer nicht chirurgischen Parodontalbehandlung wiesen die Patienten eine signifikante Abnahme des mittleren Krankheitsaktivitäts-Scores (DAS28), der Blutsenkungsgeschwindigkeit und des Serum-TNFa-Spiegels auf.

In einem systematischen Review überprüften Han und Reynold 2012 die Studien und kamen zu dem Schluss, dass die Interpretationen dieser Ergebnisse aufgrund des Beobachtungsdesigns und der geringen Anzahl von StudienteilnehmernInnen eingeschränkt sind.

Rituximab ist ein Anti-CD20-Antikörper, der zu einer mehrmonatigen Elimination von B-Lymphozyten im peripheren Blut führt. Die Wirkung von Rituximab auf Parodontitis wurde bisher nur in einer Studie untersucht. Coat et al. (2015) zeigten, dass die Behandlung mit diesem Wirkstoff $\mathrm{zu}$ einer Verbesserung der Sondierungstiefen und dem Attachmentverlust führte. Die protektive Wirkung von Rituximab auf das Parodont war einer Anti-TNF $\alpha$-Therapie überlegen (Coat et al. 2015). Die Arbeitsgruppe folgerte, dass 
B-Lymphozyten eine entscheidende Rolle im Entzündungsprozess spielen, während der „TNFa-Pathway“ leicht durch andere Zytokine kompensiert werden könnte. Weitere Studien mit größeren Kohorten sind notwendig, um die Ergebnisse zu bestätigen.

Tocilizumab (TCZ) ist ein humanisierter monoklonaler Antikörper gegen den IL-6-Rezeptor. Untersuchungen von Kobayashi et al. (2015) zeigten eine signifikant größere Abnahme der gingivalen Entzündung (BOP, ST, CAL) und eine Verbesserung des CAL im Vergleich zu einer Therapie mit TNF $\alpha$-Inhibitoren. Diese Beobachtungen wurden teilweise durch die Ergebnisse einer anderen Studie gestützt, die Parodontitis als Folge übermäßiger Entzündungsreaktionen des Wirts wie die IL-6-Überproduktion auf mikrobielle Belastung dokumentierte (Nibali et al. 2012). Aufgrund der kleinen Patientengröße kann aus diesen Befunden jedoch nicht geschlossen werden, ob die TCZ-Therapie eine positive Wirkung auf PA hat. Es sind weitere Studien notwendig, um die positive Wirkung der IL-6R-Blockade auf Parodontitis in einer größeren Patienten- und Kontrollgruppe zu bestätigen. (Kobayashi et al. 2015).

Somit liegen gegenwärtig keine ausreichenden Beweise vor, um zu bestimmen, ob konventionelle synthetische oder biologische DMARDs die lokale Produktion von inflammatorischen Zytokinen und die parodontale Entzündung reduzieren und somit bei der Kontrolle von Parodontitis vorteilhaft sind.

Bei der vorliegenden Untersuchung war die Einnahmedauer isolierter csDMARDs oder Biologika sowie die Gesamttherapiedauer mit csDMARDs (inkl. Kombinationen) nicht signifikant mit den parodontalen Zielparametern (M-T, Ø CAL, Ø ST, Parodontalzustand nach Page und Eke 2007) assoziiert. Es zeigte sich lediglich ein deutlicher Trend zu niedrigeren durchschnittlichen Sondierungstiefen bei längerer Gesamteinnahmedauer von Biologika (Anti-TNF $\alpha$-Therapeutika + Tocilizumab + Rituximab, aktuelle Therapie + Vortherapie), jedoch ohne statistische Signifikanz.

Diese Ergebnisse sind konsistent mit einer aktuellen prospektiven Verlaufsstudie von Äyräväinen et al. (2017). Die Arbeitsgruppe konnte nachweisen, dass parodontale Parameter (BOP, ST, CAL) bei unbehandelten RA-Patienten signifikant höher waren als bei chronischen RA-Patienten, die bereits medikamentös behandelt wurden. Sie konnten jedoch keinen signifikanten Effekt von konventionell synthetischen oder biologischen DMARDs auf die parodontalen Gesundheitsparameter beobachten. Es zeigte sich aber auch in ihrer Studienpopulation ein Trend zu verbesserten Sondierungswerten bei den langjährig medikamentös behandelten Patienten mit chronischer RA (Äyräväinen et al. 2017). 
Zudem zeigten Studien, dass Patienten ohne medikamentöse Behandlung vergleichbare subgingivale Mikrobiota aufwiesen wie Patienten mit chronischer PA unter immunsupressiver Therapie mit verschiedenen DMARDs (Scher et al. 2012; Ziebolz et al. 2018). Die Ergebnisse lassen darauf schließen, dass eine Therapie mit Basismedikamenten bei der RA nicht unmittelbar mit einer Verbesserung klinischer Merkmale parodontaler Erkrankung assoziiert ist. Die unzureichende Kontrolle des RA-Krankheitsprozesses könnte jedoch Parodontitis begünstigen.

\subsection{Assoziationen zwischen Medikamenteneinnahme und Zytokinspiegeln im Blut}

RA und PA zeichnen sich durch ähnliche humorale und zelluläre Immunantworten und ein gemeinsames immunogenes Profil aus (Mercado et al. 2003; Bartold et al. 2005; Marotte et al. 2006; de Pablo et al. 2009). Die lokale Hart- und Weichgewebsdestruktion umfasst die konstitutive Überproduktion von proinflammatorischen Zytokinen sowie proteolytischen Proteinen wie Matrixmetalloproteinasen. Insbesondere die lokale und

systemische Überproduktion von IL-6 scheint bei beiden Erkrankungen eine entscheidende Rolle zu spielen (Bartold et al. 2005; McInnes und Schett 2007; Brennan und McInnes 2008; de Pablo et al. 2009; Garlet 2010; Graves et al. 2011; Kobayashi und Yoshie 2015). Dies führte zu der Hypothese, dass eine auf proinflammatorische Zytokine gerichtete pharmakologische Behandlung die systemischen und lokalen Spiegel dieser Zytokine reduzieren und gleichzeitig parodontale Entzündungszustände verbessern kann (Kobayashi und Yoshie 2015).

In der vorliegenden Untersuchung wurde der Einfluss der RA-Medikation auf die Serumkonzentration ausgewählter Zytokine (IL-6, IL-10) untersucht. Die Einnahme von Tocilizumab korrelierte mit einer erhöhten Konzentration von IL-6 im Blut (127,67 \pm $169,23 \mathrm{pg} / \mathrm{ml} ; \mathrm{p}=0,005)$, die Einnahme der anderen Medikamente hatte keinen signifikanten Einfluss auf die Serumkonzentrationen von IL-6 oder IL-10.

Die vorliegenden Ergebnisse sind konsistent mit den Beobachtungen anderer Studien, die ebenfalls erhöhte Serumspiegel von IL-6 nach TCZ Medikation demonstrieren konnten (Wendling et al. 1993; Lipsky 2006; Nishimoto et al. 2008; Kobayashi et al. 2014a).

IL-6 ist ein multifunktionelles, proinflammatorisches Zytokin, das in verschiedenen Zielzellen eine Vielzahl biologischer Aktivitäten (Differenzierung, Aktivierung, 
Proliferation) aufweist und Immunreaktionen, Akute-Phase-Reaktionen, die Hämatopoese und den Knochenmetabolismus reguliert (Nishimoto und Kishimoto 2006).

Die IL-6-Signalübertragung kann auf zwei Arten erfolgen. Zum einen durch die klassische Aktivierung eines membrangebundenen IL-6-Rezeptors (IL-6R), zum anderen über die Bindung an einen löslichen Rezeptor (sIL-6R), welcher als Agonist Signale durch Interaktion mit der Zelle überträgt (IL-6-Trans-Signaling) (Scheller et al. 2006).

Tocilizumab ist ein rekombinanter, humanisierter, monoklonaler Anti-Human-IL-6-Rezeptor-Antikörper, der die IL-6-Signalgebung durch kompetitive Hemmung der IL-6Bindung hemmt (Hirano 1998). TCZ bindet sowohl den IL-6R auf der Zellmembran als auch den löslichen IL-6R im Blut und in der Synovia (Mihara et al. 2005).

Es wurde dokumentiert, dass die Serum-IL-6-Spiegel vom Gleichgewicht zwischen der IL-6-Produktion und der Clearance abhängen. Dabei gibt es zwei mögliche Eliminierungswege von IL-6 aus dem Serum: zum einen die Rezeptor-vermittelte Clearance über die Bindung von IL-6 an den IL-6Rezeptor; zum anderen durch den direkten Abbau des IL-6-Proteins. Der Haupteliminierungsweg scheint die Rezeptor-vermittelte Clearance zu sein. Zudem könnte TCZ die Eliminierung von IL-6 hemmen. Sind nach TZC-Verabreichung die Rezeptoren blockiert, reichert sich IL-6 im Serum an. Dabei reflektiert der Serum-IL-6-Spiegel während der Hemmung von IL-6R durch Tocilizumab die tatsächliche endogene Produktion von IL-6 und die wahre Krankheitsaktivität des Patienten.

Trotz des Anstiegs der Serum-IL-6-Spiegel ist die IL-6-Signalgebung vollständig gehemmt, da die IL-6-Signalgebung durch Sättigung von IL-6R mit TCZ vollständig inhibiert ist, solange freies TCZ nachweisbar ist. Daher wird vorgeschlagen, dass Serumspiegel von IL-6 unabhängig von der IL-6-Signalgebung sein können, die die Entzündungsreaktion reguliert (Nishimoto et al. 2008; Kobayashi et al. 2015). Nishimoto et al. (2008) folgerten, dass die Neutralisation der kausalen Faktoren der IL-6-Überproduktion zur Abnahme der Serum-IL-6-Spiegel durch natürlichen Proteinabbau führen wird. IL-6-Spiegel erreichen einen stationären Zustand, wenn die IL-6-Produktionsrate mit der IL-6-Abbaurate übereinstimmt (Nishimoto et al. 2008).

Somit bleibt unklar, ob die Hemmung der IL-6-Signalgebung durch Tocilizumab einen positiven Effekt auf Parodontitis hat. Die Ergebnisse von Kobayashi et al. (2014a) zeigten keine Assoziation zwischen Veränderungen der Serum-IL-6-Spiegel und Veränderungen des klinisch-parodontalen Zustandes bei Patienten mit und ohne TCZ-Therapie.

Eine mögliche Erklärung für das Fehlen von Assoziationen betrifft Unterschiede der Zytokinspiegel im Serum und im gingivalen cervicalen Fluid (D'Aiuto et al. 2007; Nibali et 
al. 2012). Als weitere Einschränkung der vorliegenden Studie muss daher die fehlende Bestimmung der GCF-IL-6-Spiegel gesehen werden, die notwendig wäre, um diese Ergebnisse zu erweitern (Kobayashi et al. 2014a).

Zudem könnte es notwendig sein, die Gesamtveränderungen der IL-6R-Signalkomponenten zu untersuchen, um die zugrundeliegenden Mechanismen zu klären, die nach IL-6RBlockade auftreten.

Des Weiteren muss berücksichtigt werden, dass in der vorliegenden Untersuchung nur zwei Zytokine bei einer kleinen Patientenkohorte betrachtet wurden. Daher ist die Interpretation dieser Ergebnisse limitiert und ermöglicht keine Rückschlüsse auf Gesamtveränderungen im Zytokinnetzwerk, welches mit RA und PA assoziiert ist (Kobayashi et al. 2014a).

\subsection{Schlussfolgerungen}

Auch diese Studie zeigt eine Assoziation von rheumatoider Arthritis und Parodontitis. Dabei deuten die Ergebnisse auf einen Zusammenhang zwischen erhöhter Krankheitsaktivität und reduzierter parodontaler Gesundheit bei RA hin. Die eingangs formulierten Hypothesen konnten jedoch nicht eindeutig bestätigt werden. Der Einfluss einzelner Parameter auf die Wechselbeziehung zwischen PA und RA bleibt unklar. Auch die Wirkung der RA-Medikation auf die genannten Zytokine und damit auf die systemische Entzündung sowie die Parodontitis konnte nicht abschließend geklärt werden.

Künftige klinische Studien/Interventionsstudien mit einem prospektiven Design, einschließlich einer unbehandelten Kontrollgruppe, wären notwendig, um aussagekräftige Schlussfolgerungen zu ziehen. Dabei sollten Veränderungen des parodontalen Biofilms und klinischer Parodontalparameter in Längsrichtung beurteilt werden, um Aufschluss über die Entwicklung und den Verlauf einer Parodontitis bei Rheuma-Patienten zu geben und einen kausalen Zusammenhang beweisen zu können. Zeitgleich müssen die unterschiedlichen Behandlungsphasen der RA (präklinische Phase, Patienten mit früher RA zum Zeitpunkt der Diagnose und Patienten mit RA in Behandlung mit csDMARDs und/oder der mit Biologika) und die gezielte medikamentöse Therapie mit dem Ziel der Remission bzw. niedriger Krankheitsaktivität Berücksichtigung finden und detailliert erfasst werden. 
Aufgrund der bisher anerkannten Assoziation beider Erkrankungen ist zu empfehlen, Patienten mit rheumatoider Arthritis in ein engmaschiges zahnärztliches Recall aufzunehmen. Nach einer umfangreichen parodontalen Sanierung sollten parodontale Parameter regelmäßig kontrolliert und in Bezug auf die Aktivität der RA ausgewertet werden. Zudem ist die Unterstützung und Motivation zu guter Mundhygiene unerlässlich. Eine gut koordinierte Zusammenarbeit zwischen Rheumatologen und Zahnärzten sollte ebenso wie die Aufklärung der Patienten selbstverständlich sein. 


\section{$5 \quad$ Zusammenfassung}

Ziel der vorliegenden Studie war es, bei Patienten mit rheumatoider Arthritis (RA) Parameter der Krankheitsaktivität (klinisch und serologisch) in Abhängigkeit von objektivierbaren Parametern des Parodontalzustandes zu erfassen. Des Weiteren wurde der Einfluss der immunsuppressiv wirkenden Rheumamedikamente auf den Parodontitisschweregrad und auf Serumspiegel definierter immunmodulatorischer Zytokine untersucht.

Es wurden 152 RA-PatientenInnen (w: 125, m: 27; mittleres Alter 59,55 \pm 9,82 Jahre) in die Studie eingeschlossen.

Zur Bestimmung der parodontalen Erkrankungslast wurden folgende Parameter erhoben: Anzahl der fehlenden Zähne (M-T), durchschnittlicher klinischer Attachmentverlust (Ø CAL), durchschnittliche Sondierungstiefen ( $\varnothing \mathrm{ST}$ ) sowie der Parodontalzustand nach Page und Eke (2007).

Die Krankheitsaktivität der rheumatoiden Arthritis wurde anhand folgender Parameter bestimmt: Alter bei Erstdiagnose, Dauer der Morgensteifigkeit in Minuten, Disease Activity Score 28 (DAS28), Serumkonzentrationen von Rheumafaktor, Antikörper gegen cyclische citrullinierte Peptide (Anti-CCP), C-reaktives Protein (CRP) und Blutsenkungsgeschwindigkeit (BSG).

Die Behandlungsdauer mit folgenden Einzelpräparaten bzw. entsprechenden Kombinationen wurde in Monaten erfasst: MTX, Leflunomid, Kombinationen konventioneller synthetischer krankheitsmodifizierender Antirheumatika (csDMARDs), Anti-TNF $\alpha$ Therapeutika, Tocilizumab, Rituximab. Zudem wurde die Gesamtdauer der Therapie mit csDMARDs sowie mit Biologika in Monaten dokumentiert.

In einer Subanalyse wurden bei 80 RA-PatientenInnen (w: 65, m: 15; mittleres Alter 64,59 \pm 2,24 Jahre) die Serumkonzentrationen der Zytokine Interleukin-6 (IL-6) und Interleukin-10 (IL-10) in Abhängigkeit von der medikamentösen Therapie mit nichtsteroidalen Antirheumatika und/oder Glucocorticoiden, MTX, Leflunomid, AntiTNF $\alpha$-Therapeutika, Tocilizumab, Rituximab sowie csDMARDs Kombinationen mittels ELISA quantifiziert.

Individuen mit vermehrtem Zahnverlust waren durchschnittlich älter und hatten einen höheren mittleren DAS28. Eine längere Dauer der Morgensteifigkeit korrelierte mit einem niedrigeren $\varnothing \mathrm{CAL}$. Mit steigendem Schweregrad der Parodontitis (Parodontalzustand nach Page und Eke 2007) nahm die Konzentration von Rheumafaktor im Blut zu. Sowohl 
ein erhöhter 1h-BSG-Wert als auch eine erhöhte Konzentration von Rheumafaktor im Blut korrelierte mit vermehrtem $\emptyset \mathrm{CAL}$. Zusammenhänge mit der Konzentration von Anti-CCP oder CRP im Blut blieben ohne Signifikanz.

Es bestand kein signifikanter Zusammenhang zwischen der Einnahmedauer isolierter csDMARDs und einem der vier parodontalen Parameter (M-T, Ø CAL, Ø ST, Parodontalzustand nach Page und Eke 2007). Auch die Gesamttherapiedauer mit csDMARDs (inkl. Kombinationen) war nicht signifikant mit einem/mehreren der benannten Parameter assoziiert.

Die Einnahme von Tocilizumab korrelierte mit einer erhöhten Konzentration von IL-6 im Blut, die Einnahme der anderen Medikamente hatte keinen signifikanten Einfluss auf die Serumkonzentrationen von IL-6 oder IL-10.

Die Ergebnisse deuten auf eine Assoziation zwischen erhöhter Krankheitsaktivität und reduzierter parodontaler Gesundheit bei rheumatoider Arthritis hin, jedoch trifft dies nicht auf alle Aktivitätsparameter vollständig zu (Morgensteifigkeit, CRP). Uneindeutig bleibt, inwieweit einzelne Parameter auf die Wechselwirkung zwischen rheumatoider Arthritis und Parodontitis Einfluss nehmen. Auch die Wirkung der RA-Medikation auf die genannten Zytokine und damit auf die systemische Entzündung sowie die Parodontitis konnte nicht abschließend geklärt werden. 


\section{$6 \quad$ Anhang}

\subsection{Fragebögen}

\subsubsection{Anamnesebogen}

Priv. Doz. Dr. Dirk Ziebolz; MSc; Universitätsmedizin Göttingen, Zentrum Zahn-, Mund- und Kieferheilkunde; Poliklinik für Präventive Zahnmedizin, Parodontologie und Kariologie; Robert-Koch-Str. 40, 37099 Göttingen; Tel.: 0551 / 39-8368

\section{Anamnesebogen}

„Klinische Querschnittsstudie zum Einfluss medikamentöser (immunsupprimierter) Therapie bei Patienten mit rheumatischen Erkrankungen auf die parodontale Gesundheit“

Pat.- / Code-Nr.:

Datum:

Bitte beantworten Sie die folgenden Fragen bzw. kreuzen Sie Zutreffendes an. Mehrfachantworten sind möglich. Die gewissenhafte Beantwortung ist eine Voraussetzung für den Erfolg der Studie!

ja nein

1. Sind Sie in ständiger ärztlicher Behandlung?

Wenn ja, weswegen?

2. Leiden Sie an einer Herzerkrankung? (z. B. A. pectoris, Endokarditis, Klappenfehler)

3. Müssen Sie ständig Medikamente einnehmen?

Wenn ja, welche?

(z. B. zur Blutzuckersenkung; gegen Herzbeschwerden, Bluthochdruck;

zur Hemmung der Blutgerinnung; Rheumamittel; Beruhigungs-/Schlaftabletten)

4. Sind Sie zurzeit in ärztlicher Behandlung?

Wenn ja, weswegen?

5. Wann sind Sie zum letzten Mal zahnärztlich untersucht worden?

6. Sind Ihre Zähne temperaturempfindlich? 
8. Bemerken Sie Stellungsveränderungen Ihrer Zähne?

9. Haben Sie manchmal einen schlechten Geschmack im Mund?

10. Haben Sie wegen Zahnlockerung bzw. Zahnfleischbeschwerden schon einmal einen Zahnarzt aufgesucht?

Wenn ja, was wurde gemacht?

11. Wurde bei Ihnen bereits eine "Parodontose"-Behandlung durchgeführt?

Wenn ja, wann?

12. Rauchen Sie oder haben Sie geraucht?

13. Seit welchem Lebensjahr rauchen oder haben Sie geraucht?

14. Wie viele Zigaretten/ Schachteln pro Tag etwa?

. Zigaretten/ Tag, ......... Schachteln/ Tag

15. Seit wie vielen Jahren rauchen Sie nicht mehr? 


\subsubsection{Fragebogen zum zahnärztlichen Verhalten}

Priv. Doz. Dr. Dirk Ziebolz; MSc; Universitätsmedizin Göttingen, Zentrum Zahn-, Mund- und Kieferheilkunde; Poliklinik für Präventive Zahnmedizin, Parodontologie und Kariologie; Robert-Koch-Str. 40, 37099 Göttingen; Tel.: 0551 / 39-8368

\section{Fragebogen zum zahnärztlichen Verhalten}

„Klinische Querschnittsstudie zum Einfluss medikamentöser (immunsupprimierter) Therapie bei Patienten mit rheumatischen Erkrankungen auf die parodontale Gesundheit“

Pat.- / Code-Nr.:

\section{Datum:}

Bitte beantworten Sie die folgenden Fragen bzw. kreuzen Sie Zutreffendes an. Die gewissenhafte Beantwortung ist eine Voraussetzung für den Erfolg der Studie!

1. Sind Sie regelmäßig in ärztlicher Behandlung?

Wenn ja, weswegen?

2. Sind Sie regelmäßig in zahnärztlicher Behandlung?

Wenn ja, weswegen?

3. Wann gehen Sie zum Zahnarzt?

[ ] nur bei Zahnschmerzen

[ ] wenn Sie die Zeit haben

[ ] regelmäßig zur Kontrolle

[ ] mehrmals im Jahr

4. Wurden Sie nach der Diagnose „Rheuma“ (von Ihrem Hausarzt, Rheumatologen, etc.) zur zahnärztlichen Untersuchung geschickt?

5. Haben Sie selbstständig den Zahnarzt nach der Diagnose aufgesucht?

6. Waren Sie vor der Diagnose beim Zahnarzt?

7. Wie wichtig ist Ihnen ein sauberer und gesunder Gebisszustand?

[ ] sehr wichtig

[] wichtig

[ ] weniger wichtig

[ ] unwichtig

8. Unterziehen Sie sich regelmäßig einer professionellen Zahnreinigung?

9. Weiß Ihr Zahnarzt, dass Sie Rheuma-Patient sind? 
10a. Wurden Sie darüber aufgeklärt, dass Sie als Rheuma-Patient als „Risikopatient" in der zahnärztlichen Praxis gelten und gewissenhafte häusliche Mundhygiene sowie die regelmäßige Durchführung der Zahnreinigung sehr wichtig sind?

10b. Durch wen wurden Sie darüber aufgeklärt?
[ ] Zahnarzt
[ ] Rheumatologe
[ ] Hausarzt
[ ] Broschüre
[]

11. Wurden Sie über den Zusammenhang zwischen Rheuma und Parodontitis, sowie Notwendigkeit und Nutzen zahnärztlicher Sanierung und dauerhafter Mundhygiene als Rheuma-Patient aufgeklärt?

Wenn ja, durch wen?
[ ] Zahnarzt
[ ] Rheumatologe
[ ] Hausarzt
[ ] Broschüre
[ ] $\ldots \ldots \ldots \ldots \ldots . . .$.

12a. Erfolgte bei Ihnen bereits eine Zahnsanierung?

12b. Wurden bei Ihnen in diesem Zusammenhang zahnärztliche Maßnahmen durchgeführt?

Wenn ja, welche?

[ ] Zahnentfernung

[ ] Kronen und Brücken

[ ] Füllungen/ Kariestherapie

[ ] Parodontologische Behandlung

[ ] Zahnreinigung

[ ] Kontrolle

[ ]

13. Blutet Ihr Zahnfleisch?

14. Wie oft putzen Sie sich Ihre Zähne und/oder Zahnersatz?

[ ] mehr als zweimal am Tag

[ ] ein bis zweimal täglich

[ ] mehrmals in der Woche

[ ] wöchentlich 
15. Putzen Sie Ihre Zähne mit einer bestimmten Technik und Reihenfolge?

Welche Technik praktizieren Sie?

[ ] von rot nach weiß

[ ] rotierende Bewegungen

[ ] kleine kreisende und rüttelnde Bewegungen

[]

16a. Wurden Sie über die häuslichen Mundhygienemaßnahmen aufgeklärt?

16b. Fühlen Sie sich gut über die Mundhygienemaßnahmen aufgeklärt?

17. Welche Hilfsmittel benutzen Sie zur häuslichen Mundhygiene?

[ ] Handzahnbürste

[] elektrische Zahnbürste

[ ] Zahnseide

[ ] Mundspüllösungen

[ ] Fluoridgel

[]

18. Wann waren Sie das letzte Mal beim Zahnarzt?

[ ] vor 0-3 Monaten

[ ] vor 3-6 Monaten

[ ] vor 6-12 Monaten

[ ] vor mehr als einem Jahr

19. Grund für den letzten Zahnarztbesuch?

[ ] Kontrolle

[ ] Schmerzen

[ ] professionelle Zahnreinigung

[ ] laufende Behandlung

[]

20. Wie hoch ist Ihr Alkoholkonsum?

[ ] täglich

[ ] wöchentlich

[ ] gelegentlich

[ ] kein Alkoholkonsum

\section{Vielen Dank!}




\subsubsection{Parodontitisfragebogen}

Priv. Doz. Dr. Dirk Ziebolz; MSc; Universitätsmedizin Göttingen, Zentrum Zahn-, Mund- und Kieferheilkunde; Poliklinik für Präventive Zahnmedizin, Parodontologie und Kariologie; Robert-Koch-Str. 40, 37099 Göttingen; Tel.: 0551 / 39-8368

\section{Parodontitisfragebogen}

„Klinische Querschnittsstudie zum Einfluss medikamentöser (immunsupprimierter) Therapie bei Patienten mit rheumatischen Erkrankungen auf die parodontale Gesundheit“

Pat.- / Code-Nr.:

Datum:

Bitte beantworten Sie, ob sie in den vergangenen 12 Monaten folgende Symptome an sich wahrgenommen haben:

\begin{tabular}{|l|l|l|}
\hline Symptom & Ja & Nein \\
\hline Zahnfleischschwellung & & \\
\hline schmerzendes Zahnfleisch & & \\
\hline empfindliches Zahnfleisch & & \\
\hline Zahnfleischbluten & & \\
\hline $\begin{array}{l}\text { zurückgehendes Zahnfleisch (Rezession, freiliegende Wurzel- } \\
\text { oberfläche) }\end{array}$ & & \\
\hline Zahnüberempfindlichkeit (Heiß/Kalt bzw. süß/sauer) & & \\
\hline Zahnlockerung & & \\
\hline Zahnwanderung/Veränderung der Zahnstellung & & \\
\hline Veränderung des Bisses & & \\
\hline Mundgeruch & & \\
\hline schlechter Geschmack & & \\
\hline Zahnschmerzen & & \\
\hline vorab Parodontalbehandlung/Taschenbehandlung & & \\
\hline regelmäßige/routinemäßige Kontrolluntersuchung & & \\
\hline beschwerde- bzw. schmerzbedingte Kontrolluntersuchung & & \\
\hline gung (1-2 jährlich) & & \\
\hline
\end{tabular}




\section{Literaturverzeichnis}

Abdelsalam SK, Hashim NT, Elsalamabi EM, Gismalla BG (2011): Periodontal status of rheumatoid arthritis patients in khartoum state. BMC Res Notes $\underline{4}, 460$

Abeles AM, Pillinger MH (2006): The role of the synovial fibroblast in rheumatoid arthritis: cartilage destruction and the regulation of matrix metalloproteinases. Bull NYU Hosp Jt Dis $\underline{64}, 20-24$

Ablij H, Meinders A (2002): C-reactive protein: history and revival. Eur J Intern Med 13, 412

Abusleme L, Dupuy AK, Dutzan N, Silva N, Burleson JA, Strausbaugh LD, Gamonal J, Diaz PI (2013): The subgingival microbiome in health and periodontitis and its relationship with community biomass and inflammation. ISME J $\underline{7}, 1016-1025$

Aletaha D, Neogi T, Silman AJ, Funovits J, Felson DT, Bingham CO, Birnbaum NS, Burmester GR, Bykerk VP, Cohen MD et al. (2010): 2010 rheumatoid arthritis classification criteria: an american college of rheumatology/european league against rheumatism collaborative initiative. Arthritis Rheum 62, 2569-2581

Al-Katma MK, Bissada NF, Bordeaux JM, Sue J, Askari AD (2007): Control of periodontal infection reduces the severity of active rheumatoid arthritis. J Clin Rheumatol $\underline{13}, 134-137$

Araújo VMA, Melo IM, Lima V (2015): Relationship between periodontitis and rheumatoid arthritis: review of the literature. Mediators Inflamm 2015, 259074

Arimatsu K, Yamada H, Miyazawa H, Minagawa T, Nakajima M, Ryder MI, Gotoh K, Motooka D, Nakamura S, Iida T, Yamazaki K (2014): Oral pathobiont induces systemic inflammation and metabolic changes associated with alteration of gut microbiota. Sci Rep $\underline{4}$, 4828

Armitage GC (1999): Development of a classification system for periodontal diseases and conditions. Ann Periodontol 4, 1-6

Atzeni F, Sarzi-Puttini P, Dell' Acqua D, de Portu S, Cecchini G, Cruini C, Carrabba M, Meroni PL (2005): Adalimumab clinical efficacy is associated with rheumatoid factor and anticyclic citrullinated peptide antibody titer reduction: a one-year prospective study. Arthritis Res Ther $\underline{8}, \mathrm{R} 3$

Avouac J, Gossec L, Dougados M (2006): Diagnostic and predictive value of anti-cyclic citrullinated protein antibodies in rheumatoid arthritis: a systematic literature review. Ann Rheum Dis $\underline{65}, 845-851$

Äyräväinen L, Leirisalo-Repo M, Kuuliala A, Ahola K, Koivuniemi R, Meurman JH, Heikkinen AM (2017): Periodontitis in early and chronic rheumatoid arthritis: a prospective followup study in finnish population. BMJ Open $\underline{7}$, e011916

Bartold PM, Marshall RI, Haynes DR (2005): Periodontitis and rheumatoid arthritis: a review. J Periodontol 76, 2066-2074

Bartold PM, Cantley MD, Haynes DR (2010): Mechanisms and control of pathologic bone loss in periodontitis. Periodontol $2000 \underline{53}, 55-69$

Bergström J (2006): Periodontitis and smoking: an evidence-based appraisal. J Evid Based Dent Pract $\underline{6}, 33-41$ 
Bernhard J, Villiger P (2001): Rheumatoide Arthritis: Pathogenese und Pathologie. Schweiz Med Forum $\underline{8}, 179-183$

Berthelot J-M, Le Goff B (2010): Rheumatoid arthritis and periodontal disease. Joint Bone Spine $\underline{77}, 537-541$

Bingham CO, Moni M (2013): Periodontal disease and rheumatoid arthritis: the evidence accumulates for complex pathobiologic interactions. Curr Opin Rheumatol 25, 345-353

Bıyıkoğlu B, Buduneli N, Kardeşler L, Aksu K, Pitkala M, Sorsa T (2009): Gingival crevicular fluid MMP-8 and -13 and TIMP-1 levels in patients with rheumatoid arthritis and inflammatory periodontal disease. J Periodontol $\underline{80}, 1307-1314$

Boers M (2003): Understanding the window of opportunity concept in early rheumatoid arthritis. Arthritis Rheum $\underline{48}, 1771-1774$

Bonfil JJ, Dillier FL, Mercier P, Reviron D, Foti B, Sambuc R, Brodeur JM, Sedarat C (1999): A "case control" study on the role of HLA DR4 in severe periodontitis and rapidly progressive periodontitis. Identification of types and subtypes using molecular biology. J Clin Periodontol 26, 77-84

Brennan FM, McInnes IB (2008): Evidence that cytokines play a role in rheumatoid arthritis. J Clin Invest 118, 3537-3545

Bruhn HD, Junker R, Schäfer H, Schreiber S (Hrsg.): LaborMedizin: Indikationen, Methodik und Laborwerte Pathophysiologie und Klinik. 3. Auflage; Schattauer, Stuttgart 2011

Brunsvold MA (2005): Pathologic tooth migration. J Periodontol 76, , 859-866

Bukhari M, Lunt M, Harrison BJ, Scott DGI, Symmons DPM, Silman AJ (2002): Erosions in inflammatory polyarthritis are symmetrical regardless of rheumatoid factor status: results from a primary care-based inception cohort of patients. Rheumatology (Oxford) 41, 246252

Calderaro DC, Corrêa JD, Ferreira GA, Barbosa IG, Martins CC, Silva TA, Teixeira AL (2017): Influence of periodontal treatment on rheumatoid arthritis: a systematic review and metaanalysis. Rev Bras Reumatol Engl Ed 57, 238-244

Chapple ILC, Brock GR, Milward MR, Ling N, Matthews JB (2007): Compromised GCF total antioxidant capacity in periodontitis: cause or effect? J Clin Periodontol $\underline{34}, 103-110$

Chen C (2001): Periodontitis as a biofilm infection. J Calif Dent Assoc 29, 362-369

Chen H-H, Huang N, Chen Y-M, Chen T-J, Chou P, Lee Y-L, Chou Y-J, Lan J-L, Lai K-L, Lin $\mathrm{C}-\mathrm{H}$, Chen D-Y (2013): Association between a history of periodontitis and the risk of rheumatoid arthritis: a nationwide, population-based, case-control study. Ann Rheum Dis $\underline{72}, 1206-1211$

Choy EH, Panayi GS (2001): Cytokine pathways and joint inflammation in rheumatoid arthritis. N Engl J Med 344, 907-916

Coat J, Demoersman J, Beuzit S, Cornec D, Devauchelle-Pensec V, Saraux A, Pers JO (2015): Anti-B lymphocyte immunotherapy is associated with improvement of periodontal status in subjects with rheumatoid arthritis. J Clin Periodontol $\underline{42}, 817-823$

Cox CJ, Kempsell KE, Gaston JSH (2003): Investigation of infectious agents associated with arthritis by reverse transcription PCR of bacterial rRNA. Arthritis Res Ther $\underline{5}, \mathrm{R} 1-\mathrm{R} 8$ 
Culshaw S, McInnes IB, Liew FY (2011): What can the periodontal community learn from the pathophysiology of rheumatoid arthritis? J Clin Periodontol $\underline{38}$, 106-113

Curtis JR, Singh JA (2011): Use of biologics in rheumatoid arthritis: current and emerging paradigms of care. Clin Ther $\underline{33}, 679-707$

D'Aiuto F, Parkar M, Tonetti MS (2007): Acute effects of periodontal therapy on bio-markers of vascular health. J Clin Periodontol $\underline{34}$, 124-129

Darveau RP (2014): Porphyromonas gingivalis neutrophil manipulation: risk factor for periodontitis? Trends Microbiol 22, 428-429

de Maat M, Kluft C (2001): Determinants of c-reactive protein concentration in blood. Ital Heart J $2,189-195$

de Pablo P, Dietrich T, McAlindon TE (2008): Association of periodontal disease and tooth loss with rheumatoid arthritis in the us population. J Rheumatol $\underline{35}, 70-76$

de Pablo P, Chapple ILC, Buckley CD, Dietrich T (2009): Periodontitis in systemic rheumatic diseases. Nat Rev Rheumatol $\underline{5}, 218-224$

de Paula Ishi E, Bertolo MB, Rossa Jr. C, Kirkwood KL, Onofre MA (2008): Periodontal condition in patients with rheumatoid arthritis. Braz Oral Res 22, 72-77

de Smit M, Westra J, Vissink A, Doornbos-van der Meer B, Brouwer E, van Winkelhoff AJ (2012): Periodontitis in established rheumatoid arthritis patients: a cross-sectional clinical, microbiological and serological study. Arthritis Res Ther 14, R222

Demmer RT, Molitor JA, Jacobs DR, Michalowicz BS (2011): Periodontal disease, tooth loss and incident rheumatoid arthritis: results from the first national health and nutrition examination survey and its epidemiological follow-up study. J Clin Periodontol $\underline{38}$, 998-1006

Deo V, Bhongade ML (2010): Pathogenesis of periodontitis: role of cytokines in host response. Dent Today $\underline{29}, 60-62,64-66$

Detert J, Pischon N, Burmester GR, Buttgereit F (2010): The association between rheumatoid arthritis and periodontal disease. Arthritis Res Ther $\underline{12}, 218$

Di Giuseppe D, Discacciati A, Orsini N, Wolk A (2014): Cigarette smoking and risk of rheumatoid arthritis: a dose-response meta-analysis. Arthritis Res Ther 16, R61

Dissick A, Redman RS, Jones M, Rangan BV, Reimold A, Griffiths GR, Mikuls TR, Amdur RL, Richards JS, Kerr GS (2010): Association of periodontitis with rheumatoid arthritis: a pilot study. J Periodontol $\underline{81}, 223-230$

Emery P, Deodhar A, Rigby WF, Isaacs JD, Combe B, Racewicz AJ, Latinis K, Abud-Mendoza C, Szczepanski LJ, Roschmann RA et al. (2010): Efficacy and safety of different doses and retreatment of rituximab: a randomised, placebo-controlled trial in patients who are biological naive with active rheumatoid arthritis and an inadequate response to methotrexate (study evaluating rituximab's efficacy in MTX inadequate responders (SERENE)). Ann Rheum Dis $\underline{69}$, 1629-1635

Esen Ç, Alkan BA, Kırnap M, Akgül Ö, Işıkoğlu S, Erel O (2012): The effects of chronic periodontitis and rheumatoid arthritis on serum and gingival crevicular fluid total antioxidant/oxidant status and oxidative stress index. J Periodontol $\underline{83}, 773-779$ 
Feldmann M, Maini RN (2003): Lasker clinical medical research award. TNF defined as a therapeutic target for rheumatoid arthritis and other autoimmune diseases. Nat Med 9, 12451250

Felson DT, Smolen JS, Wells G, Zhang B, van Tuyl LHD, Funovits J, Aletaha D, Allaart CF, Bathon J, Bombardieri S et al. (2011): American college of rheumatology/european league against rheumatism provisional definition of remission in rheumatoid arthritis for clinical trials. Arthritis Rheum $\underline{63}, 573-586$

Fiehn C, Holle J, Iking-Konert C, Leipe J, Weseloh C, Frerix M, Alten R, Behrens F, Baerwald C, Braun J et al. (2018): S2e-Leitlinie: Therapie der rheumatoiden Arthritis mit krankheitsmodifizierenden Medikamenten. Z Rheumatol 77, 35-53

Flemmig TF (1999): Periodontitis. Ann Periodontol 4, 32-38

Forner L, Larsen T, Kilian M, Holmstrup P (2006): Incidence of bacteremia after chewing, tooth brushing and scaling in individuals with periodontal inflammation. J Clin Periodontol $\underline{33}$, 401-407

Franceschi C, Bonafè M, Valensin S, Olivieri F, de Luca M, Ottaviani E, de Benedictis G (2000): Inflamm-aging: an evolutionary perspective on immunosenescence. Ann N Y Acad Sci 908, 244-254

Fransen J, van Riel PLCM (2005): The disease activity score and the EULAR esponse criteria. Clin Exp Rheumatol 23, 93-99

Garib BT, Qaradaxi SS (2011): Temporomandibular joint problems and periodontal condition in rheumatoid arthritis patients in relation to their rheumatologic status. J Oral Maxillofac Surg $\underline{69}, 2971-2978$

Garlet GP (2010): Destructive and protective roles of cytokines in periodontitis: a re-appraisal from host defense and tissue destruction viewpoints. J Dent Res $\underline{89}$, 1349-1363

Gaujoux-Viala C, Smolen JS, Landewé R, Dougados M, Kvien TK, Mola EM, Scholte-Voshaar M, van Riel P, Gossec L (2010): Current evidence for the management of rheumatoid arthritis with synthetic disease-modifying antirheumatic drugs: a systematic literature review informing the EULAR recommendations for the management of rheumatoid arthritis. Ann Rheum Dis $\underline{69}$, 1004-1009

Golub LM, Payne JB, Reinhardt RA, Nieman G (2006): Can systemic diseases co-induce (not just exacerbate) periodontitis? A hypothetical "two-hit" model. J Dent Res $\underline{85}, 102-105$

Graves DT, Li J, Cochran DL (2011): Inflammation and uncoupling as mechanisms of periodontal bone loss. J Dent Res 90, 143-153

Greenberg JD, Reed G, Decktor D, Harrold L, Furst D, Gibofsky A, DeHoratius R, Kishimoto M, Kremer JM (2012): A comparative effectiveness study of adalimumab, etanercept and infliximab in biologically naive and switched rheumatoid arthritis patients: results from the us CORRONA registry. Ann Rheum Dis $\underline{71}, 1134-1142$

Gregersen PK, Silver J, Winchester RJ (1987): The shared epitope hypothesis. An approach to understanding the molecular genetics of susceptibility to rheumatoid arthritis. Arthritis Rheum $\underline{30}, 1205-1213$

Hajishengallis G (2014): Aging and its impact on innate immunity and inflammation: implications for periodontitis. J Oral Biosci 56, 30-37 
Hajishengallis G (2015): Periodontitis: from microbial immune subversion to systemic inflammation. Nat Rev Immunol 15, 30-44

Hajishengallis G, Lamont RJ (2012): Beyond the red complex and into more complexity: the polymicrobial synergy and dysbiosis (PSD) model of periodontal disease etiology. Mol Oral Microbiol 27, 409-419

Han JY, Reynolds MA (2012): Effect of anti-rheumatic agents on periodontal parameters and biomarkers of inflammation: a systematic review and meta-analysis. J Periodontal Implant Sci $\underline{42}, 3-12$

Han YW, Wang X (2013): Mobile microbiome: oral bacteria in extra-oral infections and inflammation. J Dent Res 92, 485-491

Hartung K, Seelig H-P (2007): Labordiagnostik der systemischen Autoimmunerkrankungen. Z Rheumatol 66, 225-238

Havemose-Poulsen A, Sørensen LK, Bendtzen K, Holmstrup P (2007): Polymorphisms within the IL-1 gene cluster: effects on cytokine profiles in peripheral blood and whole blood cell cultures of patients with aggressive periodontitis, juvenile idiopathic arthritis, and rheumatoid arthritis. J Periodontol $\underline{78}, 475-492$

Heliövaara M, Aho K, Aromaa A, Knekt P, Reunanen A (1993): Smoking and risk of rheumatoid arthritis. J Rheumatol 20, 1830-1835

Herenius MMJ, Oliveira ASF, Wijbrandts CA, Gerlag DM, Tak PP, Lebre MC (2013): Anti-TNF therapy reduces serum levels of chemerin in rheumatoid arthritis: a new mechanism by which anti-TNF might reduce inflammation. PLoS One $\underline{8}$, e57802

Hettenkofer H-J, Schneider M, Braun J (Hrsg.): Rheumatologie: Diagnostik - Klinik - Therapie. 6. Auflage; Georg Thieme Verlag, Stuttgart 2015

Hierse L (2017): Parodontologie im 21. Jahrhundert. DFZ $\underline{61}$, 66-72

Hill JA, Southwood S, Sette A, Jevnikar AM, Bell DA, Cairns E (2003): Cutting edge: the conversion of arginine to citrulline allows for a high-affinity peptide interaction with the rheumatoid arthritis-associated HLA-DRB $1 * 0401$ MHC class II molecule. J Immunol $\underline{171}, 538-541$

Hirano T (1998): Interleukin 6 and its receptor: ten years later. Int Rev Immunol 16, 249-284

Hirsch HZ, Tarkowski A, Koopman WJ, Mestecky J (1989): Local production of IgA- and IgMrheumatoid factors in adult periodontal disease. J Clin Immunol 9, 273-278

Howell TH (1993): Blocking periodontal disease progression with anti-inflammatory agents. J Periodontol $\underline{64}, 828-833$

Howell TH, Williams RC (1993): Nonsteroidal antiinflammatory drugs as inhibitors of periodontal disease progression. Crit Rev Oral Biol Med 4, 177-196

Hyrich KL, Inman RD (2001): Infectious agents in chronic rheumatic diseases. Curr Opin Rheumatol $13,300-304$

Institut der Deutschen Zahnärzte (Hrsg.): Fünfte Deutsche Mundgesundheitsstudie (DMS V) Kurzfassung. 1. Auflage; BZÄK/KZBV, Berlin 2016 
Jepsen S, Kebschull M, Deschner J (2011): Wechselwirkungen zwischen Parodontitis und systemischen Erkrankungen. Bundesgesundheitsbl 54, 1089-1096

Joseph R, Rajappan S, Nath SG, Paul BJ (2013): Association between chronic periodontitis and rheumatoid arthritis: a hospital-based case-control study. Rheumatol Int $\underline{33}, 103-109$

Kassebaum NJ, Bernabé E, Dahiya M, Bhandari B, Murray CJL, Marcenes W (2014): Global burden of severe periodontitis in 1990-2010: a systematic review and meta-regression. $\mathrm{J}$ Dent Res 93, 1045-1053

Kaur S, White S, Bartold PM (2013): Periodontal disease and rheumatoid arthritis: a systematic review. J Dent Res 92, 399-408

Kim JW, Park JB, Yim HW, Lee J, Kwok SK, Ju JH, Kim WU, Park SH (2019): Rheumatoid arthritis is associated with early tooth loss: results from korea national health and nutrition examination survey V to VI. Korean J Intern Med 34, 1381-1391

Kinane DF, Preshaw PM, Loos BG, Working Group 2 of Seventh European Workshop on Periodontology (2011): Host-response: understanding the cellular and molecular mechanisms of host-microbial interactions-consensus of the seventh european workshop on periodontology. J Clin Periodontol $\underline{38}$, 44-48

Klareskog L, Stolt P, Lundberg K, Källberg H, Bengtsson C, Grunewald J, Rönnelid J, Harris HE, Ulfgren A-K, Rantapää-Dahlqvist S et al. (2006a): A new model for an etiology of rheumatoid arthritis: smoking may trigger HLA-DR (shared epitope)-restricted immune reactions to autoantigens modified by citrullination. Arthritis Rheum $\underline{54}, 38-46$

Klareskog L, Padyukov L, Lorentzen J, Alfredsson L (2006b): Mechanisms of disease: genetic susceptibility and environmental triggers in the development of rheumatoid arthritis. Nat Clin Pract Rheumatol 2, 425-433

Klareskog L, Rönnelid J, Lundberg K, Padyukov L, Alfredsson L (2008): Immunity to citrullinated proteins in rheumatoid arthritis. Annu Rev Immunol 26, 651-675

Kobayashi T, Yoshie H (2015): Host responses in the link between periodontitis and rheumatoid arthritis. Curr Oral Health Rep $\underline{2}, 1-8$

Kobayashi T, Okada M, Ito S, Kobayashi D, Ishida K, Kojima A, Narita I, Murasawa A, Yoshie $\mathrm{H}$ (2014a): Assessment of interleukin-6 receptor inhibition therapy on periodontal condition in patients with rheumatoid arthritis and chronic periodontitis. J Periodontol $\underline{85}, 57$ 67

Kobayashi T, Yokoyama T, Ito S, Kobayashi D, Yamagata A, Okada M, Oofusa K, Narita I, Murasawa A, Nakazono K, Yoshie H (2014b): Periodontal and serum protein profiles in patients with rheumatoid arthritis treated with tumor necrosis factor inhibitor adalimumab. J Periodontol $\underline{85}$, 1480-1488

Kobayashi T, Ito S, Kobayashi D, Kojima A, Shimada A, Narita I, Murasawa A, Nakazono K, Yoshie H (2015): Interleukin-6 receptor inhibitor tocilizumab ameliorates periodontal inflammation in patients with rheumatoid arthritis and periodontitis as well as tumor necrosis factor inhibitors. Clin Exp Dent Res $\underline{1}, 63-73$

Kornman KS (2008): Mapping the pathogenesis of periodontitis: a new look. J Periodontol $\underline{79}$, $1560-1568$ 
Kornman KS, Crane A, Wang H-Y, Giovlne FS di, Newman MG, Pirk FW, Wilson TG, Higginbottom FL, Duff GW (1997): The interleukin-1 genotype as a severity factor in adult periodontal disease. J Clin Periodontol 24, 72-77

Koziel J, Mydel P, Potempa J (2014): The link between periodontal disease and rheumatoid arthritis: an updated review. Curr Rheumatol Rep 16, 408

Lee DM, Weinblatt ME (2001): Rheumatoid arthritis. Lancet $\underline{358}$, 903-911

Lee JY, Choi IA, Kim J-H, Kim K-H, Lee EY, Lee EB, Lee Y-M, Song YW (2015): Association between anti-porphyromonas gingivalis or anti- $\alpha$-enolase antibody and severity of periodontitis or rheumatoid arthritis (RA) disease activity in RA. BMC Musculoskelet Disord $\underline{16}, 190$

Lee YH, Bae SC, Song GG (2014): Gene-environmental interaction between smoking and shared epitope on the development of anti-cyclic citrullinated peptide antibodies in rheumatoid arthritis: a meta-analysis. Int J Rheum Dis $\underline{17}, 528-535$

Lehmann KM, Hellwig E, Wenz H-J: Zahnärztliche Propädeutik: Einführung in die Zahnheilkunde. 11. Auflage; Deutscher Zahnärzte Verlag, Köln 2009

Li S, Yu Y, Yue Y, Zhang Z, Su K (2013): Microbial infection and rheumatoid arthritis. J Clin Cell Immunol 4, 174

Lipsky PE (2006): Interleukin-6 and rheumatic diseases. Arthritis Res Ther $\underline{8}, 4$

Loos BG (2005): Systemic markers of inflammation in periodontitis. J Periodontol $\underline{76}, 2106-$ 2115

Loyola-Rodriguez JP, Martinez-Martinez RE, Abud-Mendoza C, Patiño-Marin N, Seymour GJ (2010): Rheumatoid arthritis and the role of oral bacteria. J Oral Microbiol 2,5784

Lundberg K, Wegner N, Yucel-Lindberg T, Venables PJ (2010): Periodontitis in RA - the citrullinated enolase connection. Nat Rev Rheumatol $\underline{6}, 727-730$

Lundström E, Källberg H, Alfredsson L, Klareskog L, Padyukov L (2009): Gene-environment interaction between the DRB1 shared epitope and smoking in the risk of anti-citrullinated protein antibody-positive rheumatoid arthritis: all alleles are important. Arthritis Rheum $\underline{60}, 1597-1603$

Marotte H, Farge P, Gaudin P, Alexandre C, Mougin B, Miossec P (2006): The association between periodontal disease and joint destruction in rheumatoid arthritis extends the link between the HLA-DR shared epitope and severity of bone destruction. Ann Rheum Dis $\underline{65}, 905-909$

Martinez-Martinez RE, Abud-Mendoza C, Patiño-Marin N, Rizo-Rodríguez JC, Little JW, Loyola-Rodríguez JP (2009): Detection of periodontal bacterial DNA in serum and synovial fluid in refractory rheumatoid arthritis patients. J Clin Periodontol $\underline{36}$, 1004-1010

Mayer Y, Balbir-Gurman A, Machtei EE (2009): Anti-tumor necrosis factor-alpha therapy and periodontal parameters in patients with rheumatoid arthritis. J Periodontol $\underline{80}, 1414-1420$

Mayer Y, Elimelech R, Balbir-Gurman A, Braun-Moscovici Y, Machtei EE (2013): Periodontal condition of patients with autoimmune diseases and the effect of anti-tumor necrosis factor- $\alpha$ therapy. J Periodontol $\underline{84}, 136-142$ 
McGuire MK, Nunn ME (1996): Prognosis versus actual outcome. II. The effectiveness of clinical parameters in developing an accurate prognosis. J Periodontol 67, 658-665

McInnes IB, Schett G (2007): Cytokines in the pathogenesis of rheumatoid arthritis. Nat Rev Immunol $\underline{7}, 429-442$

McInnes IB, Schett G (2011): The pathogenesis of rheumatoid arthritis. N Engl J Med 365, 22052219

Mercado F, Marshall RI, Klestov AC, Bartold PM (2000): Is there a relationship between rheumatoid arthritis and periodontal disease? J Clin Periodontol 27, 267-272

Mercado FB, Marshall RI, Klestov AC, Bartold PM (2001): Relationship between rheumatoid arthritis and periodontitis. J Periodontol $\underline{72}, 779-787$

Mercado FB, Marshall RI, Bartold PM (2003): Inter-relationships between rheumatoid arthritis and periodontal disease. J Clin Periodontol $\underline{30}, 761-772$

Meyle J, Chapple I (2015): Molecular aspects of the pathogenesis of periodontitis. Periodontology $2000 \underline{69}, 7-17$

Miehle W, Fehr K, Schattenkirchner M, Tillmann K (Hrsg.): Rheumatologie in Praxis und Klinik. 2. Auflage; Georg Thieme Verlag, Stuttgart 2000

Mihara M, Kasutani K, Okazaki M, Nakamura A, Kawai S, Sugimoto M, Matsumoto Y, Ohsugi Y (2005): Tocilizumab inhibits signal transduction mediated by both mIL-6r and sIL-6r, but not by the receptors of other members of IL-6 cytokine family. Int Immunopharmacol $\underline{5}, 1731-1740$

Mikuls TR, O'Dell J (2000): The changing face of rheumatoid arthritis therapy: results of serial surveys. Arthritis Rheum $\underline{43}$, 464-465

Mikuls TR, Payne JB, Reinhardt RA, Thiele GM, Maziarz E, Cannella AC, Holers VM, Kuhn KA, O’Dell JR (2009): Antibody responses to porphyromonas gingivalis (p. gingivalis) in subjects with rheumatoid arthritis and periodontitis. Int Immunopharmacol $\underline{9}, 38-42$

Mikuls TR, Thiele GM, Deane KD, Payne JB, O'Dell JR, Yu F, Sayles H, Weisman MH, Gregersen PK, Buckner JH et al. (2012): Porphyromonas gingivalis and disease-related autoantibodies in individuals at increased risk of rheumatoid arthritis. Arthritis Rheum $\underline{64}, 3522-3530$

Mikuls TR, Payne JB, Yu F, Thiele GM, Reynolds RJ, Cannon GW, Markt J, McGowan D, Kerr GS, Redman RS et al. (2014): Periodontitis and porphyromonas gingivalis in patients with rheumatoid arthritis: periodontitis and p. gingivalis in RA. Arthritis Rheumatol $\underline{66}$, $1090-1100$

Mirrielees J, Crofford LJ, Lin Y, Kryscio RJ, Dawson DR, Ebersole JL, Miller CS (2010): Rheumatoid arthritis and salivary biomarkers of periodontal disease. J Clin Periodontol $\underline{37}$, 1068-1074

Mühlberg S, Jäger J, Krohn-Grimberghe B, Patschan S, Mausberg RF, Schmalz G, Haak R, Ziebolz D (2017): Oral health-related quality of life depending on oral health in patients with rheumatoid arthritis. Clin Oral Investig 21, 2661-2670

Nagler RM, Salameh F, Reznick AZ, Livshits V, Nahir AM (2003): Salivary gland involvement in rheumatoid arthritis and its relationship to induced oxidative stress. Rheumatology (Oxford) 느, 1234-1241 
Nam JL, Winthrop KL, van Vollenhoven RF, Pavelka K, Valesini G, Hensor EMA, Worthy G, Landewé R, Smolen JS, Emery P, Buch MH (2010): Current evidence for the management of rheumatoid arthritis with biological disease-modifying antirheumatic drugs: a systematic literature review informing the EULAR recommendations for the management of RA. Ann Rheum Dis $\underline{69}, 976-986$

Nibali L, Fedele S, D'Aiuto F, Donos N (2012): Interleukin-6 in oral diseases: a review. Oral Dis $\underline{18}, 236-243$

Nielen MMJ, van Schaardenburg D, Reesink HW, van de Stadt RJ, van der Horst-Bruinsma IE, de Koning MHMT, Habibuw MR, Vandenbroucke JP, Dijkmans BAC (2004): Specific autoantibodies precede the symptoms of rheumatoid arthritis: a study of serial measurements in blood donors. Arthritis Rheum 50, 380-386

Nishimoto N, Kishimoto T (2006): Interleukin 6: from bench to bedside. Nat Clin Pract Rheumatol $2,619-626$

Nishimoto N, Hashimoto J, Miyasaka N, Yamamoto K, Kawai S, Takeuchi T, Murata N, van der Heijde D, Kishimoto T (2007): Study of active controlled monotherapy used for rheumatoid arthritis, an IL-6 inhibitor (SAMURAI): evidence of clinical and radiographic benefit from an $\mathrm{x}$ ray reader-blinded randomised controlled trial of tocilizumab. Ann Rheum Dis $\underline{66}, 1162-1167$

Nishimoto N, Terao K, Mima T, Nakahara H, Takagi N, Kakehi T (2008): Mechanisms and pathologic significances in increase in serum interleukin-6 (IL-6) and soluble IL-6 receptor after administration of an anti-IL-6 receptor antibody, tocilizumab, in patients with rheumatoid arthritis and castleman disease. Blood 112, 3959-3964

Nishimoto N, Miyasaka N, Yamamoto K, Kawai S, Takeuchi T, Azuma J, Kishimoto T (2009): Study of active controlled tocilizumab monotherapy for rheumatoid arthritis patients with an inadequate response to methotrexate (SATORI): significant reduction in disease activity and serum vascular endothelial growth factor by IL-6 receptor inhibition therapy. Mod Rheumatol 19, 12-19

Nishimoto N, Amano K, Hirabayashi Y, Horiuchi T, Ishii T, Iwahashi M, Iwamoto M, Kohsaka H, Kondo M, Matsubara T et al. (2014): Drug free remission/low disease activity after cessation of tocilizumab (actemra) monotherapy (DREAM) study. Mod Rheumatol 24, $17-25$

Nishimura K, Sugiyama D, Kogata Y, Tsuji G, Nakazawa T, Kawano S, Saigo K, Morinobu A, Koshiba M, Kuntz KM et al. (2007): Meta-analysis: diagnostic accuracy of anti-cyclic citrullinated peptide antibody and rheumatoid factor for rheumatoid arthritis. Ann Intern Med 146, 797-808

O'Dell JR (2002): Treating rheumatoid arthritis early: a window of opportunity? Arthritis Rheum $\underline{46}, 283-285$

Ortiz P, Bissada NF, Palomo L, Han YW, Al-Zahrani MS, Panneerselvam A, Askari A (2009): Periodontal therapy reduces the severity of active rheumatoid arthritis in patients treated with or without tumor necrosis factor inhibitors. J Periodontol $\underline{80}, 535-540$

Page RC (1998): The pathobiology of periodontal diseases may affect systemic diseases: inversion of a paradigm. Ann Periodontol $\underline{3}, 108-120$

Page RC, Schroeder HE: Periodontitis in man and other animals. A comparative review. 1. Auflage; Karger, Basel 1982 
Page RC, Beck JD (1997): Risk assessment for periodontal diseases. Int Dent J $\underline{47}, 61-87$

Page RC, Kornman KS (1997): The pathogenesis of human periodontitis: an introduction. Periodontol $2000 \underline{14}, 9-11$

Page RC, Eke PI (2007): Case definitions for use in population-based surveillance of periodontitis. J Periodontol 78, 1387-1399

Paraskevas S, Huizinga JD, Loos BG (2008): A systematic review and meta-analyses on c-reactive protein in relation to periodontitis. J Clin Periodontol $\underline{35}, 277-290$

Payne JB, Golub LM, Thiele GM, Mikuls TR (2015): The link between periodontitis and rheumatoid arthritis: periodontist's perspective. Curr Oral Health Rep 2, 20-29

Pers J-O, Saraux A, Pierre R, Youinou P (2008): Anti-tnf- $\alpha$ immunotherapy is associated with increased gingival inflammation without clinical attachment loss in subjects with rheumatoid arthritis. J Periodontol $\underline{79}, 1645-1651$

Persson GR (2012): Rheumatoid arthritis and periodontitis - inflammatory and infectious connections. Review of the literature. J Oral Microbiol 4, 11829

Petersen PE, Ogawa H (2012): The global burden of periodontal disease: towards integration with chronic disease prevention and control. Periodontol 2000 60, 15-39

Pfeil A, Oelzner P, Böttcher J, Jung C, Wolf G (Hrsg.): Rheumatologie: Das Wichtigste für Mediziner aller Fachrichtungen. 1. Auflage; Elsevier, München 2018

Pincus T, Callahan LF, Sale WG, Brooks AL, Payne LE, Vaughn WK (1984): Severe functional declines, work disability, and increased mortality in seventy-five rheumatoid arthritis patients studied over nine years. Arthritis Rheum 27, 864-872

Pincus T, Yazici Y, Sokka T, Aletaha D, Smolen JS (2003): Methotrexate as the ,,anchor drug“ for the treatment of early rheumatoid arthritis. Clin Exp Rheumatol 21, S179-185

Pischon N, Pischon T, Kröger J, Gülmez E, Kleber B-M, Bernimoulin J-P, Landau H, Brinkmann P-G, Schlattmann P, Zernicke J et al. (2008): Association among rheumatoid arthritis, oral hygiene, and periodontitis. J Periodontol $\underline{79}$, 979-986

Potempa J, Mydel P, Koziel J (2017): The case for periodontitis in the pathogenesis of rheumatoid arthritis. Nat Rev Rheumatol $\underline{13}$, 606-620

Prakash S, Dhingra K, Priya S (2012): Similar hematological and biochemical parameters among periodontitis and control group subjects. Eur J Dent $\underline{6}, 287-294$

Preshaw PM, Taylor JJ (2011): How has research into cytokine interactions and their role in driving immune responses impacted our understanding of periodontitis? J Clin Periodontol $\underline{38}, 60-84$

Rantapää-Dahlqvist S, de Jong BAW, Berglin E, Hallmans G, Wadell G, Stenlund H, Sundin U, van Venrooij WJ (2003): Antibodies against cyclic citrullinated peptide and IgA rheumatoid factor predict the development of rheumatoid arthritis. Arthritis Rheum $\underline{48}, 2741-$ 2749

Razali M, Palmer RM, Coward P, Wilson RF (2005): A retrospective study of periodontal disease severity in smokers and non-smokers. Br Dent J 198, 495-498 
Reichert S, Schlumberger W, Dähnrich C, Hornig N, Altermann W, Schaller H-G, Schulz S (2015): Association of levels of antibodies against citrullinated cyclic peptides and citrullinated $\alpha$-enolase in chronic and aggressive periodontitis as a risk factor of rheumatoid arthritis: a case control study. J Transl Med $\underline{13}, 283$

Renz H (Hrsg.): Praktische Labordiagnostik. 1. Auflage; De Gruyter, Berlin 2009

Reynolds JJ, Meikle MC (1997): Mechanisms of connective tissue matrix destruction in periodontitis. Periodontol 2000 14, 144-157

Ribeiro J, Leão A, Novaes AB (2005): Periodontal infection as a possible severity factor for rheumatoid arthritis. J Clin Periodontol $\underline{32}, 412-416$

Rink L, Kruse A, Haase H: Immunologie für Einsteiger. 2. Auflage; Springer, Berlin 2015

Romero-Sanchez C, Rodríguez C, Santos-Moreno P, Mesa AM, Lafaurie GI, Giraldo-Q S, DeAvila J, Castillo DM, Duran M, Chalem PC et al. (2017): Is the treatment with biological or non-biological DMARDs a modifier of periodontal condition in patients with rheumatoid arthritis? Curr Rheumatol Rev $\underline{13}, 139-151$

Rosenstein ED, Greenwald RA, Kushner LJ, Weissmann G (2004): Hypothesis: the humoral immune response to oral bacteria provides a stimulus for the development of rheumatoid arthritis. Inflammation $28,311-318$

Saini R, Marawar PP, Shete S, Saini S (2009): Periodontitis, a true infection. J Glob Infect Dis 1 , $149-150$

Salaffi F, Sarzi-Puttini P, Girolimetti R, Atzeni F, Gasparini S, Grassi W (2009): Health-related quality of life in fibromyalgia patients: a comparison with rheumatoid arthritis patients and the general population using the SF-36 health survey. Clin Exp Rheumatol 27, 6774

Sanz M, Bäumer A, Buduneli N, Dommisch H, Farina R, Kononen E, Linden G, Meyle J, Preshaw PM, Quirynen M et al. (2015): Effect of professional mechanical plaque removal on secondary prevention of periodontitis and the complications of gingival and periodontal preventive measures. J Clin Periodontol 42, 214-220

Saxer UP, Walter C, Bornstein MM, Klingler K, Ramseier CA, Zürich P (2007): Einfluss des Tabakkonsums auf das Parodont - ein Update (II). Schweiz Monatsschr Zahnmed 117, 153-169

Scheller J, Ohnesorge N, Rose-John S (2006): Interleukin-6 trans-signalling in chronic inflammation and cancer. Scand J Immunol 63 , 321-329

Scher JU, Ubeda C, Equinda M, Khanin R, Buischi Y, Viale A, Lipuma L, Attur M, Pillinger MH, Weissmann G et al. (2012): Periodontal disease and the oral microbiota in new-onset rheumatoid arthritis. Arthritis Rheum 64, 3083-3094

Schlagenhauf U (2017): Die Rolle der Ernährung in der Ätiologie parodontaler Erkrankungen. Zahnmedizin up2date 11, 387-405

Schmalz G, Davarpanah I, Jäger J, Mausberg RF, Krohn-Grimberghe B, Schmidt J, Haak R, Sack U, Ziebolz D (2019): MMP-8 and TIMP-1 are associated to periodontal inflammation in patients with rheumatoid arthritis under methotrexate immunosuppression - first results of a cross-sectional study. J Microbiol Immunol Infect $\underline{52}$, 386-394 
Schmickler J, Rupprecht A, Patschan S, Patschan D, Müller GA, Haak R, Mausberg RF, Schmalz G, Kottmann T, Ziebolz D (2017): Cross-sectional evaluation of periodontal status and microbiologic and rheumatoid parameters in a large cohort of patients with rheumatoid arthritis. J Periodontol $\underline{88}, 368-379$

Schneider M, Lelgemann M, Abholz H-H, Blumenroth M, Flügge C, Gerken M, Jäniche H, Kunz R, Krüger K, Mau W et al.: Interdisziplinäre Leitlinie Management der frühen rheumatoiden Arthritis. 3. Auflage; Springer, Berlin 2011

Schulze H, Dommisch H (2013): Parodontitis: Nur eine Infektion? wissen kompakt $\underline{7}$, 3-11

Schütt S, von Baehr V (2012): Die Immunpathogenese der Parodontitis - Heutiges Wissen ermöglicht neue diagnostische und therapeutische Wege bei Problempatienten. ZWR $\underline{121}$, $618-623$

Silvestre-Rangil J, Bagán L, Silvestre FJ, Bagán JV (2016): Oral manifestations of rheumatoid arthritis. A cross-sectional study of 73 patients. Clin Oral Investig 20, 2575-2580

Sjöström L, Laurell L, Hugoson A, Håkansson JP (1989): Periodontal conditions in adults with rheumatoid arthritis. Community Dent Oral Epidemiol 17, 234-236

Smolen JS, Beaulieu A, Rubbert-Roth A, Ramos-Remus C, Rovensky J, Alecock E, Woodworth T, Alten R, OPTION Investigators (2008): Effect of interleukin-6 receptor inhibition with tocilizumab in patients with rheumatoid arthritis (option study): a double-blind, placebocontrolled, randomised trial. Lancet $\underline{371}$, 987-997

Smolik I, Robinson D, El-Gabalawy HS (2009): Periodontitis and rheumatoid arthritis: epidemiologic, clinical, and immunologic associations. Compend Contin Educ Dent 30, 188-190, 192, 194

Sokka T, Pincus T (2009): Erythrocyte sedimentation rate, c-reactive protein, or rheumatoid factor are normal at presentation in $35 \%-45 \%$ of patients with rheumatoid arthritis seen between 1980 and 2004: analyses from finland and the united states. J Rheumatol $\underline{36}$, $1387-1390$

Solomon DH, Karlson EW, Rimm EB, Cannuscio CC, Mandl LA, Manson JE, Stampfer MJ, Curhan GC (2003): Cardiovascular morbidity and mortality in women diagnosed with rheumatoid arthritis. Circulation 107, 1303-1307

Steel DM, Whitehead AS (1994): The major acute phase reactants: c-reactive protein, serum amyloid $\mathrm{p}$ component and serum amyloid a protein. Immunol Today $\underline{15}, 81-88$

Stein JM: Moderne Parodontologie in der Praxis: Grundlagen, Klassifikation und Diagnostik. 1. Auflage; Spitta Verlag, Balingen 2010

Susanto H, Nesse W, Kertia N, Soeroso J, van Reenen YH, Hoedemaker E, Agustina D, Vissink A, Abbas F, Dijkstra PU (2013): Prevalence and severity of periodontitis in indonesian patients with rheumatoid arthritis. J Periodontol $\underline{84}, 1067-1074$

Symmons DPM (2002): Epidemiology of rheumatoid arthritis: determinants of onset, persistence and outcome. Best Pract Res Clin Rheumatol 16, 707-722

Tak PP, Rigby WF, Rubbert-Roth A, Peterfy CG, van Vollenhoven RF, Stohl W, Hessey E, Chen A, Tyrrell H, Shaw TM, IMAGE Investigators (2011): Inhibition of joint damage and improved clinical outcomes with rituximab plus methotrexate in early active rheumatoid arthritis: the image trial. Ann Rheum Dis $\underline{70}, 39-46$ 
Tak PP, Rigby W, Rubbert-Roth A, Peterfy C, van Vollenhoven RF, Stohl W, Healy E, Hessey E, Reynard M, Shaw T (2012): Sustained inhibition of progressive joint damage with rituximab plus methotrexate in early active rheumatoid arthritis: 2-year results from the randomised controlled trial image. Ann Rheum Dis $\underline{71}$, 351-357

Teeuw WJ, Slot DE, Susanto H, Gerdes VEA, Abbas F, D’Aiuto F, Kastelein JJP, Loos BG (2014): Treatment of periodontitis improves the atherosclerotic profile: a systematic review and meta-analysis. J Clin Periodontol $\underline{41}, 70-79$

Thé J, Ebersole JL (1996): Rheumatoid factor from periodontitis patients cross-reacts with epitopes on oral bacteria. Oral Dis 2 , 253-262

Thumb N, Bröll H, Czurda R, Siegmeth W, Smolen J (Hrsg.): Praktische Rheumatologie. 4. Auflage; Springer, Wien 2001

Tomás I, Diz P, Tobías A, Scully C, Donos N (2012): Periodontal health status and bacteraemia from daily oral activities: systematic review/meta-analysis. J Clin Periodontol $\underline{39}, 213-$ 228

Üstün K, Erciyas K, Kısacık B, Sezer U, Pehlivan Y, Öztuzcu S, Gündoğar H, Onat AM (2013): Host modulation in rheumatoid arthritis patients with tnf blockers significantly decreases biochemical parameters in periodontitis. Inflammation $\underline{36}, 1171-1177$

van der Helm-van Mil AHM, le Cessie S, van Dongen H, Breedveld FC, Toes REM, Huizinga TWJ (2007): A prediction rule for disease outcome in patients with recent-onset undifferentiated arthritis: how to guide individual treatment decisions. Arthritis Rheum 56, $433-440$

Verzeletti GN, Gaio EJ, Rösing CK (2007): Effect of methotrexate on alveolar bone loss in experimental periodontitis in wistar rats. Acta Odontol Scand $\underline{65}, 348-351$

Visser H, le Cessie S, Vos K, Breedveld FC, Hazes JMW (2002): How to diagnose rheumatoid arthritis early: a prediction model for persistent (erosive) arthritis. Arthritis Rheum $\underline{46}$, $357-365$

Walter C, Weiger R, Zitzmann NU (2010): Accuracy of three-dimensional imaging in assessing maxillary molar furcation involvement. J Clin Periodontol 37, 436-441

Wegner N, Lundberg K, Kinloch A, Fisher B, Malmström V, Feldmann M, Venables PJ (2010): Autoimmunity to specific citrullinated proteins gives the first clues to the etiology of rheumatoid arthritis. Immunol Rev 233, 34-54

Wells G, Becker J-C, Teng J, Dougados M, Schiff M, Smolen J, Aletaha D, van Riel PLCM (2008): Validation of the 28-joint disease activity score (DAS28) and european league against rheumatism response criteria based on c-reactive protein against disease progression in patients with rheumatoid arthritis, and comparison with the DAS28 based on erythrocyte sedimentation rate. Ann Rheum Dis 68, 954-960

Wendling D, Racadot E, Wijdenes J (1993): Treatment of severe rheumatoid arthritis by antiinterleukin 6 monoclonal antibody. J Rheumatol 20, 259-262

Willburger RE, Müller K, Knorth H (2006): Pharmakologische Therapie der rheumatoiden Arthritis. Dtsch Arztebl 103, 1308-1309

Wolfe F (1997): Comparative usefulness of c-reactive protein and erythrocyte sedimentation rate in patients with rheumatoid arthritis. J Rheumatol 24, 1477-1485 
Wolff B, Berger T, Frese C, Max R, Blank N, Lorenz H-M, Wolff D (2014): Oral status in patients with early rheumatoid arthritis: a prospective, case-control study. Rheumatology (Oxford) $\underline{53}, 526-531$

Wu M, Chen S-W, Jiang S-Y (2015): Relationship between gingival inflammation and pregnancy. Mediators Inflamm 2015, 623427

Zampeli E, Vlachoyiannopoulos PG, Tzioufas AG (2015): Treatment of rheumatoid arthritis: unraveling the conundrum. J Autoimmun $\underline{65}, 1-18$

Zhang X, Teng Y-TA (2006): Interleukin-10 inhibits gram-negative-microbe-specific human receptor activator of NF- $\mathrm{BB}$ ligand-positive CD4+-Th1-cell-associated alveolar bone loss in vivo. Infect Immun $\underline{74}$, 4927-4931

Ziebolz D, Pabel SO, Lange K, Krohn-Grimberghe B, Hornecker E, Mausberg RF (2011): Clinical periodontal and microbiologic parameters in patients with rheumatoid arthritis. $\mathrm{J}$ Periodontol $\underline{82}, 1424-1432$

Ziebolz D, Rupprecht A, Schmickler J, Bothmann L, Krämer J, Patschan D, Müller GA, Mausberg RF, Schmidt J, Schmalz G, Patschan S (2018): Association of different immunosuppressive medications with periodontal condition in patients with rheumatoid arthritis: results from a cross-sectional study. J Periodontol $\underline{89}, 1310-1317$ 